\title{
THE IMPACTS OF CLIMATE CHANGE ON THE AVALABILITY OF GRANULAR RESOURCES IN THE INUVIALUIT SETTLEMENT REGION, NORTHWEST TERRITORIES
}

by

Emily Borsy

Bachelor of Arts in Geographic Analysis, Ryerson University, 2006

\author{
Athesis \\ presented to Ryerson University \\ in partial fulfillment of the \\ requirements of the degree of \\ Master of Applied Science \\ in the program of
}

Environmental Applied Science and Management

Toronto, Ontario, Canada, 2009

CEmily Borsy, 2009 


\section{DECLARATION}

I hereby declare that I am the sole author of this thesis.

I authorize Ryerson University to lend this thesis to other institutions or individuals for the purpose of scholarly research.

Emily Borsy

If further authorize Ryerson University to reproduce this thesis by photocopying or by other means, in total or in part, at the request of other institutions or individuals for the purpose of scholarly research.

Emily Borsy 


\begin{abstract}
THE IMPACTS OF CLIMATE CHANGE ON THE AVALABILITY OF GRANULAR RESOURCES

IN THE INUVIALUIT SETTLEMENT REGION, NORTHWEST TERRITORIES
\end{abstract}

\author{
Emily Borsy \\ Master of Applied Science \\ Environmental Applied Science and Management
}

Ryerson University, 2009

Physical community infrastructure is vulnerable to changes in permafrost regimes resuting from warming in Arctic environments. The vulnerability of community infrastructure is greatly exacerbated by factors related to the accessibility of aggregates that are used to insulate built form from the active layer of the permafrost. The ability of communities to address stresses brought about by melting permafrost is a function of access to aggregates, the ability to transport them, and competition for gravel between users. In the Inuvialuit Settlement Region readily accessible aggregate is in short supply, and concerns about resource allocation pre-date current prognoses about the impact of global warming. The prospect is that while demand for gravel will increase as permafrost is degraded, competition from new activities along with degradation of winter roads may further stress supplies.

This research project examines the manner in which institutional arrangements, the geography of aggregate distribution, transportation, and competition from emerging new activities exacerbate vulnerabilities associated with permafrost melt in the Inuvialuit Settlement Region. 


\section{ACKNOWLEDGEMENTS}

I would like to thank my academic advisor, Professor Frank Duerden for his invaluable guidance, leadership and wisdom, as well as for the tremendous opportunities I was provided to carry out my research in Canada's north.

1 must also express my gratitude to Bob Gowan of Indian and Northern Affairs Canada, for his insight and expertise that were of great benefit to the development of this thesis.

I would also like to thank the Inuvialuit people for their contributions to my research, as well as for their assistance and hospitality throughout the duration of my thesis work. A specia thanks as well to Todd Romaine and the Inuvialuit Land Administration for their guidance and support throughout my research. In addition, I would like to thank all of the stakeholders who were interviewed for their time and valuable insight. 


\section{Table of Contents}

Page

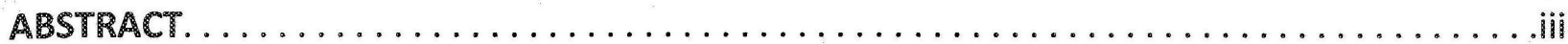

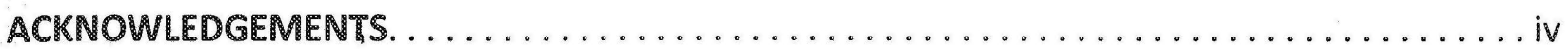

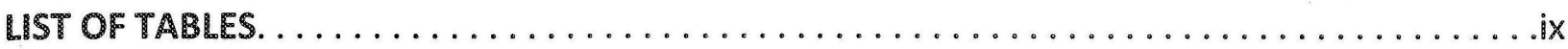

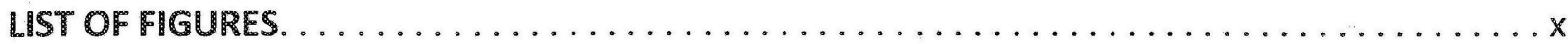

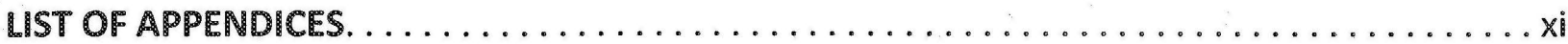

\section{CHAPTER 1: INTRODUCTION}

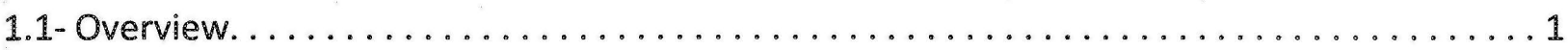

1.2-Purpose and Objectives. . . . . . . . . . . . . . . . . . . . .

\section{CHAPTER 2: CONTEXT}

2.1-The Inuvialuit Settlement Region. .......................

2.2- Permafrost and Aggregates in the Arctic. . . . . . . . . . . . . . . . . . .

2.2.1-Permafrost Characteristics. . . . . . . . . . . . . . . . 7

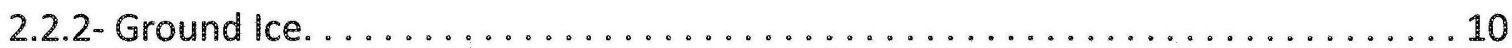

2.2.3- Ground Movement. . . . . . . . . . . . . . . . . . . . . . .

2.3-Permafrost Engineering. . . . . . . . . . . . . . . . . . . . . . . . .

2.3.1- Significance of Granular Resources. . . . . . . . . . . . . . . . 14

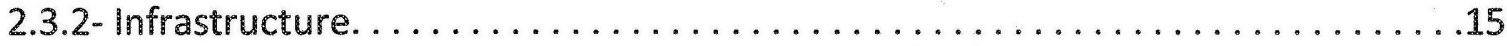

2.3.2.1- Buildings. . . . . . . . . . . . . . . . . . . . . . . 15

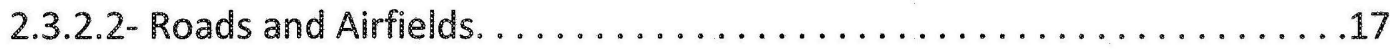

2.3.2.3-Pipelines. . . . . . . . . . . . . . . . . . . . . . . . 17

2.3.3-Alternative Methods of Thaw Prevention. . . . . . . . . . . . . . . . . . . 19

2.4- Impacts of Climate Change on Permafrost and infrastructure in the Arctic.........20

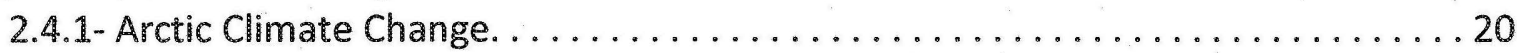

2.4.2-Climate Change and Permafrost. . . . . . . . . . . . . . . . . . . . . .

2.4.3-Climate Change and Community Infrastructure. . . . . . . . . . . 22

2.4.3.1-Buildings. . . . . . . . . . . . . . . . . . . 22

2.4.3.2-Roads and Airfields. . . . . . . . . . . . . . . . . . . . 24 
2.5- Aggregates in the Inuvialuit Settlement Region.

2.6- Uncertainties About Gravel in the Inuvialuit Settlement Region. .

2.7- Research Questions.

\section{CHAPTER 3: METHODOLOGY}

3.1-Objectives.

3.2- Secondary Information

3.3-Spatial Analysis.

3.4- Primary Information.

3.5- Field Work. .......................................... 45

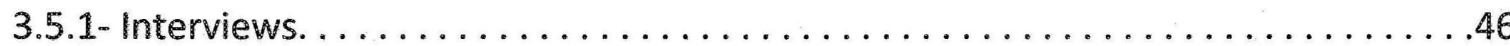

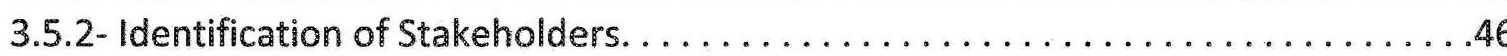

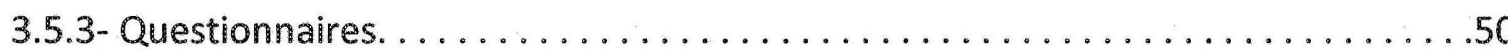

\section{CHAPTER 4: DECONSTRUCTING THE AGGREGATE MANAGEMENT REGIMES IN THE ISR}

4.1- Land and Resource Jurisdiction. . . . . . . . . . . . . . . . . . . . . . . 53

4.2- Obtaining Gravel Within The Inuvialuit Settlement Region. ................. 55

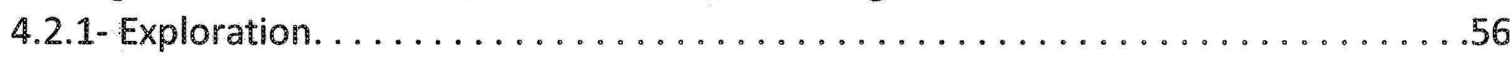

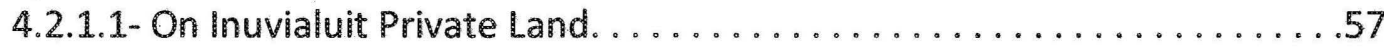

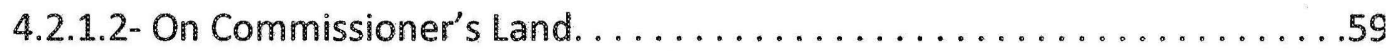

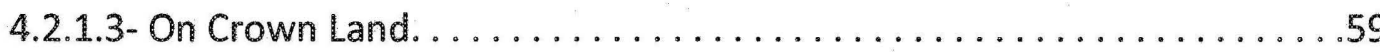

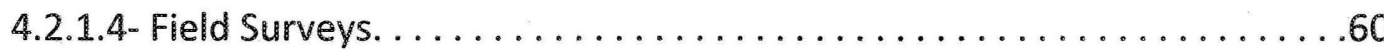

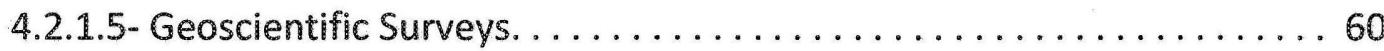

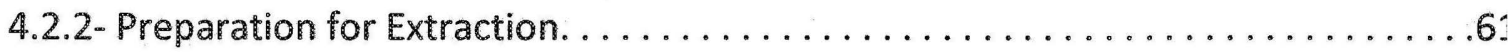

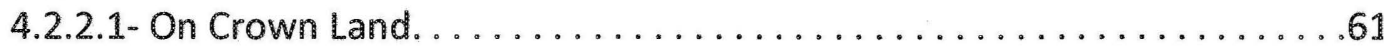

4.2.2.2- On Commissioner's Land. . . . . . . . . . . . . . . . . . . 62

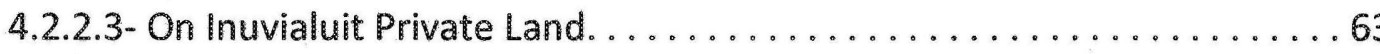

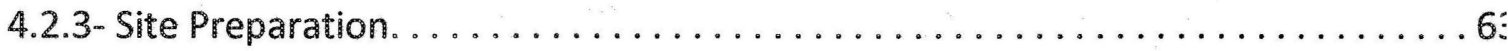

4.2.4- Extraction. . . . . . . . . . . . . . . . . . . . . . . . . . . . . . .

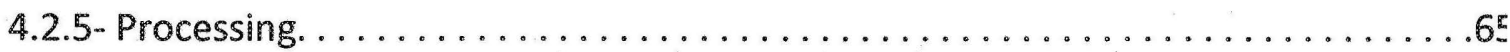

4.2.6- Site Remediation. . . . . . . . . . . . . . . . . . . . . .

4.3- Quarry Fees in the Inuvialuit Settlement Region. ....................66 
4.4- Decision Making Process for Obtaining Gravel. ....................... 67

\section{CHAPTER 5: ATTITUDES TOWARDS THE MANAGEMENT REGIME IN THE ISR}

5.1- Concerns About Granular Resource Management in the Inuvialuit Settlement Region. . 70

5.2- Granular Resource Management Plans. .......................... 71

5.3- Current Granular Resource Management in the Inuvialuit Settlement Region. . . . . . . 74

5.4- Factors Hindering the Development of a Granular Resource Management Plan. . . . . . .75

5.5- Development of a Granular Resource Management Plan. . . . . . . . . . . . . . . 77

5.6- Concerns About Granular Resource Management and Climate Change............ 80

\section{CHAPTER 6: DEMAND}

6.1- Demand Forecasts. .81

6.2 - Historical Demand Forecasts in the Inuvialuit Settlement Region. . . . . . . . . . . 82

6.3- Historical Demand for Granular Resources. . . . . . . . . . . . . . . . . . . . 84

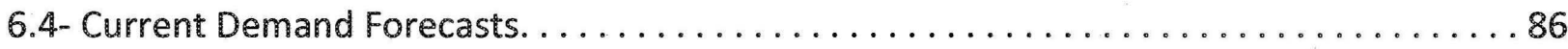

6.5- Current Demand for Gravel in the Inuvialuit Settlement Region. . . . . . . . . . . 88

6.6- Competing Demands for Granular Resources........................ 89

6.6.1- Mackenzie Gas Project. ............................... 90

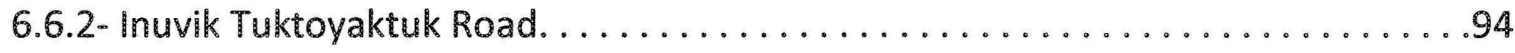

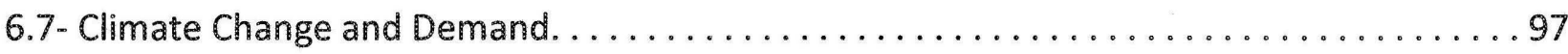

\section{CHAPTER 7: SUPPLY}

7.1- Supply Inventories.

7.1.1- Granular Material Quality................................100

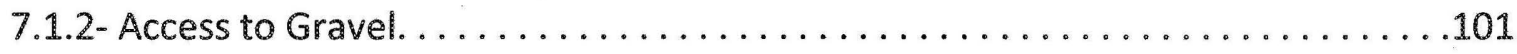

7.1.3- Constraints to Pit Development............................

7.2- Historical Supply Inventories for the Inuvialuit Settlement Region. .104 


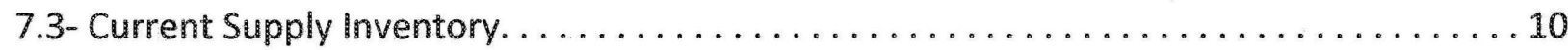

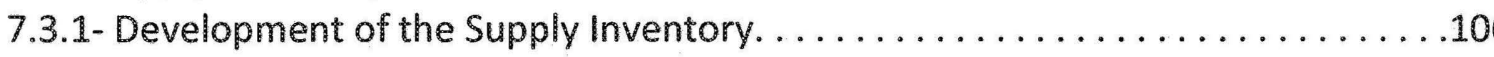

7.3.2- Present Constraints to Community Gravel Supplies. ..................10

7.3.2.1-Ground Ice...................................

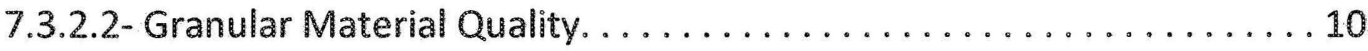

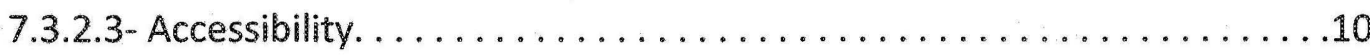

7.3.3- Current Community Gravel Supplies. ........................ 11

7.4- Impacts of Climate Change on Supply. ............................. 119

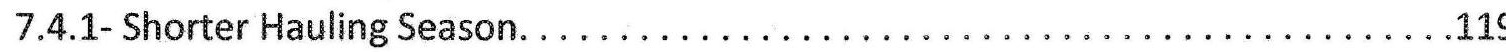

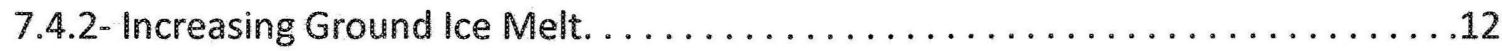

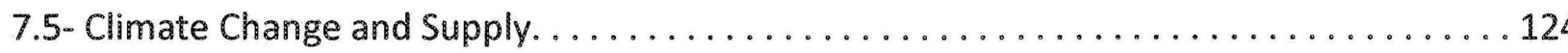

\section{CHAPTER 8: DISCUSSION AND CONCLUSIONS}

8.1- The Implications of Climate Change for the Availability of Granular Resources in the ISR.127

8.1.1- Climate Change and Demand for Granular Resources. . . . . . . . . . . 12

8.1.2- Climate Change and Supply of Granular Resources................. 128

8.2- Towards a Granular Resource Management Plan. ..................... 139

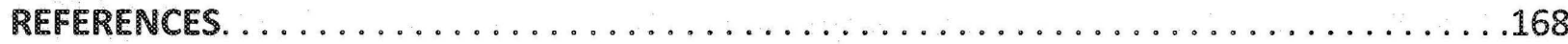




\section{List of Tables}

Table 6.1- Forecasted Demand for Territorial and Municipal Users in Inuvialuit Settlement

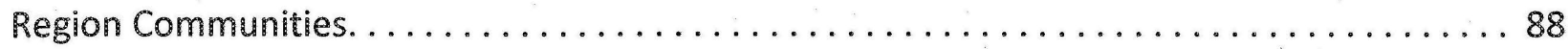

Table 6.2-Primary Borrow Sites for the Mackenzie Gas Project in the Inuvialuit Settlement

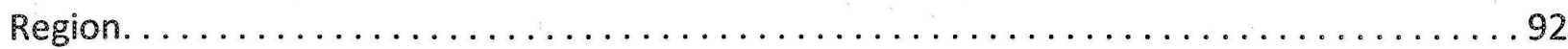




\section{List of Figures}

Page

Figure 2.1- Inuvialuit Settlement Region Boundaries and Community Locations. . . . . . . . .6

Figure 2.2- Spatial Distribution and Continuity of Permafrost in Canada. ...........8

Figure 2.3-Permafrost Layers and Location of Ground Ice Within the Soil. ..............9

Figure 2.4- Permafrost Thaw Beneath a Utilidor, Inuvik, NWT. . . . . . . . . . . . 27

Figure 4.1-Distribution of $7(1)(a)$ (Surface and Subsurface Rights) and $7(1)(b)$ (Surface Rights Only) Lands in the Inuvialuit Settlement Region. . . . . . . . . . . . . . . . . . . 55

Figure 6.1 - Proposed Route for the Inuvik Tuktoyaktuk Road..................99

Figure $6.2-$ Gravel Requirements for the Inuvik Tuktoyaktuk Road. . . . . . . . . . . . . 97

Figure 7.1- Characteristics of a Generic Granular Resource Deposit in the Inuvialuit Settlement Region. ................................................. 10

Figure 7.2- Ice Road Season and Average Annual Temperature for the Inuvik-Tuktoyaktuk Ice Road. 


\section{List of Appendices}

Appendix A-Questionnaire.

Appendix B- Questionnaire Responses. . . . . . . . . . . . . . . . . . . . . .144

Appendix C-Regulatory and Decision Making Process. . . . . . . . . . . . . . 148

Appendix D-Demand. . . . . . . . . . . . . . . . . . . . . . . . . . . . . .

Appendix E-Constraints to Supply. . . . . . . . . . . . . . . . . . . . . 154

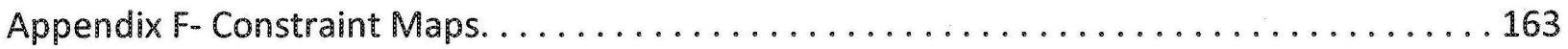





\section{1- Overview}

The Arctic region is experiencing some of the most rapid and severe environmental changes on the planet (Hassol, 2004). There is evidence that the Arctic region has warmed at almost twice the global average rate of $0.74^{\circ} \mathrm{C}$ over the past 100 years (Intergovernmental Panel on Climate Change (IPCC), 2007). Over the past fifty years, a change of 2 to $3^{\circ} \mathrm{C}$ has been observed over the Canadian Western Arctic (Zhang, et al., 2000 in Furgal and Prowse, 2008, pg. 61). In the Mackenzie District specifically, between 1948 and 2005, there was a warming of $2^{\circ} \mathrm{C}$ while the average increase for Canada over the same period was $1.2^{\circ} \mathrm{C}$ (Furgal and Prowse, 2008, pg.67). The impacts of warming air temperatures caused by climate change on permafrost, or frozen ground, are already being observed. Since the 1980 s, the temperature at the top layer of permafrost in the Arctic has increased by up to $3^{\circ} \mathrm{C}(\mathrm{PCC}, 2007)$. When the temperature of permafrost increases, settling of the ground occurs and the thickness of the active layer increases, creating significant vulnerabilities for community infrastructure (Hassol, 2004, pg. 88, IPCC, 2007, pg. 655).

Frozen ground plays a role in supporting Arctic infrastructure. Current engineering designs for infrastructure construction are based upon the known properties of the frozen ground including thawing properties, and seasonal frost heave and settlement patterns (Andersland and Ladanyi, 2004). Climate change will likely cause the properties of the permafrost to change, therefore altering engineering requirements for constructing infrastructure. The anticipated engineering response to the consequence of permafrost melt is to use more granular material as a base for buildings, roads, airstrips and utility lines in order to minimize thawing due to exposure of the ground to warmer temperatures. Other technologies 
for abating the impacts of thawing permafrost on infrastructure, such as thermosyphons currently have much larger price tags to implement, and therefore are not usually economicall viable for infrastructure in small communities (Wolfe, 1998, pg. 20).

The Inuvialuit Settlement Region (ISR), in Canada's Western Arctic is one Arctic region that will experience the impacts of climate change on infrastructure. Its ability to prevent infrastructure failure depends on the availability of granular resources. Gravel is found within the Inuvialuit Settlement Region, however, it is unevenly dispersed throughout the region making gravel difficult to access for some communities. Likewise, there are constraints to developing many of the sources-they may be located in an ecologically significant area, seasonally inaccessible, contain massive ground ice, or be of poor quality.

Aside from constraints to access, a complex regulatory system within the region has made the management of granular resources unclear in the past and is only beginning to be simplified at present. In addition to historical issues facing granular resource acquisition and management, climate change may present more obstacles to abating infrastructure failure in the ISR communities. The available supply of granular resources could be limited by the decreasing length of the ice and tundra road season while demand for gravel will increase due to elevated requirements for more granular resources to create thicker insulating layers between the permafrost and infrastructure. Furthermore, oll and gas development is occurring in the region, placing additional demands on already stressed resources. 


\section{2- Purpose and Objectives}

The purpose of this paper is to identify the potential impact of climate change on the availability of aggregate resources in the Inuvialuit Settlement Region. This is achieved through the investigation of the impacts of climate change on the supply of and demand for granular resources, as well as the managerial capacity of land owners within the Inuvialuit Settlement Region. The overall objective is to obtain an understanding of the implications of a changing environment for the supply of aggregates to communities in the ISR. 


\section{1- The Inuvialuit Settlement Region}

The Inuvialuit are descendents of the Thule people and culture from northwestern Alaska. The first known Thule settlement in Canada was on Banks Island in approximately 1,00 A.D. (Canadian Museum of Civilization Corporation, 2001). From this settlement, the Inuvialuit culture evolved, becoming adapted to the environmental characteristics of Canada's Western Arctic (Morrison, 2008, Online). Historically, a significant characteristic of the Inuvialuit cultur has been hunting-both on land, and at sea, for geese, muskox, caribou, fish and beluga whale (Inuvialuit Regional Corporation, 2007). Hunting served as the basis of the early Inuvialuit economy, allowing for the production of food and clothing for survival.

Before European contact in the early 1800 s, there were six Inuvialuit Nations, with a total population of approximately 2,500. In 1861, the Hudson's Bay Company opened up a trading post for trade with the Inuvialuit, and closed it in 1866 due to declining revenues. During this time however, the Inuvialuit were plagued by disease including measles and smallpox, greatly diminishing the population in the 1870 s. The turning point towards modernization of the Inuvialuit culture occurred in the 1890 s when whalers came to Herschel Island to hunt bowhead whales. The Inuvialuit were no longer isolated from the rest of the world. Through the whalers, goods such as flour and hunting equipment were easily accessible and this newfound lack of isolation is said to have destroyed the traditional Inuvialuit culture. Just as the traders had done, the whalers introduced more disease, causing epidemics that diminished the Inuvialuit population from 2,500 to 250 in 1905 to 150 in 1910 (Canadian Museum of Civilization Corporation, 2001). 
The region's population has since recovered and grown to nearly 6,000 people in 2006 (Statistics Canada, 2006). In 1984, the Canadian Parliament approved the Western Arctic Claims Act and the Inuvialuit Final Agreement (FA), giving the Inuvialuit ownership of land, with some surface and subsurface rights to that land and creating the Inuvialuit Settlement Region (ISR). The ISR is located in Canada's Western Arctic and spans from the Alaska-Yukon border to Victoria Island in the Beaufort Sea. With an area of 450,000 square kilometers, the ISR includes the Mackenzie Delta, Victoria Island and Banks Island. There are six communities that lie within the ISR: Aklavik (population 594), Inuvik (3,484), Paulatuk (294), Sachs Harbour (122), Tuktoyaktuk (870) and Ulukhaktok (formerly known as Holman) (398) (Statistics Canada, 2006). The currentISR population consists of both Inuvialuit and non-indigenous people who often work in the natural resource and government sectors. Although Inuvik and Aklavik fall under the Inuvialuit Final Agreement and are inhabited by both Inuvialuit and Gwich'in people, they geographically fall within the Gwich'in Settlement Area (GSA) which is directly south of the Inuvialuit Settlement Region. Despite their locations within the GSA, the land directly surrounding these communities is part of the Inuvialuit Final Agreement. The boundaries of the ISR are depicted in Figure 2.1. 


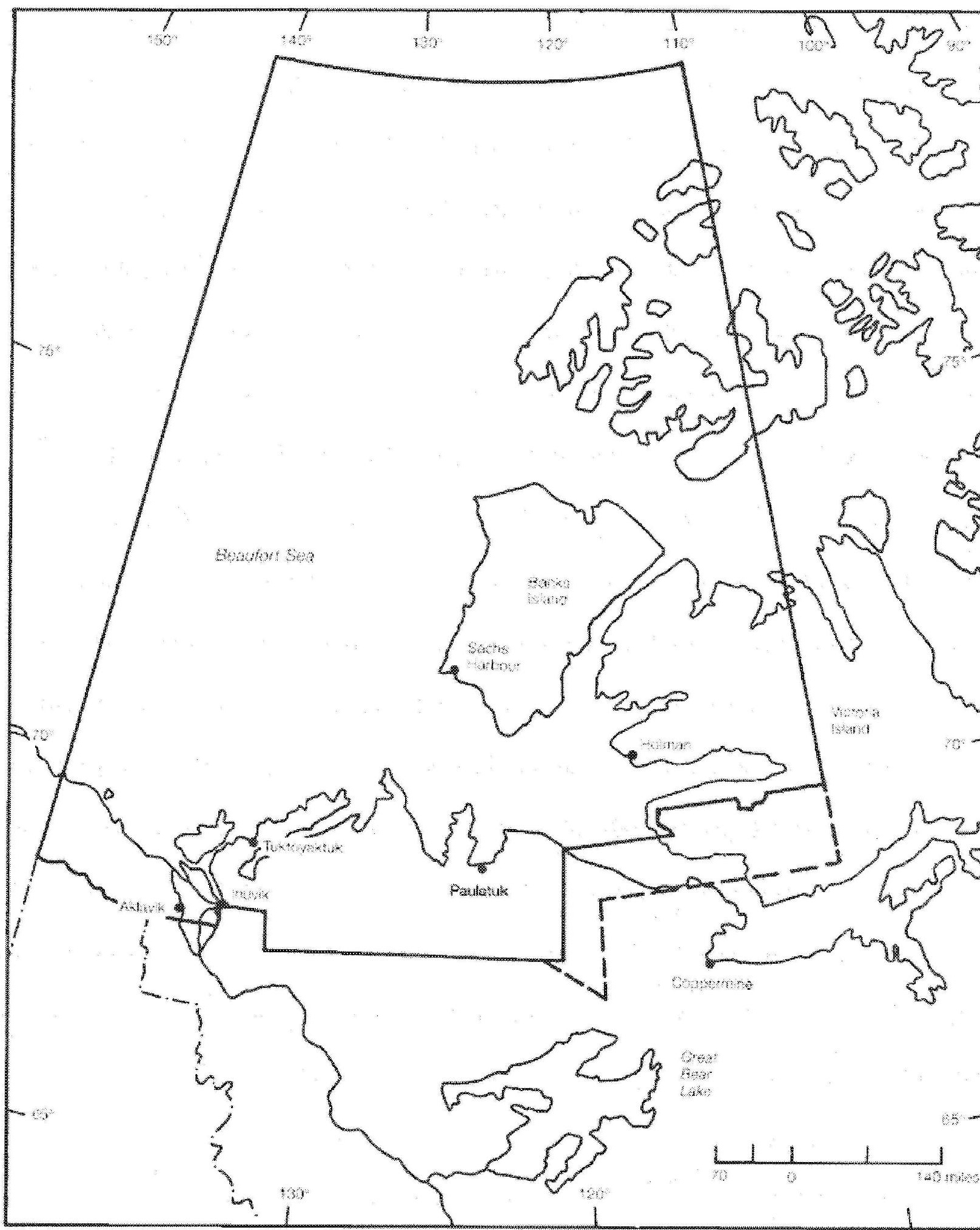

Figure 2.1- Inuvialuit Settlement Region Boundaries and Community Locations Source: International Development Research Centre (nd) 


\subsection{Permafrost and Aggregates in the Arctic}

\subsection{1-Permafrost Characteristics}

Permafrost is defined as subsurface material that remains frozen for two or more continuous years ( Nelson, et al., 2002). Permafrost remains below zero degrees Celsius throughout the year, and is caused by the cooling of the ground in the winter, which produces a frozen layer that lasts throughout the following summer (Geological Survey of Canada, December 2007, Online). Between twenty and twenty-five percent of the entire earth's land surface is underlain by permafrost, covering approximately 10.5 million square kilometers. It is estimated that permafrost lies beneath fifty percent of Canada's totalland area (French, 2007; Slater and Lawrence, 2005).

Generally, permafrost is categorized in two ways: continuous or discontinuous. Areas of continuous permafrost have frozen ground everywhere beneath the ground surface. There are two classifications of discontinuous permafrost: widespread zones that have permafrost under fifty to ninety percent of the land area, and sporadic zones, which have permafrost under ten to fifty percent of the land area. The spatial distribution of permafrost zones in Canada is indicated in Figure 2.2. The Inuvialuit Settlement Region lies within the continuous permafrost zone in Canada, and reaches depths of between one hundred and two hundred metres in Inuvik and five hundred metres in Tuktoyaktuk (Wolfe, 1998; Couture, et al., 2002). 


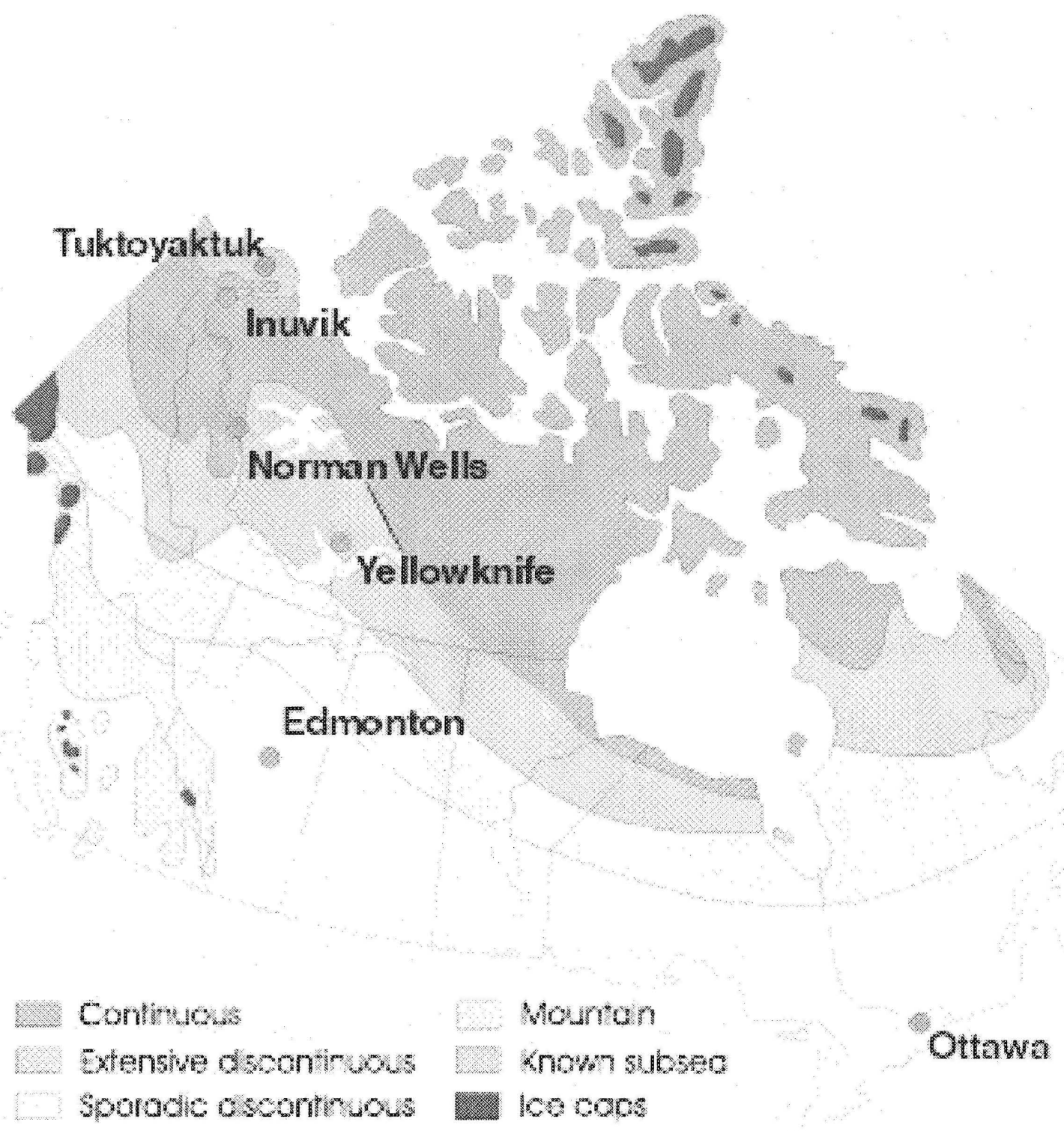

Figure 2.2- Spatial Distribution and Continuity of Permafrost in Canada Source: Natural Resources Canada, 2007

Above the permafrost lies a layer of ground (the active layer, Figure 2.3), which freezes and thaws throughout the year with changes in season. In the continuous zone, the active laye sits immediately above the permafrost layer. In discontinuous permafrost zones, the active layer may be separated from the permafrost layer by a talik zone, which remains unfrozen 
throughout the year, as seen in Figure 2.3 below (French, 2007, pg.111). The thickness of the active layer is dependent on the air-surface temperature of the ground, which causes freezing and thawing. The active layer thickness generally decreases as latitude increases, due to the fact that mean annual air temperature also decreases with higher latitude. The active layer ranges from approximately one metre deep in the southern permafrost zones to fifteen centimeters deep in the most northern latitudes (Andersland and Ladanyi, 2004, pg. 7). Within the Inuvialuit Settlement Region, the active layer is approximately half a metre thick in Tuktoyaktuk and one metre thick in Inuvik (Couture, et al., 2002; French, 2007, pg. 178).

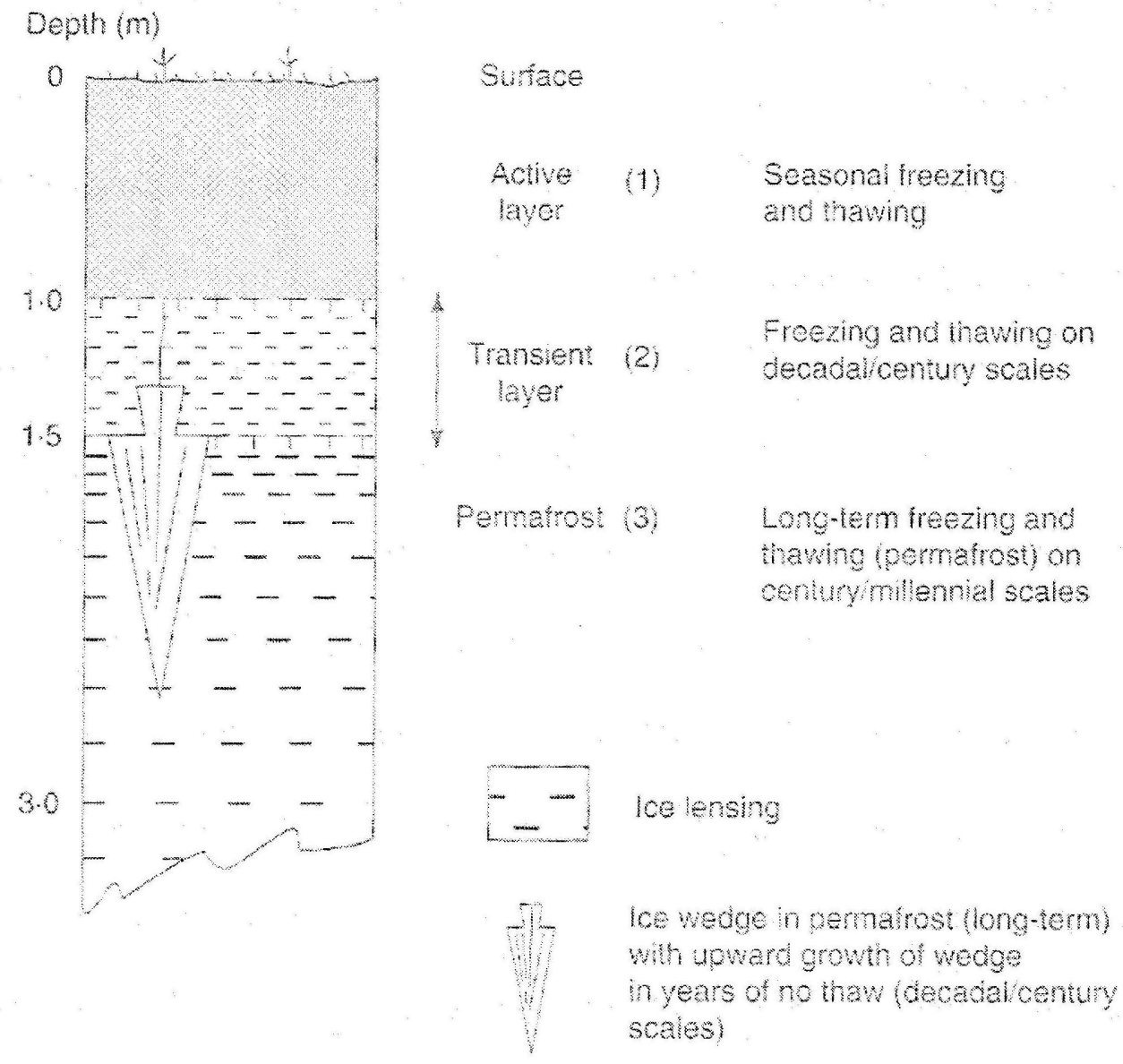

Figure 2.3- Permafrost Layers and Location of Ground Ice Within The Soil Source: French, 2007, pg.112 


\subsection{2- Ground Ice}

Due to the nature of the Arctic climate, when moisture enters the ground from the atmosphere or from melting snow and ice on the surface, it eventually forms ground ice. The term ground ice refers to any ice formed in permafrost and the active layer, and occurs in pores, cracks and cavities of the permafrost (French, 2007, pg. 153). The amount of ground ice present in the permafrost varies by region, and the Inuvialuit Settlement Region lies within a region of moderate $(5-15 \%)$ to high $(>15 \%)$ levels of ice content (Heginbottom, 2000$)$. According to borehole samples that have been taken in the Tuktoyaktuk area, sixty-three percent of the sampled areas contain at least half a metre of massive ice within the upper ten metres of permafrost (Couture, et al., 2002).

There are several types of ground ice that form in permafrost landscapes, including ice wedges, ice lenses and pore ice, the types which have the largest impact on ground movement related damage to infrastructure. Ice wedges are some of the most distinctive features of a permafrost landscape, and are more prominent in the northern parts of the Arctic (French, 2007, pg. 176; Heginbottom, 2000). Ice wedges form inside cracks in the ground that are created when the ground contracts as the air temperature falls before winter. These cracks ar often less than a centimeter wide, but several metres deep. During the spring melt and summer precipitation period, water enters a crack and freezes during the following winter (Andersland and Ladanyi, 2004, pg. 8). Some ice wedges may run as deep as twenty-five metre (Indian and Northern Affairs Canada, 1982). When the top of an ice wedge thaws due to summer temperatures, a trough is usually formed in the ground that runs the length of the ice wedge (Couture and Pollard, 2007). 
Pore ice forms when water from precipitation or snowmelt enters the soil matrix, and stays in the pores between the soil particles, eventually freezing. Research has indicated that pore ice is more likely to form in finer soils with smaller pores at a shallower depth compared to gravel with larger pore spaces (Fourie, et al., 2007).

Ice lenses are another type of ground ice and form when water travels through the active layer towards the permafrost where it freezes and accumulates (Wolfe, 1998, pg. 18). The size of an ice lens increases as long as there is a source of water in the soil, and can range from a few millimeters to ten metres thick (Indian and Northern Affairs Canada, 1982). Ice lenses are commonly found in a series above one another, separated by a layer of permafrost (Penner, 1962). Pingos are also common in the Mackenzie Delta and especially on the Tuktoyaktuk Peninsula, occurring in shallow lakes (Heginbottom, 2000). Pingos are massive ground ice that is covered in soil and vegetation, and are caused by the freezing of shallow lakes on top of their permafrost lake beds, creating uplift pressure in certain areas, resulting in hill-like formations (Andersland, 2004, pg.10). Whereas ice lenses are generally invisible to the eye and therefore can have unexpected impacts on infrastructure, pingos are visible on the landscape, and are avoided during construction.

\subsection{3- Ground Movement}

When moisture freezes to form ground ice, it expands in volume by nine percent (Wolfe, 1998, pg.18). Conversely, when the ice thaws, it decreases in volume. The freeze-thaw phenomenon of ground ice in permafrost causes ground to move, and is the most influential factor on the stability of infrastructure built on the surface above. The freezing and thawing 
processes that cause movement of the ground that can impact infrastructure include: frost heave, thaw settlement and the formation of thermokarst landscapes (Wolfe, 1998; Andersland and Ladanyi, 2004; Heginbottom, 2000).

Frost heave occurs when the soil and the moisture within the soil freezes, creating ground ice that causes uplifting forces due to its volume expansion (Wolfe, 1998, pg. 19; Andersland and Ladanyi, 2004, pg. 16). Heave is primarily attributed to the formation of ice lenses (French, 2007, pg.352). The magnitude of vertical expansion of the soil due to ice lenses has a wide range, but frost heave of four to eight inches is not uncommon (Penner, 1962).

Thaw settlement (or thaw weakening) occurs as the ice melts in the spring, when the volumetric area once occupied by ice decreases and soil settles into this area (Wolfe, 1998, pg. 19). When an ice lens, pore ice or ice wedge melts, the moisture cannot penetrate underlying frozen ground. As a result, high pore-water pressure occurs, ultimately reducing the strength of the soil (French, 2007, pg. 242). A reduction in soil strength decreases its bearing capacity. As summer progresses, and the thaw depth increases, the pore-water pressure falls because the surplus water can dissipate further throughout the soil matrix, allowing the soil to regain some of its strength and bearing capacity (Andersland and Ladanyi, 2004, pg. 39). In relation to thaw permafrost can be considered either thaw stable or thaw unstable, and this categorization is dependent on the amount of moisture within the frozen ground. The permafrost in the Inuvialuit Settlement Region can be thaw unstable due to the high amount of ground ice contained in the permafrost.

Another process that impacts the stability of infrastructure is the formation of thermokarst landscapes. Thermokarst occurs when the melting of ground ice in the permafrost 
causes the ground to settle, creating depressions in the ground. Melting that leads to thermokarst landscapes is due to a rise in the ground surface temperature because of a changing climate, change in vegetation cover, or anthropogenic changes such as the construction of infrastructure on the permafrost (Andersland and Ladanyi, 2004, pg. 10). The thermokarst features that are created due to thawing depend on the type of ground ice that is melting. When small amounts of pore ice melt, shallow depressions in the ground surface are created. However, when ice wedges melt, troughs that run the length of the wedge are created across the ground surface. The melting and landscape changes are usually exacerbated when the depressions or troughs fill with water to become shallow lakes because precipitation or melt water cannot drain away (De Schutter, 2004).

Along with increases in mean annual air temperature, the thaw of permafrost is also influenced by disturbances in vegetation. Vegetation acts as an insulator to the permafrost, and the removal of vegetation for the construction of roads, buildings or pipelines changes the thermal regime of the ground. The presence of vegetation including trees, shrubs and peat can decrease permafrost degradation that is caused by air temperature (Yi, et al., 2007). Like vegetation, snow cover also serves as an insulator to the soil. In the spring it delays the warming of the soil as the air temperature rises. The greater the depth of snow the longer it will take to melt, and this impacts how soon and how deep the permafrost will thaw in the summer (Vi, et al., 2007). 


\section{3-Permafrost Engineering}

Infrastructure is defined by the Arctic Climate Impact Assessment as "facilities with permanent foundations or the essential elements of a community" (Instanes, 2004).

Infrastructure is related to community socio-economic well being and for the purposes of this project, only community infrastructure is studied. Aside from community infrastructure like housing, schools, medical facilities, roads, airstrips, and utility lines, other infrastructure in the Arctic serves as natural resource extraction and military support (Instanes, et al., 2005).

\subsection{1- Significance of Granular Resources}

Gravel is used extensively in northern communities as a construction material, serving as a base for infrastructure such as roads and pipelines as well as an abatement measure, preventing the thaw of underlying permafrost and damage to infrastructure that is related to ground movement (French, 2007, pg. 353).

Most northern infrastructure is underlain by a gravel pad. The purpose of a gravel pad twofold: to create a new active layer, and to prevent the warmth of the infrastructure from thawing the underlying permafrost (French, 2007, pg. 353). By creating a layer of aggregates before a building is constructed, a new, non-frost susceptible active layer is created (Strub, 1996). The frost susceptibility of soil refers to its likelihood of increasing in volume due to freezing, on account of its water content conductivity (Padilla, et al., 1997). The existing active layer usually consists of materials that are fine grained and more densely distributed, which makes it more difficult for water to travel through the soil, hence making the formation of ground ice and frost susceptibility more probable (Andersland, 2004, pg. 39). Compared to 
finer grained solls gravel is highly porous, allowing precipitation and melt water to travel through to deeper soil zones or laterally. Therefore, the presence of a layer of gravel will not allow the accumulation of high ice content as the existing active layer of finer grained soil does (French, 2007, pg. 28, Penner, 1962). Without ice content, infrastructure damage caused by the types of ground movement previously described is less likely.

In order to prevent thaw of the underlying permafrost and the ground movement associated with thaw, gravel pads of two to three metres thick are usually required. The pad should also extend at least one and a half metres beyond the building footprint, in order to deter thaw caused by roof runoff, or radiating heat (Strub, 1996). A gravel pad for a building: should be laid during the summer months, when the gravel is thawed, and can be compacted. It can take a year for a pad to settle and to take on the characteristics and function of a new. active layer. During the course of the year, the permafrost table is expected to rise to a level just above the original ground surface (lbid).

\subsection{2-Infrastructure}

\subsubsection{1-Buildings}

Light buildings, such as housing are built on piles in the Arctic. Piles are constructed of either timber, steel, concrete or composite materials, serving the purpose of elevating the building off of the ground in order to reduce permafrost thaw caused by heat radiating from the building. By raising the building off the ground, an airspace is created between the building and the ground, allowing the heat produced by the building to be removed by moving air (Andersland and Ladanyi, 2004, pg. 179). 
In the Inuvialuit Settlement Region, timber piles are commonly used due to their relative inexpensiveness, and the availability of timber from the Mackenzie Delta. Timber piles can range from six to fifteen metres in length, and from 15 to 25 centimetres in diameter at the top and from 30 to 35 centimetres at the bottom. Piles are installed by excavating a hole to the desired depth, inserting the pile, and then filling the hole with soil or backfill. Once the hole is filled and the ground refreezes, an adfreeze bond is created between the soil and the pile, giving the pile added strength and bearing capacity (French, 2007, pg. 352).

Buildings built on piles are vulnerable to both frost heave and thaw settlement, both of which can compromise the integrity of the structure. During the winter, the uplifting forces of frost heave can lift a building and its piles above their original height. Then, during the spring thaw settlement occurs, allowing the building and piles to move back to their original height (but not necessarily). If this occurs repeatedly to piles, the building is subject to a phenomenon known as frost jacking, causing extensive damage to the structure of the building, as the jacking of the piles may be different for each pile (Wolfe, 1998, pg. 19).

Between the building and the permafrost, a gravel pad is laid in order to preserve the thermal regime of the frozen ground. The required thickness of a gravel pad to be effective can be calculated taking into consideration the thermal conductivity of the active layer and the gravel, and the mean annual air temperature. If too little gravel is used, the permafrost beneath the building will thaw (French, 2007, pg. 356). 


\subsubsection{2-Roads and Airfields}

The construction of all roads and airfields in the Inuvialuit Settlement Region require aggregates as a base. Roads and airfields by nature increase the mean annual surface temperature of the ground beneath them by several degrees compared to the original conditions of the land (Couture, et al., 2002). Therefore, a thick base of frost-stable gravel must be employed as the base of a road. A typical road embankment in the Arctic should include gravel fill of between one and two metres thick in order to prevent permafrost thaw, in addition to ten centimeters of higher grade gravel for the surface of the road (Andersland and Ladanyi, 2004, pg. 292).

In the past, the engineering of roads and airstrips has been challenging. In Aklavik, when the construction of an airstrip was first attempted in 1951, the engineers removed several layers of topsoil, leaving exposed permafrost. The result of this was land settlement of eight to ten feet within the first year, making the construction of an airstrip on the land unfeasible (Stoneman-McNichol, 1983, pg. 8).

Ice lenses are commonly found under roads and their growth can cause a road to heave, while their thawing can cause the road to subside. When an ice lens melts beneath a road, the soil loses its strength, and the additional weight of vehicles can cause the road surface to break (Penner, 1962).

\subsubsection{3-Pipelines}

In larger Arctic communities, such as Inuvik, the distribution of municipal services such as water supply and sewage removal presents engineering challenges. In non-permafrost 
regions, water and sewer lines run below ground, however if this method was implemented in the permafrost, the pipes would freeze, preventing services from being delivered. Likewise, if the pipes were heated underground to prevent freezing, the heat radiated form the utility lines would thaw the surrounding permafrost.

The solution to the delivery of municipal services in the Canadian Arctic has ranged from burying and heating the pipes, and surrounding them with non frost susceptible gravel, to elevating the utility lines on piles above the permafrost, heating and encasing them in plywood or aluminum to create 'utilidors.' The first method has been employed in Dawson City, Yukon Territory, where the original utility line system was constructed in 1908 , and was built underground directly in the permafrost, and heated to keep the lines thawed. The utility lines subsequently experienced failure due to thaw settlement and frost heave. The second method of ground movement abatement for utility lines is utilidors, which were implemented in Inuvik when the town was constructed in the 1960 s (French, 2007, pg.258). Utilidors also require a layer of gravel beneath them in order to prevent the heat from the utilidor from thawing the underlying permafrost. Both methods are expensive in terms of maintenance and upkeep, and hence they are only feasible in communities with larger populations. Smaller communities, including the five remaining Inuvialuit Settlement Region communities rely on individual water storage tanks and sewage holding tanks for buildings and homes, which are filled and emptied regularly. 


\subsection{3- Alternative Methods of Thaw Prevention}

The use of granular resources as an insulating layer is the preferred method of permafrost preservation in the continuous permafrost zone due to their relative low cost. Other insulating technologies are more expensive to acquire and transport, while granular resources are more locally available. However, there are other technologies that may be used to insulate the permafrost for expensive, larger projects. For smaller projects such as homes, granular material is the most economically feasible method of thaw abatement (McLeod, 2008, Interview).

Thermosyphons, which have been employed in Arctic engineering since the 1950s, are used to extract heat from the ground and disperse it into the surrounding air. The technology involves the transportation of liquid carbon dioxide through tubes which are buried in the permafrost underneath the infrastructure. The carbon dioxide in the tubes evaporates to a gas, which causes heat to be extracted from the soil, henceforth cooling the soil. The gas then travels up the thermosyphons, where it is converted back to a liquid by condensers and the heat extracted from the ground is released (Wolfe, 1998, pg. 20).

Despite their supposed success in abating permafrost thaw compared to the use of gravel pads, more expensive and advanced solutions such as thermosyphon foundations are vulnerable to permafrost thaw and settlement as well. The Western Arctic Visitor's Centre in Inuvik has experienced settlement, and there is a current tender to remediate the existing thermosyphon system using steel piles and a beam foundation (NWT Construction Association, 2008 , Online). For larger buildings, another method of preserving the permafrost is to place insulated mats between the ground and the gravel pad and the gravel pad and the building, and 
then implementing open ended culverts within the gravel pad that allow for circulation of air underneath the building in order to remove radiating heat and cool the ground (French, 2007, pg.356).

\section{4- The Impacts of Climate Change on Permafrost and Infrastructure in the Arctic}

\subsection{1-Arctic Climate Change}

The most important factor in the distribution and disposition of permafrost in the north is climate. According to Overpeck, et al. (1997), the Arctic climate has been characterized by warming, causing glacial retreat, sea-ice melt and permafrost thaw for the past four hundred years. However, the rate of change has been incomparable to any other period since the beginning of the current interglacial period, which began 10,000 years ago. The climate of the Canadian Arctic has been increasingly changing over the past 50 years (Furgal and Prowse, 2008, pg.59). The greatest temperature increases have been observed over the western Arctic, with a change of $2^{\circ} \mathrm{C}$ to $3^{\circ} \mathrm{C}$ over the past 50 years (Zhang, et al., 2000 in Furgal and Prowse, 2008, pg.61). In the Mackenzie District, specifically between 1948 and 2005 there was a warming of $2^{\circ} \mathrm{C}$, while the average increase for Canada over the same period was $1.2^{\circ} \mathrm{C}$ (Furgal and Prowse, 2008, pg. 67). The annual temperatures in Inuvik have increased by $3^{\circ} \mathrm{C}$ since the 1940 s, and it is suggested that the temperature increases are even more pronounced with higher latitudes (NWT ENR, 2008). Furthermore, between 1950 and 1998 in the western Arctic there were fewer extreme low temperature days and more extreme high temperature days during winter, spring and summer (Bonsal, et al., 2001 in Furgal and Prowse, 2008, pg. 67). Based on various global climate models and scenarios, the Intergovernmental Panel on Climate 
Change suggests that the entire Arctic region could warm between 2 and $9^{\circ} \mathrm{C}$ by the year 2100 (Anisimov, et al., 2007). The Mackenzie Delta alone could see an increase in mean annual air temperature of between 4 and $5^{\circ} \mathrm{Cby}, 2050$ (Couture, et al., 2002).

\subsection{2- Climate Change and Permafrost}

The implication of a changing climate on permafrost will be the thickening of the active layer, the thawing of permafrost and the melting of ground ice caused by an increase in the mean annual surface temperature (Instanes, 2004). Furthermore, the entire Arctic permafrost zone will decrease in extent, by approximately twenty-two percent by 2050 and ninety percent by 2100 , if climate change occurs as predicted (Heginbottom, 2000; Anisimov and Nelson, 1997; Lawrence and Slater, 2005). A study using two global climate models indicates that if there is a mean annual temperature increase of 4.9 to 6.5 degrees Celsius due to climate change, the summer thaw season in the Canadian high Arctic could extend by twenty-six days. Due to an extended thaw season, the depth of thaw could also increase by twelve to seventy centimeters (Couture and Pollard, 2007). Because the permafrost of the Mackenzie Valley is considered moderately to highly sensitive to climate change, these impacts could be felt to their full extent in the Inuvialuit Settlement Region (Couture, et al., 2003).

Based upon the Hadley climate model with a moderate emissions scenario for greenhouse gases, the Arctic Climate Impact Assessment (2004) states that areas around the Arctic ocean (like Tuktoyaktuk, Paulatuk, Sachs Harbour, and Ulukhaktok in the ISR) and populated areas further inland such as Inuvik and Aklavik have high potential for climate change induced infrastructure damage (Hassol, 2004). It has been noted that the magnitude of the 
impacts of climate change on geomorphic processes in permafrost landscapes have been largely unresearched (Couture and Pollard, 2007; Yi, et al., 2007). However, it is realized that climate change related changes to the cryosphere will have negative implications for infrastructure of all kinds (Furgal and Prowse, 2008, pg. 59)

\subsection{3- Climate Change and Community Infrastructure}

The impacts of permafrost thaw may be devastating to community infrastructure. If the active layer thickens, the stability of infrastructure including roads, airstrips, pipelines and foundations will be compromised. Couture, et al. (2003) concluded that if permafrost thaws due to climate warming, many building foundations will lose their strength and settle, and pilings will be susceptible to frost heave. Roads and highways, as well as airfields and runways will require more maintenance because of damage due to thaw-induced settlement of the ground. Linear infrastructure, such as pipelines will experience more vertical displacement due to frost heave and thaw, requiring more maintenance and repairs (Couture, et al., 2003). The impacts of climate change on infrastructure are primarily a function of how much ice lies within the permafrost and is susceptible to increased thaw (Couture, et al., 2002).

\subsubsection{1- Buildings}

Building foundations are already highly affected by ground movement, and these ground movements will be exacerbated by climate change. Furthermore, the bearing capacity of the piles on which the buildings sit may be reduced as the active layer thickens, as less of the 
pile will be within the permafrost, and hence there will be less adfreeze bond strength between the ground and the pile (Couture, et al., 2002).

Some engineering firms have incorporated the consideration of climate change scenarios into their design plans for buildings. EBA Engineering Consultants Ltd., is a company that provides engineering and scientific consulting services including Arctic engineering services. EBA has put into practice a procedure which takes climate change into consideration for the design of infrastructure on permafrost. The procedure includes screening the situation for climate change risks, including infrastructure sensitivity to climate change, or permafrost sensitivity to infrastructure presence. Once the vulnerabilities to climate change are identified, the consequences of such change are examined, defining the risk that climate change poses on a project (Hayley, 2004, Online).

An example of climate change consideration for infrastructure within the ISR was the construction of the Inuvik Regional Health Centre which was completed in 2002 in Inuvik. Through the screening principles described above, it was determined that permafrost sensitivity under the health centre was high because of the presence of shallow ground ice in the Inuvik area. Because of these ground characteristics, the risk of failure was rated as major or medium-high because the structural design of the health centre could not withstand movements caused by permafrost thaw and ground settling, as well as the fact that hospital closure would have significant impacts on the communities it serves (Hayley, 2004, Online).

Once the risk of climate change related infrastructure failure was determined, a different type of foundation was selected. Before the alternative foundation design was put into practice, it was evaluated under three climate change scenarios which were based on 
Inuvik air temperature records in order to anticipate the long term trends of the foundation design (Hayley, 2004, Online). As opposed to the traditional timber or steel pile supports generally used in Inuvik for foundations, an alternative technology of thermosyphons was employed for the health centre.

\subsubsection{2-Roads and Airfields}

The economic activities of the Inuvialuit Settlement Region depend highly on the Dempster Highway that leads to Inuvik from the south. If the highway fails due to permafrost settlement, vehicles carrying goods and resources will not be able to reach the community by surface routes, and will necessitate air transport. This would put economic strain on the community as air transport is much costlier than ground transport, and the goods are unavailable locally. Infrastructure for air transport is also crucial, because the other five ISR communities are isolated from road transport networks, with the exception of Tuktoyaktuk and Aklavik which are accessible in the winter by ice road. Therefore, the airstrips must be maintained in order to ensure that goods can be received by communities. The impacts of climate change are quickly observable in roads and airstrips (Couture, et al., 2003). Both frost heave and thaw settlement that naturally occur over the course of a year will be exacerbated by climate change, decreasing the quality of roads for transportation (Hassol, 2004)

There are several methods that could be employed in order to abate road and airstrip failure due to permafrost degradation. The method most commonly used to reduce road settlement in the Northwest Territories is to remove one to one and a half metres of frostsusceptible soil and fill the area with gravel (Wolfe, 1998, pg. 24). Alternative methods of 
abatement include the use of polystyrene to insulate a road embankment, reducing the heat intake of the underlying ground during the summer and reducing the heat extracted from the ground during the winter. It is also possible to ventilate the road embankment by placing air ducts within the embankment perpendicular to the road. During the winter, heat is extracted from the embankment using convection when the wind passes through the air ducts. In the summer, the ducts are closed (Beaulac, et al., nd). More expensive technologies, such as thermosyphons can be used under roads and airstrips, but these work only in the winter when the underlying soil is warmer than the air. It has been estimated that the present cost of repairing transportation infrastructure damaged by climate change is $\$ 1$ million per year in the Northwest Territories (NWT ENR, 2008, Online).

\subsection{4- Observations of Infrastructure Damage and Climate Change}

Impacts of climate change on permafrost and infrastructure have already been observed through both scientific observation and traditional knowledge. The thaw depth of the permafrost in the Mackenzie Delta has been measured by the Geological Survey of Canada, and it has been found that the depths have increased between 1993 and 2003. This is due to an overall increase in permafrost temperature, which was observed to be approximately 0.1 degree Celsius per year in the 1990 s (Couture, et al., 2003). This pattern of increased thaw depth due to increased permafrost temperature will only continue as the mean annual air temperature in the western Arctic increases. Discussion with Neil MacLeod from EBA Consultants, Lid., has indicated that the amount of gravel used for the construction of new infrastructure has already increased by fifteen to twenty percent (Macleod, 2008, Interview). 
Overall, researchers have concluded that the timeframe and magnitude of permafrost degradation due to climate change is relatively uncertain (Heginbottom, 2000).

The most drastic impacts on community infrastructure that have been observed and recorded in the Arctic thus far are in Russia. Buildings and transportation infrastructure alike have been either deformed or destroyed by permafrost thaw that is said to be induced by climate change. Yakutusk, Russia has seen the damage of over 300 buildings due to thawsettlement. In other areas, railway lines have been distorted, runways have become unusable, and pipelines have broken (Hassol, 2004).

Within the Inuvialuit Settlement Region, infrastructure failure occurs but is not necessarily recorded. However, some researchers, such as Couture, Robinson and Burgess (2000) suggest that roads, foundations, utilities and embankments have suffered damage related to permafrost thaw due to natural and anthropogenic changes throughout the Mackenzie Valley. During an interview Kurt Wainman of Northwind Industries, Limited, in Inuvik was able to point out an instance of thaw settlement underneath a utilidor that was constructed only several years prior (Figure 2.4) (Wainman, 2007, Interview). 


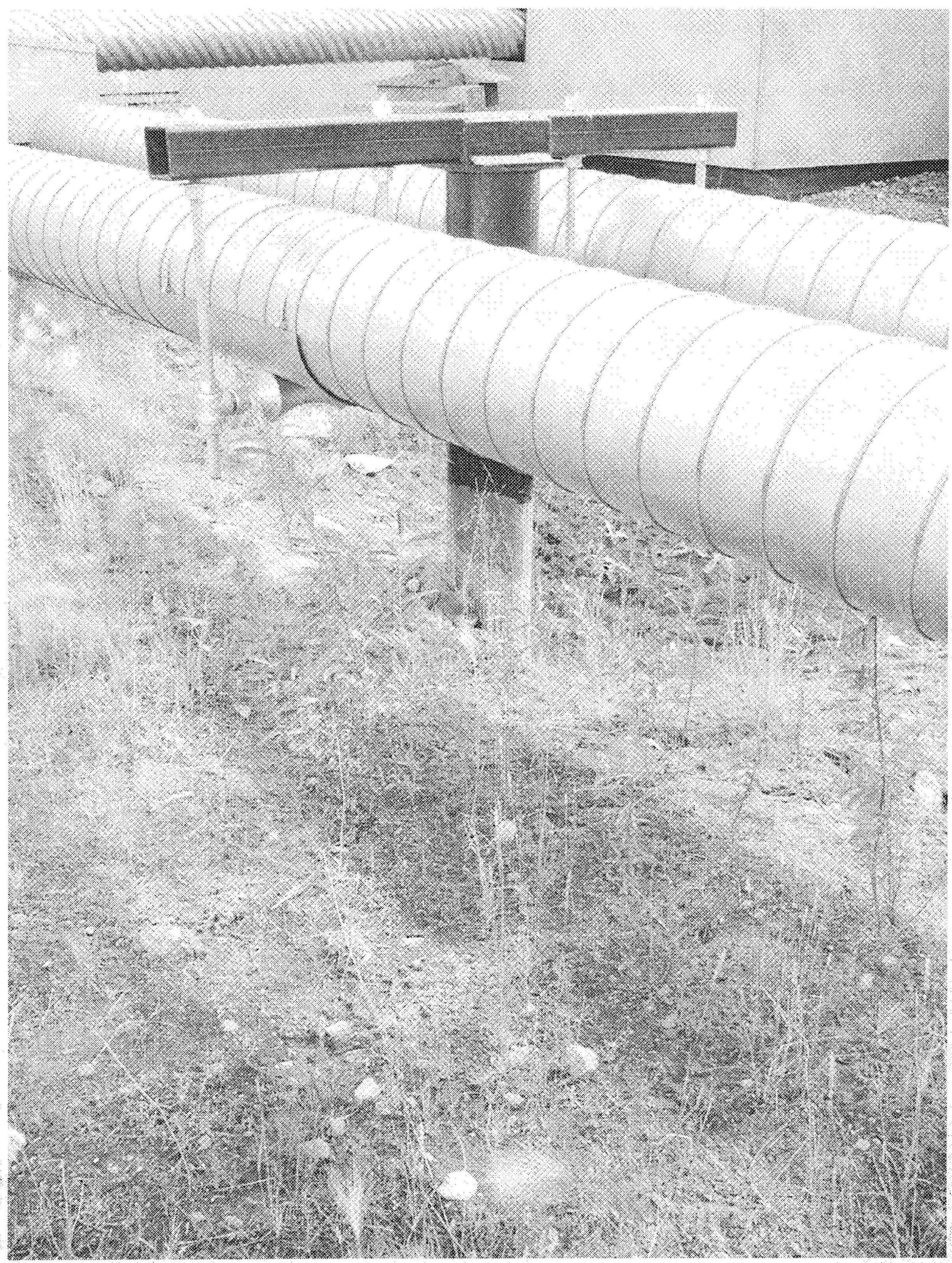

Figure 2.4- Permafrost thaw beneath a utilidor, Inuvik, NWT.

Source: Personal Photograph, 2007 
In the Inuvialuit Settlement Region, traditional knowledge (the knowledge of the Inuit people who have been living on the land for generations) and observations about the changing environment have also been recorded by researchers. Aklavik residents have observed that shorter winters are causing permafrost to thaw sooner. Shorter winters area also known to impact the amount of time available for transportation across the tundra and frozen water (Jozic, 2005). Residents of Inuvik have reported increasing disappearance of permafrost, and increased depth of the active layer (Nickels, et al., 2002), while residents of Tuktoyaktuk have observed melting permafrost. Residents of Sachs Harbour have observed longer and warmer summers, and shorter, warmer winters. They have also observed an increased depth in the active layer of permafrost after the spring thaw (Nickels, et al., 2005; Berkes and Jolly, 2001).

\section{5- Aggregates in the Inuvialuit Settlement Region}

Undoubtedly, granular resources are essential to Inuvialuit Settlement Region communities. Their importance was made evident in the planning of the community of Inuvik. In 1954, the federal government's department of Northern Affairs and National Resources set out to identify a site for the community, which would serve as the new government centre for the western Arctic (Stoneman-McNichol, 1983, pg. 7). The existing centre, Aklavik, was found to be sinking due to flooding and melting permafrost. The federal government chose to relocate the majority of the 1,500 residents and government services of Aklavik to Inuvik which would be built to be more stable, withstanding environmental change (Jozic, 2005).

One of the primary criteria for selecting the site for Inuvik was its proximity to sources of gravel, which would be used for infrastructure construction and maintenance (Stoneman- 
McNichol, 1983; Johnson, 2006). As such, a site for the town was chosen near a large source of glacio-fluvial gravel which lay a few kilometers away from the town. Since the town's conception, gravel has served as a vital resource-the entire town was built upon a continuous gravel pad (French, 2007, pg. 358).

The Inuvialuit Final Agreement, implemented in 1984, was created in order to give the Inuvialuit people guaranteed rights from the Government of Canada, including those to land and wildlife management. The goals of the IFA were to preserve the Inuvialuit cultural identity, to enable the Inuvialuit to be equal and meaningful participants in the northern and national economy and society, and to protect and preserve the Arctic wildlife and environment. In an attempt to ensure that the goal of socio-economic success of the Inuvialuit people is achieved, the guidelines for the management of resources are set out in the IFA. The document sets out three priorities for the management of granular resources in the Inuvialuit Settlement Region, which are summarized as follows:

1. The Inuvialuit should reserve enough sand and gravel of appropriate quality and within reasonable transport distances on Inuvialuit lands to meet the public community needs in the ISR and Inuvik, based on 20 year forecasts of the volumes required from Inuvialuit Iands prepared by the Inuvialuit and other appropriate levels of government that should be updated no less frequently than every 5 years (IFA Section $7(27)$ )

2. The Inuvialuit should reserve enough sand and gravel of appropriate quality on Inuvialuit lands for private and corporate needs of the Inuvialuit people, and not for sale, based on 20 year forecasts of required volumes prepared by the Inuvialuit Land Administration (IFA Section 7(28)) 
3. The Inuvialuit should make available sand and gravel for projects approved by appropriate government agencies (IFA Section 7(29))

The IFA makes it clear that there is interest in gravel from a number of stakeholders. Granular resources are required for meeting public community needs-for infrastructure construction and maintenance (such as transportation routes and building foundations) carried out by the Government of the Northwest Territories or Municipal and Community Affairs. Furthermore, after granular resource requirements for public needs are met, gravel is also required for the private and corporate interests of the Inuvialuit people. This includes the use of gravel for construction purposes at their private dwelling, as well as for construction for their business operations and developments. For example, an Inuvialuit owned construction business may require a gravel pad for their construction equipment to be stored upon, or an Inuvialuit business may use gravel to develop a subdivision or apartment building. Finally, if public and private demands are met, the Inuvialuit have an interest in making gravel available for projects approved by government agencies, such as the Mackenzie Gas Project which may be approved by the federal government.

The Government of the Northwest Territories (GNWT) and Municipal and Community Affairs (MACA) also have an interest in gravel for infrastructure development and maintenance. Community governments (MACA) are responsible for obtaining granular material for the construction of infrastructure such as arenas, community centres, firehalls, garages, retirement homes, health care offices, visitor centres, schools, sewage lagoons, and water supply systems. The GNWT requires gravel for projects that are carried out and funded by the territorial 
government, such as transportation routes and airfields. All of these projects fall under the first priority (Section 7(27)) of the Inuvialuit Final Agreement. Furthermore, the federal government also has interest in gravel for its own projects such as the construction of government buildings.

Recognizing the significance of gravel and the range of stakeholder interests, granular resource forecasts are required by the Inuvialuit Final Agreement. These forecasts are reports about the granular resource demands of specific users over a certain length of time. They can contain information from both public and private users, and encompass a timeframe of several years, with forecasts for future demand. Granular resource demands estimated in the report are for operation and maintenance of existing infrastructure, the construction of new infrastructure, and for proposed infrastructure which may or may not be approved yet. A forecast also includes information about what type of granular resources are required, and where they are proposed to come from.

Since the Inuvialuit Final Agreement was implemented in 1984, four granular resource demand forecasts have been conducted $(1987,1991,1995$ and 2001) in an attempt to meet the requirements of Section $7(27)$. The forecasts have been conducted intermittently, rather than at five year intervals as required by the IFA, and there has been no update within the last seven years. The Government of the Northwest Territories conducted its own Territorial Granular Resource Forecast in 2007 , but it accounts for only a portion of the entire demand within the Inuvialuit Settlement Region. The lack of consistency in conducting granular resource forecasts at regular intervals for all levels of interest is symptomatic of the issues that hinder the management of granular resources in the region. 
In order to ensure that demands for gravel can be met in a sustainable manner, the maintenance of a gravel supply inventory would be very useful, but this is not required by the Inuvialuit Final Agreement. However, the estimation of gravel supply is not easy and is regularly inaccurate because it is too expensive to carry out ground reconnaissance, and estimates are largely made based on air photos. Supply inventories only take into account gravel where it is demanded, for example, near communities, or private natural resource development sites where reconnaissance is funded by the developer (Gowan, Personal Communication, 2007). Furthermore, it is highly likely that gravel is removed from borrow sources without permits, which makes it impossible to monitor how much gravel remains in the community gravel supplies (Romaine, Personal Communication, 2007).

The existence of gravel does not necessarily make it a viable source of supply to a community. Major physical and environmental constraints may prevent a plentiful source of high quality gravel from being developed and extracted, and these constraints may ultimately limit the overall supply of gravel. Physical constraints to developing granular borrow sources include excessive overburden over the deposit or excessive ice or moisture, preventing gravel from being economically and easily extracted. The preservation of wildlife and the surrounding physical environment must also be maintained while developing and extracting gravel in the Inuvialuit Settlement Region, in order to achieve one of the overlying principles of the Inuvialuit Final Agreement: to "protect and preserve the Arctic wildlife, environment and biological productivity" for the traditional activities of the beneficiaries (Inuvialuit Regional Corporation, Online, 2007). The supply of gravel is thus also limited by ecologically sensitive areas, including wildlife migration and breeding grounds, as well as those susceptible to soil erosion, destruction 
of permafrost, and soil or water contamination (Northern Granular Resources Program, May, 1996).

\section{6- Uncertainties About Gravel in the Inuvialuit Settlement Region}

Despite its fundamental importance to community growth and wellbeing, resource managers and members of the granular resource industry alike agree that gravel is one of the most mismanaged resources in the Inuvialuit Settlement Region (Personal Communication, 2007,2008 ). At the outset of this project, lengthy interviews were conducted with two people who had expert knowledge about granular resources in the ISR: Robert Gowan, Manager of Land Programs for Indian and Northern Affairs Canada (INAC), and Todd Romaine, Chief Land Administrator of the Inuvialuit Land Administration.

Robert Gowan has been involved with granular resources in the north since the inception of his career in the 1970s, testing for and evaluating aggregates. At INAC, Mr. Gowan has played a major role in Arctic granular resource studies and management plans, including the Inuvialuit Final Agreement Implementation Plan. Mr. Gowan highlighted that the management of granular resources has been a longstanding issue facing the inuvialuit Settlement Region. From his perspective, some of the major obstacles to developing a successful granular resources management plan are:

- A lack of coordination between governmental bodies to meet the priorities of the Inuvialuit Final Agreement, including regular demand forecasts.

- An unclear picture of how much gravel is available to the communities, because the supply inventory is primarily based on where development activity exists. 
- A high staff turnover and overstretched staff make it difficult to advance the development and implementation of a granular resources management plan in the Inuvialuit Settlement Region.

Todd Romaine is the current Chief Land Administrator for the Inuvialuit Land Administration (ILA), which, as part of its mandate oversees the allocation of granular resources on Inuvialuit Private Land. From the perspective of the Inuvialuit Land Administration, gravel is the most important resource management issue facing the ILA. Some of the defining issues of granular resource management in the Inuvialuit Settlement Region are:

- Granular resource borrow sites within close proximity to the communities have been depleted, and it is expensive and difficult to access further sources.

- The lack of a regional framework and coordination between the Inuvialuit and the Territorial and Federal governments makes the sustainable allocation and management of granular resources difficult.

- There will be increased demands for gravel in the Inuvialuit Settlement Region in the near future with the development of the Mackenzie Gas Project, and the possible Inuvik-Tuktoyaktuk Highway. There may also be increased demands for gravel due to climate change.

It is apparent from a literature review and discussion with land managers that there is a lack of critical information on aggregate resource management in the ISR. Crucial to determining how granular resources should be managed, especially in the face of climate change is an understanding of how the ownership of gravel is distributed in the inuvialuit 
Settlement Region, and how gravel is obtained from these land owners. There is no document available with consolidated information about who has ownership of what gravel, and what the regulatory process is for developing and obtaining gravel as an end user from each of these owners. Without this information, it is difficult to identify whether the process by which gravel is obtained in the ISR matches the way legislation dictates and whether licensing, monitoring and enforcement of gravel extraction follows legislation.

Also lacking is an accurate supply inventory of gravel, and a current demand forecast of the gravel required by users within the region. Both of these are essential tools for the sustainable allocation of resources in the face of future demand and climate change. Without the above information it is difficult to produce a prognosis for granular resources in the Inuvialuit Settlement Region. This hinders the development of a management plan which can minimize community vulnerability to a changing environment in which granular resources are in short supply and high demand for infrastructure construction and maintenance. 


\section{7- Research Questions}

From reviewing literature and discussions with land managers, several research questions became apparent, highlighting what needs to be known about the impacts of climate change on the availability of gravel resources in the Inuvialuit Settlement Region:

a) What are the current interests in granular resources? How are they regulated and obtained compared to how legal frameworks describe the process?

b) How will the demand for gravel for use in infrastructure construction and maintenance be affected by climate change?

c) How will the supply and availability of gravel be impacted by climate change?

d) How can the management regime for granular resources adapt to address issues arising from climate change?

The answers to these questions serve the purpose of ultimately answering the project research question:

What are the implications of climate change for the availability of granular resources in the Inuvialuit Settlement Region? 


\section{1-Objectives}

For this paper, it is clear that several questions must be answered in order to develop a consolidated account of the state of granular resources in the ISR at present, and how supply and demand may change with a warming climate. Ultimately, the management of granular resources in such a way that reduces community vulnerability is dependent on information that is not yet researched or consolidated.

What is not known is how climate change will specifically impact the infrastructure in the Inuvialuit Settlement Region, how the supply of and demand for gravel to abate infrastructure failure will change with climate change, and how the management of gravel will need to be adapted in order to accommodate these changes.

The impact that climate change will have on infrastructure in the ISR is uncertain, due to the fact that there have been very few ISR-specific studies conducted and most of these studies are at a broader spatial scale. However, a hypothesis of the manner in which infrastructure may be impacted by climate change is developed in this paper by drawing upon secondary information from Arctic-wide impact assessments, ISR focused studies, and primary information from people living and working in the ISR who have observed infrastructure failure due to a changing environment.

Before determining the factors impacting the availability of granular resources in the region, it is necessary to deconstruct and understand the management regime of granular resources in the ISR. With three resource owners and various factors (i.e. cost and distance) affecting a user's decision-making process about where and from whom to obtain gravel, the seemingly simple process of obtaining gravel can be complex. Chapter 4 draws upon 
information from government documents including Acts and Regulations, and Pits and Quarries Guidelines from Indian and Northern Affairs Canada (INAC, 1982) for the purpose of detailing the process of obtaining granular resources from the different land owners from the beginning (permit application) to the end (site remediation).

In order for granular resource managers to allocate gravel in a sustainable manner and in accordance with the priorities of the Inuvialuit Final Agreement, information about the disposition of the gravel sources within the ISR is necessary. The existing gravel inventory of the Inuvialuit Land Administration contains data about the amount of gravel in each known source, the season and method of access to the pits, and physical or environmental constraints to developing the pits. This information is used in combination with static maps to develop a set of maps in a Geographic Information System (GIS) that allows for the analysis of how the supply of gravel could be impacted by climate change. The potential impacts of climate change on supply are analyzed based on the suggestions of secondary literature and expert information from interviews about how climate change will impact seasonal transportation methods, ground ice melt, and ultimately the ability to obtain gravel.

The other primary variable for consideration in granular resources management is demand for gravel. A demand forecast for all levels of jurisdiction within the Inuvialuit Settlement Region does not exist, making the allocation of resources difficult and uncertain because the present and future demand for gravel is unclear. Using all available demand information from government and private gravel users, an account of what is known about demand is developed. This is done through the consolidation of available data about the issuance of quarry permits on Crown and private land since the inception of the Inuvialuit Final 
Agreement. Furthermore, secondary information and interviews with infrastructure planners and engineers are used to hypothesize the magnitude of increased demand that will be placed on gravel due to climate change. This information is crucial to the future development of granular resource demand forecasts that will be essential for managing gravel in the face of climate change.

Through the use of primary and secondary information, this project aims to fill the research gaps that exist about granular resources in the Inuvialuit Settlement Region. In trying to fill these gaps, the obstacles that hinder the management of granular resources, such as a lack of demand forecast participation, or an inconsistent supply inventory emerge.

\section{2- Secondary information}

Secondary information was used in this report to develop a framework for answering the research questions, identifying what is known about granular resources and their management in the ISR, and in doing so, highlighting what is unknown and must be discovered through primary research. Furthermore, secondary information is synthesized in this project to create information that can be used for critical analysis of the supply of, demand for, and management of gravel. The secondary research for this project draws upon governmental reports, legislative documents, consulting reports, journal articles and data from administrative bodies.

Climate change reports and impact assessments including the Intergovernmental Panel on Climate Changes's Fourth Assessment Report (2007), the Arctic Climate Impact Assessment (2004), the Northwest Territories' Climate Change Impacts and Adaptation Report (2008), and 
the Government of Canada's From Impacts to Adaptation: Canada in a Changing Climate (2008) were used for identifying the prognosis for the Arctic region, the Canadian Arctic, and the Inuvialuit Settlement Region. There are no reports about the potential changes brought about by a warming climate specifically for the ISR, but the broader reports were used to project the changes that could occur in the ISR. Reports for the Geological Survey of Canada (Couture, et al., 2002) and Environment Canada (Maxwell, 1997) were used to find observations about temperature, precipitation and permafrost thaw specifically for the Mackenzie Delta, which are each individually indicative of a changing environment. By drawing upon reports from a broader spatial context and studies specific to certain climate characteristics within the Mackenzie Delta, a prognosis for the Inuvialuit Settlement Region was developed.

The regulatory process for obtaining granular resources is complex in the Inuvialuit Settlement Region in part due to the fact that there are three governing bodies with jurisdiction over gravel that lies on their land within the ISR. In order to determine whether granular resources are being extracted and managed according to the regulations that have been laid out by government legislation, a flow chart of the physical and regulatory processes for obtaining gravel was generated. Another flow chart was then created about the factors that influence a user's decision as to where to obtain gravel from. Flow charts were derived using governmental publications including Indian and Northern Affairs' Guide to Mineral Exploration and Development in the Northwest Territories, and the relevant legislative documents such as the Territorial Lands Act, the Commissioner's Lands Act, the Territorial Quarrying Regulations, and the Inuvialuit Final Agreement. The process for obtaining gravel, as dictated by acts and 
regulations was later compared to primary accounts (through interviews) of how gravel is actually obtained by granular resource users. In comparing the theoretical and actual processes, gaps in the monitoring of gravel extraction and enforcement of regulations were identified.

The knowledge of historical and present supply of and demand for granular resources is crucial to managing granular resources as the climate warms. According to the Inuvialuit Final Agreement, demand forecasts for granular resources in the Inuvialuit Settlement Region are to be completed every five years, forecasting for the twenty years ahead. Historically, these forecasts have not been carried out as often as required by the IFA due to various constraints. The forecasts, which were completed by consulting companies including EBA Engineering Consultants, Ltd. (1987), Hardy BBT, Ltd. (1991), and North of 60 Engineering, Ltd. (1995 \& 2001), were obtained. In reviewing the historical granular resource forecasts that have been carried out for the ISR, constraints that have diminished the accuracy and timeliness of the reports were identified. The constraints faced in the past are indicative of the issues faced by current granular resource managers in completing forecasts. These constraints translate to obstacles that must be overcome in order to develop accurate forecasts that will aid the management of gravel in the face of climate change. Furthermore, a database of historical demand was derived based on available data about quarry activity in the ISR since the implementation of the Inuvialuit Final Agreement in 1984. Historical data about quarry licenses issued by the Inuvialuit Land Administration were obtained for the years 1984-2000 from a North of 60 Engineering, Ltd. report (2001), and for the years 2000-2007, from an Inuvialuit Land Administration database. Information about quarry permits is not directly available from 
Indian and Northern Affairs Canada, and as such was derived through information about the issuance of Land Use Permits for quarry activity on Crown land. Land Use Permits issued within the ISR were selected from a database by doing a query on a map within Indian and Northern Affairs Canada's NWT Region Spatial Data Viewer (Department of Indian Affairs and Northern Development, 2006), The information from the various sources was compiled in order to create a chart detailing historical quarry activity within the region, as well as information about the granular resource user, and what the gravel was being used for. This allowed for analysis of temporal trends of granular resource usage, and of the most common users/uses of gravel within the ISR.

Along with demand, another essential part of determining the prognosis for granular resources in the Inuvialuit Settlement Region is gravel supply and how it will change with climate change. Currently, a supply inventory of granular resource borrow sites, their locations, amounts of gravel, and constraints to extraction exists, based upon a 1987 supply inventory by EBA Engineering Consultants, Ltd. was obtained from the Inuvialuit Land Administration. The supply inventory is currently used when approving quarry permits in order to determine whether enough supply exists at the borrow source the user would like to extract from.

\section{3- Spatial Analysis}

For this project, the supply inventory was used in conjunction with maps of the borrow sites to create digital maps that contain information that can be analyzed in a Geographic Information System. Such a system is not currently implemented for spatial analysis of supply of and demand for gravel in the Inuvialuit Settlement Region (Harlow, 2008, Personal 
Communication). For the purposes of this project, the use of a GIS allows for the practical analysis of the gravel supply, taking into account constraints to accessibility and development, as well as constraints caused by climate change.

In order to create maps to be used for spatial analysis, the locations of the granular resource sites were plotted on Northwest Territories boundary shapefiles through heads-up digitizing. The location maps were then joined to the supply inventory database, which contains information about the amount of granular resources available at the site, and constraints to developing the site such as ice within the ground, poor quality, sporadic deposits, wildlife or environmental significance, or seasonal inaccessibility.

Once the maps were joined to the supply database, the granular resource borrow sites were buffered at increments of 10,15,20 and further increments of 10 kilometres each. An initial buffer of 10 kilometres was implemented because a hauling distance of greater than 10 kilometres is considered "long distance" in the Territorial Granular Resource Forecast (2007). Through buffering, the number of pits within a reasonable hauling distance of the communities became apparent. Once categorized by distance from their respective community, the pits were identified as "unconstrained" or "constrained" to development and extraction of granular material. If a pit had year-round access to gravel, as well as no constraints to development, it was considered "unconstrained," meaning that it was feasible to develop. Those pits that had only seasonal access, and/or constraints to development were considered "constrained," meaning that they are developable, but it would be less feasible and/or more expensive to do so. This categorization allowed for the analysis of which pits are actually feasible and hence 
desirable sources of granular material, and how far a user must travel to obtain materials of the appropriate quality for their project.

In order to determine which of the feasible sources could be made inaccessible or undevelopable due to warmer temperatures, further constraint analysis was carried out. If a source was accessible year round, and had no constraints to development, as well as no massive ground ice with the potential to melt with warming temperatures, it was considered "unimpacted by climate change." However, if a source was only accessible during the winter season by ice or tundra road, or had massive ground ice that was susceptible to melting it was categorized as "impacted by climate change." From this constraint analysis, the sources that will not be impacted by climate change are highlighted, allowing for discussion of how community granular resource supply may further decrease in the face of climate change. The results of the constraint mapping are available in tabular form in Appendix $E$, and the maps are available in Appendix F.

\section{4- Primary information}

It is evident from reviewing published data that there is a lack of information that is critical to assessing the impacts of climate change on the availability of granular resources in the region. Secondary research identified the information gaps that could hinder the management of granular resources. In an attempt to fill these gaps, people involved with granular resources in the Inuvialuit Settlement Region on a daily basis were interviewed. The purpose of the interview process was twofold: to gain information about granular resources, their use and management in the Inuvialuit Settlement Region that is otherwise unavailable 
through literature, and to realize the concerns held by the people of the ISR about how climate change may impact their communities in regards to infrastructure and granular resources. The information obtained from the interviews was then integrated into the report in order to support discussion of community vulnerability and potential adaptations of granular resource management to climate change.

\section{5- Field Work}

For approximately three weeks in August, 2007, field work was carried out in the Inuvialuit Settlement Region. Travelling to the ISR allowed for the collection of both primary and secondary information as well as for gaining a first-hand perspective of the operations of northern communities. In order to carry out research in the ISR, a research license was obtained from the Aurora Research Institute as required by the NWT Scientists Act. Relevant organizations within the study area were given the opportunity to approve the research and provide feedback or requests. Not only Inuvialuit organizations were contacted, because Inuvik, the primary location for research consists of Gwich'in and Metis populations as well, who all contribute to the socio-economic situation of Invuik. The organizations consulted for the research license included: the City of Yellowknife, the Gwich'in Social and Cultural Institute, Hamlet of Tuktoyaktuk, Inuvialuit Community Development Division, Inuvialuit Land Administration, Inuvik Community Corporation, Inuvik Metis, Nihtat Gwich'in Council, North Slave Metis, Northwest Territories Metis Nation, Town of Inuvik, Tuktoyaktuk Community Corporation and Yellowknife Dene First Nation. The Town of Inuvik and Tuktoyaktuk 
Community Corporation expressed interest in helping to establish contacts for interviews, and requested copies of the report upon completion.

\subsection{1-Interviews}

A questionnaire was designed to draw upon the specialized knowledge of each of the participants. The questionnaires consisted of both specific questions to the participant's line of work, and common, opinion-based questions about the participant's concerns for their community and granular resources in the face of climate change. Factual questions about the stakeholder's area of expertise provide insight about how gravel is managed, obtained, and used for construction in the ISR, which is otherwise unavailable through literature. Answers to opinion-based questions can be used to identify the concerns of community members about the impacts of climate change on their communities, and how they feel granular resources should be managed in order to meet these impacts. Furthermore, anecdotal observations about infrastructure and climate changes in the communities give direction for further research into whether the observation was actually on account of climate change, or due to cyclical environmental phenomena. In conducting interviews, more information is gained that contributes to the development of a prognosis for the ISR and granular resources in a changing environment.

\subsection{2-Identification of Stakeholders}

Before departure to the Inuvialuit Settlement Region, communication was established with the Inuvialuit Land Administration, the body which manages Inuvialuit owned granular 
resources. Upon arrival in Inuvik, Mike Harlow and Kyle Sherwin of the Inuvialuit Land Administration provided an update of the status of granular resource management in the ISR, and provided initial contacts for interviews. When conducting research about a topic that includes a broad range of stakeholders from various industry backgrounds, networking is an essential resource. For example, the land administrators issue permits for gravel extraction and therefore can identify gravel pit developers who may be useful to interview. Meanwhile, gravel pit developers may be able to identify those who are demanding gravel for infrastructure development.

The granular resources industry in the ISR is complex because there are many stakeholders from different backgrounds with interests in granular resources. The individual stakeholders can be classified into the following four categories:

1. Granular Resource Management-Participants in this category are involved in the issuing of permits and licenses for extracting gravel, monitoring gravel supply, or forecasting demand for granular resources. Their interests are in regulating the use of granular resources, as well as determining whether there will be enough supply to meet the demands of communities and of private entities within the ISR. Granular resource managers may have concerns about the current management system for granular resources. They may also have observations about whether impacts of climate change on the demand for granular resources have already been observed, and what changes could be made to management practices to accommodate the impacts of climate change. 
2. Granular Resource Extraction, Processing and Hauling- These interviewees are involved in quarrying granular resources and processing them into desired forms. They may also be involved in the transportation of equipment to and from the borrow sites, as well as the hauling of gravel from the supply site to the demand site. They may have observations about climate change and accessibility, and concerns about how gravel will be obtained in order to meet demands in the face of a changing climate.

3. Infrastructure Planning, Construction and Maintenance-Stakeholders in this category include engineering consultants, public infrastructure planning officials, and private contractors. These participants are familiar with the gravel demanded by the construction and maintenance of Arctic infrastructure. They may have observed changes in the amount of gravel required for construction already, and may have insight about how much gravel will be demanded in order to abate the impacts of climate change on infrastructure.

4. Community Government Members-Community government members are knowledgeable in the operations and concerns of the ISR communities. They may be in mayoral positions, or sit on community organization boards. These stakeholders are familiar with the overall issues facing communities, and the concerns of the community members. They may be able to identify the specific concerns of community members about the management of gravel, especially in regards to environmental concerns and 
constraints that may conflict with the values of the Inuvialuit people. Community government members may suggest ways in which the communities are/should be adapting to the potential impacts of climate change on granular resources demanded by vulnerable infrastructure.

Potential respondents were identified in two ways. In March of 1999, a Granular Resources Directory was published by the Department of Indian Affairs and Northern Development. The purpose of the directory was to assist governing bodies with the sustainable development of granular resources by identifying stakeholders from all backgrounds. This directory was useful for obtaining contact information for stakeholders relevant to this project including construction companies, extractors, haulers, engineering consultants and people in government roles.

Bob Gowan (INAC, Ottawa) was able to provide contact information for stakeholders in government positions that were knowledgeable of the granular resources situation in the Northwest Territories and the ISR. As well, once interviews were conducted, the interviewees often provided suggestions for further contacts that may be of interest.

Once identified, stakeholders were contacted through e-mail or by telephone in order to determine whether they would be willing to participate in the interview process. Interviews were conducted in person during the field visit in August, 2007, or by email response or telephone between 2007 and 2008.

The stakeholders who participated in the interview process included Bob Gowan of Indian and Northern Affairs Canada, Todd Romaine, Mike Harlow and Kyle Sherwin of the 
Inuvialuit Land Administration, Mardy Semmler of the Gwich'in Tribal Council, Eddie Dillon of the Tuktoyaktuk Community Corporation, Kurt Wainman of Northwind Industries, Ltd., Jordan Fedosoff of Matco Transportation Systems, Neil MacLeod of EBA Engineering Consultants and Roy Wilson of Imperial Oil Resources. Brief communication also occurred with Susan Chaytor of Alpha Corporation and Fred Collins of the Government of the Northwest Territories.

\subsection{3- Questionnaires}

Questions for stakeholders in the granular resources management category were designed to obtain an accurate picture of how granular resources are actually managed at present by the manager's specific level of jurisdiction. These questions are vital, because the way in which gravel is managed is often different from how regulatory documents suggest it must be managed. Further questions asked for details on how gravel supply inventories and demand forecasts are conducted within the specific level of jurisdiction, and what issues are faced in completing accurate inventories and forecasts. Finally, questions about how the prospect of climate change could be factored into the management of granular resources in the future were posed.

Interviewees in the second category, those in the granular resources extraction, processing and hauling industry firstly focused on how gravel is extracted and processed in the ISR, and during what time of the year the activities are carried out. Questions about accessibility of resources were raised in order to determine what seasons are most important for the granular resources industry, and therefore analyze what the seasonal impacts of climate change may be on granular resources processing and transportation in the future. Participants 
were asked for their observations, if any, about environmental changes that are already occurring and impacting their operations. Finally, questions were asked about how they predicted their businesses could adapt to a changing climate.

The participants from the infrastructure planning, construction and maintenance category were asked questions intended to gain a perspective about the importance of gravel in the construction of infrastructure in the ISR. Furthermore, questions were asked about the relative advantages of granular resources compared to other technologies for insulating permafrost. Since these people have knowledge of specific projects, they were asked for their observations about the impacts of climate change on infrastructure, and whether they have experienced difficulties in obtaining gravel for projects. As well, the interviewees were asked about their expectations about what the additional requirements for granular resources will be for infrastructure construction with a warmer climate.

The final category of respondents consisted of members of community government, who were not necessarily directly related to the granular resources industry. These people were asked for their observations about concerns related to climate change, and specifically stresses on granular resources due to climate change. Community based stakeholders were asked about community concerns about gravel use, availability, and management, as well as whether the management of gravel should be an issue of top priority. As well, they were asked for suggestions about how the management of granular resources may need to change in order for communities to adapt to climate change.

The information obtained through participant interviews was used throughout the report in order to provide insight where information could not be found in literature. As well, it 
was used in the analysis of the overall management of granular resources, giving suggestions and direction as to how management must adapt in the face of climate change and increasing demands for granular resources. The entire questionnaire can be found in Appendix $A$ and the most significant results of the interviews are located in Appendix B. 


\section{1- Land and Resource Jurisdiction}

Within the 450,000 square kilometers of the Inuvialuit Settlement Region, there are three land owners: the Inuvialuit (Inuvialuit private lands), the Government of the Northwest Territories (Commissioner's lands), and the Federal Government of Canada (Crown lands).

Inuvialuit private lands comprise approximately twenty percent of the lands within the ISR. The Inuvialuit Land Administration has jurisdiction over Inuvialuit private lands that fall under the categories of " $7(1)(a)$ " and "7(1)(b)" lands as defined in the Inuvialuit Final Agreement. $7(1)(a)$ lands refer to lands to which the Inuvialuit hold both surface and subsurface rights, while $7(1)(b)$ lands refer to lands to which the Inuvialuit hold only surface rights. Surface rights were granted to the inuvialuit for granular resources only, while subsurface rights include rights to granular resources, as well as oil, gas, other hydrocarbons, coal, sulphur and minerals. The dispersal of $7(1)(a)$ and $7(1)(b)$ lands can be seen in Figure 4.1 . $7(1)(a)$ lands consist of approximately 13,000 square kilometers of land, which lie in 1,800 square kilometer blocks surrounding each of the six ISR communities. 7(1)(b) lands consist of 78,000 square kilometers which lie further afield from the communities.

Nearly eighty percent of the land within the ISR belongs to the federal government. Crown lands within the ISR are administered by the Minister of the Department of Indian and Northern Affairs and Northern Development. The Minister "is responsible for resources in the Northwest Territories, and has control, management and administration of all lands situated in the Northwest Territories belonging to Her Majesty in right of Canada not under management, charge or direction of any other Minister or agency of the Government of Canada (INAC, 15 
November 2007, Online). The DIAND also administers the subsurface rights on $7(1)(b)$ Inuvialuit Private lands and subsurface rights for resources on Commissioner's Lands.

Commissioner's land is land which has been transferred from the Government of Canada to the Commissioner of the Northwest Territories. This land accounts for two percent of the land within the Northwest Territories. Commissioner's lands within the ISR are administered by the Lands Administration section of the Government of the Northwest Territories' Department of Municipal and Community Affairs. MACA administers the Commissioner's land by "selling, leasing, or otherwise disposing of land within municipal boundaries of communities in the Northwest Territories" (Government of the NWT, nd, Online). Thus, MACA is responsible for the management of gravel on Commissioner's lands which is used by the GNWT Departments of Transportation and Public Works and Services. 


\section{LEGEND: \\ Inuvialuit Final Agreement, Signed 1984 \\ - Inuvalut Settement Regon Surface and sub-surtace rights \\ - Suface rohts only}

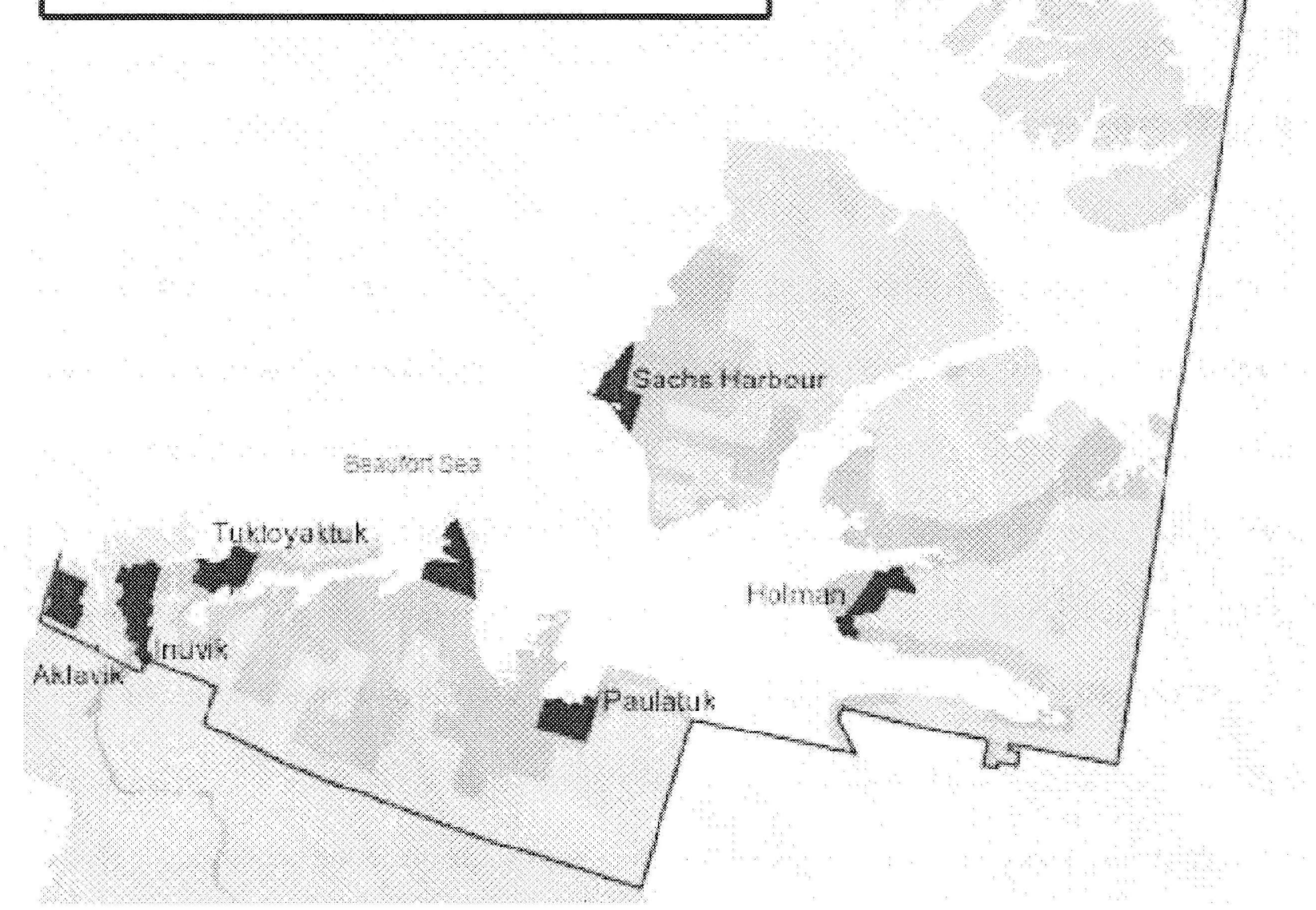

Figure 4.1- Distribution of $7(1)(a)$ (Surface and Subsurface Rights) and $7(1)(b)$ (Surface Rights Only) Lands in the inuvialuit Settlement Region Source: Alpha Corporation (March 2007)

\section{2- Obtaining Gravel Within the Inuvialuit Settlement Region}

There are seven broad stages to acquiring granular resources in the Northwest

Territories: exploration, regulatory approvals, financing, site preparation, extraction, processing and site rehabilitation. The rigour with which these stages are carried out is 
dependent on who has jurisdiction over the land on which the potential borrow source lies, and whether it is an existing or newly discovered borrow source. The following are descriptions of the seven stages of obtaining gravel, based on the existing legal frameworks for the various levels of jurisdiction. The process has been portrayed visually in flow-chart format in Appendix C, Diagram 1.

\subsection{1- Exploration}

In the case that a new granular resource borrow source is being sought out for example, for the Mackenzie Gas Project), the exploration stage is necessary and consists of field research and measurement activities which are used to gain information about the location of the source and characteristics of the deposit. There are five general stages to geological exploration including literature research studies, field surveys, geoscientific studies, test drilling and market feasibility studies.

The preliminary assessment of an area for granular resource potential does not require regulatory approval as it is non-invasive and involves the review of published information which may help to identify potential borrow sources. Research may also include communication with local community members and established sand and gravel developers in order to gain information that may not have been published. Before any further exploration may be done in the Inuvialuit Settlement Region, each of the jurisdictional bodies has regulatory approval requirements which must be achieved. 


\subsubsection{1- On Inuvialuit Private Land}

Applications for Access Agreements, Participation Agreements and Cooperation Agreements, as well as for Land Use Permits must be submitted to the Inuvialuit Land Administration for approval. An Access Agreement grants the right to travel across Inuvialuit Private Lands and to exercise rights issued by the ILA other than those in the Participation Agreement. It is required for a Reconnaissance Permit, Quarry Concession, or Quarry License granted by the ILA (Indian and Northern Affairs Canada (a), 2005). A Participation Agreement is an agreement between the proponent and the ILA, which sets out the rights and obligations for the ILA and the proponent about the proposed activities to be carried out on Inuvialuit lands. It must be obtained before the granting of a Land Use Permit (Indian and Northern Affairs Canada (a), 2005). A Land Use Permit is issued by the ILA, and allows for an operation to be carried out on Inuvialuit Private Lands. It permits the use of explosives, heavy equipment, drilling equipment and other granular resource development-related activities. It may be issued for a period of up to two years (Indian and Northern Affairs Canada (b), 2005).

Before the applications for these permits and agreements are approved, consultation with the local community must occur. In the general consultation procedure, the assistant land administrator sends a memorandum and copy of the application to various parties of interest including: each member of the Inuvialuit Land Administration Commission (ILAC), the local community corporation (CC), the local Hunters and Trappers Committee (HTC), and if necessary the Inuvialuit Regional Corporation, Inuvialuit Game Council (IGC), the NWT Wildlife Management Advisory Council or the Wildlife Management Advisory Committee, the Inuvialuit Development Corporation (IDC) and the Fisheries Joint Management Committee (FJMC). The 
assistant land administrator requests comments on the application to be made within a specific time period. The application will be reviewed at an ILAC meeting, where representatives of the parties above may voice their comments or objections before the ILAC or may send written comments and concerns. The applicant may also attend the public portion of the meeting and may be allowed to make a presentation to the ILAC. Only the ILAC commissioners and the ILA staff will attend a commissioner's session to make decisions about the application. The application will be approved, deferred with requirements for further information or a proposal to the Environmental Impact Screening Committee, or rejected by the Land Administrator (Indian and Northern Affairs Canada (a), 2001).

If the application is accepted, the Access Agreement, Participation Agreement, Cooperation Agreement and Land Use Permit are obtained by the proponent. However, if during the community consultation process the application is deferred, an Environmental Impact Screening and Review process must be carried out. The application for the project must be submitted to the Environmental Impact Screening Committee (EISC) which consists of six permanent members, three appointed by the federal government (to represent the government of Canada, the Yukon and the NWT) and three appointed by the Inuvialuit Game Council. An Environmental Impact Screening Panel then reviews the application, to determine whether there will be environmental impacts, including conflicts with community conservation plans, harvesting, wildlife management plans, and other environmental concerns. If the project is deemed to have no negative environmental impacts then it is referred to the Environmental Impact Review Board, who will then approve the application. After this, a Land Use Permit is 
issued by the lLA (Indian and Northern Affairs Canada (b), 2001). If there are negative environmental impacts, the proponent and ILA are notified.

\subsubsection{2- On Commissioner's Land}

In order to develop granular resources on or acquire them from Commissioner's land, it is necessary to apply for a Land Use Permit. This will be screened by Municipal and Community Affairs (MACA). Any applications for use of Commissioner's lands are made to the lands officer in the community containing the land. Within MACA, the Lands Administration Directorate conducts the screening of the application, and if there are no significant negative environmental impacts, issues the permit. If there are environmental concerns, the application is sent for review by the Commissioner's Land Review Committee which ensures that applications conform with the policies of the GNWT, including environmental policies (Indian and Northern Affairs Canada (b), 2001).

\subsubsection{3- On Crown Land}

Before continuing exploration for granular resources on Crown land, an application must be made for a Land Use Permit to the District Manager of the Department of Indian and Northern Affairs North Mackenzie District in Inuvik. The Land Use Permit authorizes temporary use of the land for activities associated with a quarrying, and is designed to minimize environmental disturbance, containing conditions regarding environmental protection of the location, the type and size of equipment used and restoration. A security deposit is required to acquire a Land Use Permit from DIAND. The application undergoes the community consultation process and ISR Environmental Impact Screening and Review process as described in the Inuvialuit Private Lands section (Section 4.2.1.1). If the application meets the approval of 
the community consultation and environmental review process, the District Manager of DIAND will issue the Land Use Permit.

\subsubsection{4- Field Surveys}

Once permits have been obtained, a geologist may visit sites which were identified through literature research and consultation with local people. The geologist will review local land features and collect information about areas that appear promising. The potential granular resource sites are roughly measured, and samples of granular material are collected for identification and analysis.

\subsubsection{5- Geoscientific Surveys}

If the field surveys indicate that there is granular resource potential, closer examination may be carried out on the most promising sites using geological mapping, test pitting, and sampling in order to determine the location, volume, extent and quality of sand and gravel deposits. These activities may require a range of equipment from backhoes to truck-mounted augers.

Test pitting is a method of surveying in which a grid pattern is laid out over the potential deposit, and test pits of about five metres deep are dug 100 metres apart. If two neighbouring pits test positive for gravel, it is assumed that the material between is consistent, and this process continues throughout the entire grid. Once the test pit is completed, the volume of the deposit can be calculated. If significant sand and gravel is found, a 125 kilogram sample is collected, labeled and sent to the lab for testing for quality and characteristics.

In combination with test pitting, geophysical surveys may also be used, employing electronic instruments to measure the characteristics of underlying sand and gravel deposits. 
Seismic and electromagnetic systems are used to measure thickness and depth as well as the type of material lying beneath. After surveying is complete, a geological map is drawn of the location of the sand and gravel deposit, with a grid showing the location of the test pits and the results of the geophysical surveys. Once the feasibility of extracting gravel has been determined, further regulatory approvals are required before extraction can begin. These approvals vary by jurisdiction and are discussed below.

\subsection{2- Preparation for Extraction}

\subsubsection{1- On Crown Land}

A Land Use Permit (LUP) is required for quarrying on Crown lands for both new and existing pits. The LUP allows the temporary use of land (maximum three years) for activities associated with quarrying. The permit contains conditions about environmental protection of the location, timing of the operation, the type and size of equipment that may be used, and abandonment and cleanup of the site. Within the ISR, LUPS are authorized by the DIAND North Mackenzie District, District Manager in Inuvik. In the case of a new pit, if the user intends to use the land for extracting resources for more than two years, they must obtain a Surface Lease, which is required under the Territorial Lands Act. Whether or not a Surface Lease is necessary, a Quarry Lease is also required for a new pit under the Territorial Quarrying Regulations in order for an individual to quarry a site for up to 10 years to remove granular resources (Indian and Northern Affairs Canada (c), 2005).

If a user intends to quarry an existing pit on Crown land, a Quarry Permit is required. A Quarry Permit allows a user to remove a specific amount of material from a certain piece of 
land over a limited time period. The permit expires when the quantity of material allowed by the permit has been extracted, or one yearfrom the date of issue, whichever comes first.

It must be noted that a Quarry Permit is not required for any resident of the Northwest Territories to take less than fifty cubic yards of sand, gravel or stone from territorial lands each year. Residents may take these resources without the payment of any fees or dues, but they must be for personal use and may not be sold or bartered. However, if interest in surface rights on the land has been recognized by the Crown, granular resources cannot be taken.

\subsubsection{2- On Commissioner's Land}

If a user desires to establish, operate and restore a quarry on Commissioner's land, they must obtain a Quarry Administration Agreement. Typically, Municipal and Community Affairs or departments of the Territorial government would be users requiring Quarry Administration Agreements. This agreement passes on the responsibility of issuing quarry permits, collection of fees and royalties, and charging of development fees to the holder of the Quarry Administration Agreement.

If a user wishes to acquire granular material from an existing quarry on Commissioner's land, they must obtain a Quarry Permit from the Deputy Minister or Municipal and Community Affairs (MACA) who hold a Quarry Administration Agreement. The quarry permit authorizes the amount of gravel that may be removed, and details the fees which the user is responsible to pay. The Government of Canada, Government of the Northwest Territories and MACA are issued permits without the payment administration and development fees or royalties.

When gravel is to be acquired from a new pit, the developer must obtain a Quarry Lease from the Deputy Minister. A maximum of 65 hectares can be developed, and the materials 
extracted must be used or marketed immediately. The user must pay an annual rental fee for the lease, which may last for up to ten years, and must pay a royalty for material extracted.

Any person can remove no more than forty cubic metres of gravel from Commissioner's land each year for personal use, without a permit or payment of royalties or fees (NWT Department of Justice, 1990).

\subsubsection{3- On Inuvialuit Private Land}

In order to develop a new quarry on Inuvialuit Private Land, a Quarry Concession must be obtained from the Inuvialuit Land Administration, which grants the right to develop a quarry and extract gravel on a piece of Inuvialuit private land. A quarry concession is valid for up to thirty years. If a user wishes to obtain gravel from an existing quarry, a Quarry License must be obtained. The license allows the user to enter and operate on Inuvialuit lands, while limiting the type and amount of gravel that may be extracted. Royalty fees are charged per cubic metre of material removed from the pit.

Any person has the right to obtain a quarry license for the removal of up to 38 cubic metres of gravel per year from Inuvialuit private land for personal use and not for resale.

\subsection{3- Site Preparation}

The preparation of a granular resource extraction site is generally carried out in the winter in the Inuvialuit Settlement Region, in order to avoid disturbing the terrain surrounding the borrow source. The site may be reached by an all weather road, or a seasonal ice or tundra road. Initially, snow is cleared from the excavation site and work areas, and moved to a location where it will not drift or melt into the borrow source (EBA Engineering Consultants, Ltd., 1987, Aklavik). Trees and topsoil must then be removed from the site, and soil should be 
stockpiled adjacent to the site for use during site remediation. The development of access roads and drainage mechanisms such as culverts, ditches and collection pools may also be required before the quarry can function (Indian and Northern Affairs Canada, 1982).

The implementation of drainage solutions is crucial, because excess moisture within the excavation site makes gravel more difficult to excavate, reduces the quality of the material, and prevents the source from thawing. Runoff from massive ice or snow melt should be redirected to retention ponds using drainage ditches (EBA Engineering Consultants, Ltd. (a), 1987).

\subsection{4- Extraction}

Backhoes, front end loaders, bulldozers, rippers, loaders and trucks are used to extract gravel from a borrow source. In the winter, gravel can be extracted by ripping frozen granular resources from the ground and either windrowing or stockpiling it for loading and transportation. This type of recovery is possible for borrow sources that are above ground (positive relief), and therefore are more easily recovered than gravel frozen into the ground. If the extraction project is large enough, it may be economical to blast the frozen ground in order to make more granular material readily removable (EBA Engineering Consultants, Ltd. (a), 1987).

During the summer, gravel can be stripped from a borrow source and placed in windrows or stockpiles as it thaws, beginning when the thaw depth reaches approximately half a metre. The ground progressively thaws as overlying gravel is removed, allowing for a cyclical process of extraction (EBA Engineering Consultants, Ltd. (a), 1987). 


\subsection{5- Processing}

To meet the specific needs of some projects, processing is necessary. Processing requires specific equipment to crush, sort, wash and stockpile the material. A gravel operation may make between 5 and 10 different products. Some gravel is used for fill, bedding, subbase or basecourse without processing; however most domestic sand and gravel are processed prior to use. In general, a front end loader dumps raw gravel from the pit into a hopper where the largest rocks are screened out. Conveyor belts carry a continuous stream of material through crushers which break up the stones, which are then screened by grain size and bigger chunks are reprocessed. The sand and gravel products are then loaded directly into trucks, (Indian and Northern Affairs Canada, 1982).

Neil MacLeod, an engineer with EBA Engineering Consultants, Ltd. estimates that approximately eighty percent of granular resources used for infrastructure construction and maintenance in the Northwest Territories are obtained from natural gravel deposits and require minimal processing, and the remaining twenty percent is created by crushing rock that has been quarried.

\subsection{6- Site Remediation}

Restoration of the quarry site must be carried out whether the pit is being left temporarily or permanently. The quarry area must be cleared of waste or debris that was deposited at the site during quarry operation. As well, it must be ensured that drainage ditches are left open to allow water to run away from the pit area. Quarries deeper than the water table may be left to flood naturally, as an acceptable form of restoration (Indian and Northern 
Affairs Canada, 1982). However, if this is not the case, the site should be covered with the overburden that was stockpiled when the pit was being developed. This will allow the area to proceed with revegetation (EBA Engineering Consultants, Ltd. (a), 1987).

\section{3- Quary Fees in the Invialuit Settlement Region}

The cost of obtaining gravel within the Inuvialuit Settlement Region varies by land owner. Acquiring gravel from Crown land requires a $\$ 150$ permit fee, and royalties of $\$ 1.50 /$ cubic metre of sand or gravel. A Land Use Permit (Class B) is also required for the use of Crown land, at a cost of $\$ 150$ plus $\$ 50$ per hectare of land.

On Commissioner's land, there is a $\$ 150$ permit fee, and a $\$ 1.50 /$ cubic metre fee for royalties, as well as $\$ 1.50 /$ cubic metre for each of the following: quarry restoration, road maintenance and administration. Therefore a cubic metre of gravel extracted from a pit on Commissioner's land will cost $\$ 6.00 /$ cubic metre. Furthermore, a Land Use Permit must be obtained for operation on Commissioner's land, at a cost of $\$ 250$ for the application, along with a $\$ 250 /$ vear payment and $\$ 15 /$ square kilometer of land used (GNWT Municipal and Community Affairs, 2008, Online).

The royalty fee for the removal of sand and gravel from inuvialuit private land changes each year, and the calculation of fees is set out in the Inuvialuit Final Agreement. Section 7(23) states that the royalty fee is equal to a maximum of $\$ 0.75 /$ cubic yard $(\$ 0.99 /$ cubic metre) multiplied by b/a, where " $a$ " is the Gross National Product of Canada in current dollars for 1982, and " $b$ " is the Gross National Product of Canada in current dollars for the year prior to the year of application. Therefore, the cost of obtaining gravel in 2008 according to the $2008 / 2009$ 
Inuvialuit Land Administration Fee Schedule is $\$ 2.50 /$ cubic yard $(\$ 3.29 /$ cubic metre). This fee also includes fees for administration and reclamation. Royalty fees for granular resources from Inuvialuit private lands are distributed amongst the beneficiaries (Inuvialuit people) of the Western Arctic Claim. In addition to the gravel royalty fee, there is a quarry license fee of $\$ 41.27$, as well as a fee of $\$ 1,237$ for each inspection of the quarry, which are carried out sporadically throughout the lifetime of the quarry. Furthermore, for the duration of quarry activity on Inuvialuit private land, an environmental monitor must be present, at a cost of $\$ 2,063.28$ /day for the first thirty days, and $\$ 3,301.25$ for each day after (Romaine, 2008, Personal Communication). The cost of a Land Use Permit (Class B) which is required in order to operate a quarry on Inuvialuit private land is $\$ 2,475.94$ plus $\$ 1,237.97$ per hectare of land being used.

Fees for reclamation that are charged by the Commissioner and the Inuivaluit Land Administration are deposited into a land reclamation fund. When the quarry has been exhausted of gravel by various users, the money from the land reclamation fund is used to recontour, shape and clean the pit (Romaine, 2008, Personal Communication).

\section{4- Decision Making Process for Obtaining Granular Resources}

Economic feasibility is the primary factor that influences the decision of a user about where to obtain gravel from for a project. The decision making process for federal, territorial, Inuvialuit and private users can be seen in Appendix C, Diagram 2. There are two aspects of cost that are considered when obtaining gravel: the cost of buying the gravel from the land 
owner, and the cost of the physical process of developing a quarry, extracting gravel and transporting it.

Intuitively, a user would choose to acquire gravel from the land owner with the lowest fees. When taking all cost aspects of operating a quarry and obtaining gravel into account in the Inuvialuit Settlement Region, the least expensive source is the Crown, followed by the Commissioner, and finally the Inuvialuit. Therefore, if the nearest source of gravel of appropriate quality and quantity is on Crown land, it would be the most likely source utilized by a user. However, if the nearest appropriate source of gravel is on Inuvialuit private land, a decision must be made about whether it is more economically viable to pay for gravel with the higher costs associated with it being on private land, or to incur the costs of traveling to a more distant source on Crown land, where royalty and environmental monitoring fees are less. Although the cost of transportation of gravel and construction of access roads may be more expensive due to a longer haul distance, the savings in royalty fees may outweigh these costs. Therefore, in the ISR, gravel is ideally obtained from Crown land over Inuvialuit private land (Romaine, 2008, Personal Communication). Meanwhile, gravel on Commissioner's land is generally reserved for use by the territorial or municipal government for community infrastructure construction and maintenance.

The other factor in the decision of where to obtain gravel is that of the cost of developing and extracting from a new pit compared to using an existing one. If a project requires a large amount of a specific quality of gravel, and there is a yet undeveloped source closer than an existing pit, a decision must be made about which scenario will ultimately cost more to the user. It may be the case that it will cost less to create a new access road, remove 
overburden, obtain a quarry lease (Crown) or quarry concession (private) than to travel to the nearest existing pit.

Therefore, as can be seen in Appendix C, the user will choose a source of gravel based on appropriate quality and quantity of material, and the least costly source available. 


\section{1- Concems About Granular Resource Management}

The importance of granular resource management was made clear at the 2006 Northwest Territories Granular Users Forum, hosted by Indian and Northern Affairs Canada in Yellowknife. Todd Romaine (Chief Land Administrator, Inuvialuit Land Administration), Dan Elliott (Senior Granular Resource Officer, Indiana and Northern Affairs Canada), and Fred Collins (Projects and Geotechnical Officer, Public Works and Services, Government of the Northwest Territories) were asked during an expert panel discussion about the importance of granular resource management in the Northwest Territories. Todd Romaine expressed that granular resources are the most undervalued and over utilized resources in the territory, and that an integrated management plan for all levels of government is crucial to the management of gravel. Dan Elliott stated that granular materials are a scarce resource in the Northwest. Territories and as such require management. He suggested that areas of improvement include the upkeep of demand forecasts, and ensuring that gravel is developed and extracted efficiently and in a sustainable manner. This includes the prevention of high grading (using material of better quality than is necessary for a project), through the development of pit management plans for quarry sites. Finally, Fred Collins emphasized that gravel must be managed sustainably in order to meet the needs of future generations, and that the effective management of gravel has economic benefits to users (Terriplan Consultants, March 2007, pg. 10).

During the interview portion of this project, all participants were asked about their concerns for granular resource management within the Inuvialuit Settlement Region. All respondents agreed that management of gravel is an issue of priority in the ISR. The specific 
concerns of stakeholders are reviewed in the table in Appendix B. Some stakeholders are concerned that the priorities of the Inuvialuit Final Agreement are not being met in full, even twenty-four years after it was signed. It is also recognized that completing demand forecasts should be a priority for the ILA and INAC, since one has not been completed in seven years. The fact that there are no conclusive pit management plans in place for most borrow sources raises concerns that gravel is not being used in the most sustainable way possible. Others worry about whether there will be enough gravel to meet competing demands, emphasizing that a management plan should be in place before private enterprises are granted rights to granular resources. Furthermore, there are concerns about monitoring and enforcement of the amount of gravel quarried and whether the limitations of quarry permits are complied to.

From many stakeholder perspectives, it is very clear that the management of granular resources is an issue of priority within the Northwest Territories and the Inuvialuit Settlement Region. However, it appears that there are several steps that must be taken in order to develop a comprehensive granular resource management plan for the ISR and these will be discussed throughout the chapter.

\section{2- Granular Resource Management Plans}

A granular resource management plan is essential to the sustainable management of granular resources. The Department of Indian and Northern Development suggested in May, 1996, that a granular resource management plan should contain all the information necessary for resource managers to effectively manage granular resources (DIAND, May 1996, pg. 22). 
There are several elements that must be included in a management plan in order to achieve this goal: objectives and information about supply, demand and future development scenarios. It is essential that objectives be determined at the outset of developing a granular resource management plan in order to ensure that the plan contains the elements required to achieve these objectives. The objectives of the management plan should define the geographic area to which the management plan will apply, and the purpose of developing a granular resource management plan. In the case of the Inuvialuit Settlement Reigon, the geographic region would be the entire ISR, including $7(1)(a)$ and $7(1)(b)$ private lands, Crown lands and Commissioner's lands. The objectives would likely be to develop a joint management plan among the three land owners to ensure that the priorities of the Inuvialuit Final Agreement are achieved; making certain that the future demands of the six ISR communities can be met. In order to achieve the objectives of the granular resource management plan, one necessary element is an accurate supply inventory. This data will allow granular resource managers to determine whether there is enough supply to meet the demands of the quarry permit application (Department of Indian and Northern Affairs and Northern Development, May 1996). As well, it will aid in the location of the nearest (and likely most cost-efficient) Source of gravel of the appropriate quality and quantity required by the user. Furthermore, an accurate supply inventory can be used in conjunction with demand surveys in order to determine whether there will be enough gravel to meet the first priority of the Inuvialuit Final Agreement (public and community needs) for the next twenty years before allocating gravel to a second (Inuvialuit private needs) or third (private project approved by government) priority 
user. Without accurate inventory of available granular resources, the objective of sustainable granular resource development cannot be met.

An understanding of demand is also required for a granular resources management plan. An account of historical demand is beneficial to forecasting demands. Furthermore, current demand forecasts are of necessity to make sure that the priorities of the Inuvialuit Final Agreement are met (DIAND, May 1996). A granular resource management plan in the Inuvialuit Settlement Region would benefit from a consolidated report of gravel usage, drawing upon the four previous demand surveys that have been carried out since the inception of the IFA. This account would include information about the amount of gravel used during different activities within the region, for example, gravel usage during oil and gas exploration in the late 1970 s and early 1980 s. The historical data could then be used by granular resource managers to predict how activity, such as petroleum development or population growth will likely impact resource demand in the future.

Perhaps the most crucial element to a granular resource management plan is a demand forecast for the upcoming twenty years. The Inuvialuit Final Agreement requires that forecasts be carried out every five years, for the following twenty year period. In order to create a complete demand forecast, all users of gravel (Inuvialuit, federal, territorial, municipal) within the Inuvialuit Settlement Region must be surveyed about their resource requirements for the upcoming five years (using a survey template such as that in Appendix D). A demand forecast that takes into account all potential uses of granular resources allows resource managers to make informed decisions about whether second and third priority projects can be afforded gravel, or whether those demands will interfere with future community requirements. Without 
a current demand forecast, it is impossible to determine whether resources are being allocated sustainably, because the future demand is unknown.

Along with demand forecasts, development scenarios should also be included in a granular resource management plan. Development scenarios account for development that is speculative-although the project may not take place. If it does it has the potential to place increased demand on granular resources (DIAND, May 1996). In the case of the ISR, a portion of the granular resource management plan should be dedicated to the potential stress placed on granular resources by projects such as the Mackenzie Gas Project and the Inuvik to Tuktoyaktuk Road, as well as the potential for infrastructure related to population increase due to economic development within the region.

\section{3- Current Granular Resource Management in the Inuvialuit Settlement Region}

The management of gravel is for the most part common across the three levels of jurisdiction that lie within the Inuvialuit Settlement Region. Generally, gravel is managed through a permit process as is described at length in Chapter Four of this paper. The Inuvialuit Land Administration, Indian and Northern Affairs Canada and Municipal and Community Affairs issue permits for land use and the extraction of gravel on private, Crown and Commissioner's lands in the ISR. A permit application undergoes screening and consultation with organizations including Hunters and Trappers Committees and Environmental Impact Screening Committees in order to determine whether the quarry operations will be environmentally feasible (Terriplan Consultants, March 2007, pg.7). If it is, the administrative body that owns the land on which the resources lie must determine whether there is the appropriate amount of resources to 
meet the requirements of the user's application. If these criteria are met, a quarry permit or license and a land use permit will be issued and the user will be allowed to extract gravel. Furthermore, the Inuvialuit Land Administration has built monitoring and enforcement into the quarrying process, requiring (at the expense of the user) an environmental monitor to be present throughout the entire operation to ensure that the amount of gravel extracted does not exceed the permitted amount (Romaine, 2008, Personal Communication). Indian and Northern Affairs Canada also monitors the extraction of gravel, on a less frequent basis than the ILA using environmental inspectors to assess the quarry operation intermittently (Terriplan Consultants, March 2007). When monitors are not inspecting the excavations of users, the honour system is relied upon, and the user may not be estimating the amount of gravel removed accurately, potentially underestimating their hauls (Gowan, 2008, Personal Communication). Gravel extraction on Commissioner's land is monitored through the use of quarrying reports which are submitted to Municipal and Community Affairs, detailing the movement of gravel from the pit to the project site and the amount extracted on a daily basis. Although this management process may meet the objectives of preventing environmental impacts and not exhausting the current supply of gravel, it does not take into consideration the overall objective of a granular resource management plan-to ensure the sustainable management of granular resources in the face of future demand.

\section{4- Factors Hindering the Development of a Granular Resource Management Plan}

The personal turnover in land management roles has been a significant factor in the slow development of a granular resource management plan for the Inuvialuit Settlement 
Region. When the progress of the management plan was assessed in 2006 by Alpha Corporation, it was noted that personnel turnover in both the Inuvialuit Land Administration and the Department of Indian and Northern Affairs has caused delays in the development of a plan, because new personnel need to be informed about the objectives of the plan and updated on what has already been achieved and the remaining work to be completed.

It is also difficult to propose ideas for a management plan without having the personnel to carry out the proposed ideas. For example, when developing pit management plans for borrow sources, including stipulations for monitoring of extracted resources and enforcement of reclamation plans, these activities may be theoretically ideal, but may be impossible to implement in reality. Although the ILA has requirements for monitoring and enforcement when quarry license are granted, the ILA has few employees with this expertise. It is suggested that a reasonable solution to this problem would be to cost share DIAND granular resource technicians when their skills and expertise are required for Inuvialuit Private Lands (Alpha Corporation, 2006). Despite the method through which this may be achieved, it is clear that part of a granular resource management plan should focus on how the goals of the plan will be achieved including the hiring of personnel to help meet the goals of sustainable resource management, such as monitoring and enforcement during pit activity.

Another factor that hinders the management of granular resources is the low participation rate in demand surveys. In the past, (for example, the 1991 forecast), the response rate of gravel users has been very low making the gravel demand survey incomplete and of little value as a tool for planning for demand because the overall demand from users is unknown. Susan Chaytor of Alpha Corporation suggests that participation rate in demand 
forecasting is always somewhat dismal in the north, likely due to a lack of personnel who can dedicate their time to completing the demand forecast for the upcoming 20 years.

Furthermore, the best method of communication in the north seems to be in person or by phone, instead of email, fax or leaving messages. Therefore, the process can be more time consuming for the organization carrying out the survey as well. Ms. Chaytor suggested that it might be ideal to have a local organization collect data from the gravel users within their community, and have the consulting company consolidate the data once it has been obtained (Chaytor, 2008, Personal Communication).

\section{5-Development of a Granular Resource Management Plan}

It is suggested that Indian and Northern Affairs Canada is responsible for providing information, support and leadership to land claims and their management of granular resources, ultimately coordinating or jointly planning a management regime for gravel within a specific geographic region such as the Inuvialuit Settlement Region (DIAND, May 1996). This is demonstrated through a Memorandum of Understanding between INAC and the Inuvialuit Regional Corporation, to jointly develop a granular resource management plan with the objectives of conserving aggregates for their most appropriate use, focusing planning where there are resource shortages or significant future demands and adhering to requirements of the Inuvialuit Final Agreement (Terriplan Consultants, March 2007). Thus, the first stage of developing a granular resource management plan discussed in Section 5.2 has been completed. Because there are several land owners in the Inuvialuit Settlement Region, the creation of a joint management plan will encourage the coordinated management of resources, while 
avoiding duplication of efforts towards other essential elements of a management plan including supply inventories and demand surveys. Since proximity and cost are the primary factors influencing where users will take gravel from, a user that falls under one jurisdictional category will not necessarily take gravel from their corresponding land (ie// GNWT Department of Transportation may take gravel from Inuvialuit private lands for the construction of the Inuvik Tuktoyaktuk highway). According to Phil Chidgzey of Alpha Corporation, the consulting company that assessed and reviewed the current granular resource management plan in the ISR, a joint management plan for granular resources will provide a "coordinated and systematic approach," encouraging the sharing of research and project data regarding supply and demand (Terriplan Consultants, March 2007). As such, joint management is not only a beneficial tool for land managers but essential to ensuring that the priorities of the IFA and the best interests of the Inuvialuit people are met.

Alpha Corporation's 2006 report on the status of the development of a granular resource management plan for the ISR outlined the progress that had been made as of 2006 . Accomplishments included: the memorandum of understanding between the Inuvialuit Regional Corporation and the Department of Indian and Northern Affairs about joint management, consultation with the Inuvialuit Land Administration, DIAND and other stakeholders, the development of a web based GIS prototype for the purpose of centralizing granular resources data, some community granular resource supply evaluations (Aklavik, Paulatuk and Tuktoyaktuk), and further assessments of potential borrow sources near Aklavik and Tuktoyaktuk (Alpha Corporation, 2006). 
In order to complete the management plan, an up-to-date supply inventory must be compiled, and it is suggested by Alpha Corporation that the inventory includes maps of the locations of pits, their access routes, other potential deposits and the amount of gravel within each source (Alpha Corporation, 2006). Furthermore, demand forecasts for all potential users of gravel within the Inuvialuit Settlement Region must be obtained. Demands for gravel by departments of the territorial and municipal governments are already provided in the Territorial Granular Resource Strategy (2007), leaving information outstanding from the federal government, Inuvialuit government and private users.

Pit management plans with extraction, operating and remediation guidelines must also be developed for all sources of gravel within the Inuvialuit Settlement Region in order to ensure that gravel is being quarried in the most efficient and sustainable way possible (Alpha Corporation, 2006). Alpha corporation suggests that this could be done by streamlining existing management strategies of the federal government and the ILA. This would require a combination of the DIAND Pit and Quarry Management Guidelines (Indian and Northern Affairs Canada, 1982) and ILA requirements for environmental monitoring to develop and allencompassing set of pit management guidelines that could then be adapted to specific borrow sources using additional data about the characteristics and location of the borrow source.

Finally, a working group of personnel from the Inuvialuit Land Administration and Indian and Northern Affairs Canada must be established to review and initiate these outstanding items of the granular resource management plan. Once the necessary components (supply inventory, demand forecasts, pit management plans) of the management plan are complete, a draft of the plan must be written. This draft must be published and then presented to ISR communities for 
consultation. In doing so, any additional community concerns can be incorporated into the management plan, and community support for the management of the resources essential to their communities can be gained (Romaine in Terriplan Consultants, 2007).

\section{6- Concerns about Granular Resource Management and Climate Change}

Interviews with stakeholders indicated that there are concerns about granular resource availability and climate change. Most concerns led back to the idea that in order to adapt to climate change, management would have to be adapted as well. As can be seen in Appendix B, some participants were concerned about climate change causing a shorter hauling season. This would suggest that resource managers will require more knowledge of the accessibility and supply of borrow sources, and which sources will actually be feasible to obtain gravel from if the hauling season is shortened. Another concern raised was for Aklavik, which has only winter access to gravel. It was suggested that better forecasting needs to occur in order to predict demand and have enough gravel stockpiled to last through the construction season (Semmler, 2008 , Interview). As well, better pit management plans may be required to deal with the potential melting of massive ice within the ground due to climate change. Pit management plans could build in precautionary measures to avoid the exposure of ground ice to the atmosphere, ultimately ensuring that resources within the pit remain useable. Some stakeholders have also observed increases in demand for granular resources, perhaps due to warming temperatures, indicating that a management plan should be developed as soon as possible to begin to prepare for further infrastructure vulnerabilities and granular resource demand. 


\section{1- Demand Forecasts}

Granular resource forecasts are reports about the granular resource demands of various users over a specified period of time. They can contain gravel requirements for both public and private users for the following five years, with forecasts for an additional fifteen years.

Generally there are three categories of demand for granular resources: community or public, government, and private or industrial. Community or public demands include demands for gravel for community operations, maintenance and for small scale residential development. Government demands for gravel are usually for infrastructure and projects funded by the Government of the Northwest Territories or the federal government. Finally, private or industrial demands are for gravel required by private companies including oil and gas developers, and local businesses such as contractors (Alpha Corporation, 2007). There are also three categories of use for granular resources: operation and maintenance, planned capital projects, and speculative capital projects. Operation and maintenance requirements for granular resources are for repairs and upgrades to existing infrastructure. Planned capital projects are those that will occur within the short term ( 5 years). Speculative capital projects are those that may or may not occur within the next twenty years, and are usually large scale, such as oil and gas development or the construction of a new highway (Ibid). A granular resource demand forecast includes information about what type of granular resources are required for these projects, and where the materials are proposed to be extracted from. Overall, a granular resource forecast serves as a tool for the sustainable short and long term management of granular resources, ultimately aiding managers to allocate resources based on supply and demand. 


\section{2- Historical overview of demand forecasts for the Inuvialuit Settlement Region}

Since the Inuvialuit Final Agreement was implemented in 1984, four granular resource demand forecasts have been conducted for the ISR in 1987, 1991, 1995 and 2001 in an attempt to meet the requirements of Section $7(27)$ of the agreement. Thus, the forecasts have not been conducted at five year intervals as is required under Section 7(27), instead intermittently.

These forecasts take into consideration both public demands from all levels of government as well as private demands. The Government of the Northwest Territories also conducts a granular resource forecast for any infrastructure they construct, operate and maintain.

In 1987, demand for granular resources in the six ISR communities was studied by EBA Engineering Consultants, using a questionnaire and follow-up interview format with potential granular resource users. The forecasted demand for the twenty year period following 1987 was 17.4 million cubic metres. Ninety-two percent of the projected demand was for speculative projects (oil and gas development), five percent was for capital projects and three percent was for infrastructure maintenance requirements.

In 1991, Hardy BBT Limited conducted another granular resources forecast. The forecast presented demand in five year blocks from 1987 to 2006 . The 1991 forecast was built upon the 1987 forecast conducted by EBA, and updated demand information was requested of the granular resource users. However, only seven of the twenty-one identified potential users responded to the survey. The respondents were primarily from the oil and gas sector or the federal government (Alpha Corporation, March 2007, pg.9). Therefore, there was not enough response to create an accurate supply/demand model. Hardy BBT concluded that a more extensive granular resource demand survey was required for the region (Hardy BBT Ltd., July 
1990). The demand projected for the 20 year period between 1987 and 2007 was re-forecasted to be 26 million cubic metres for Aklavik, Inuvik and Tuktoyaktuk alone, which is a large increase from the 1987 EBA forecast (Alpha Corporation, March 2007, pg.9).

A third demand forecast was conducted in 1995 by North of 60 Engineering Ltd., for the period of 1995-2015. The 1995 forecast incorporated a record of how much gravel had actually been used between 1985 and 1994 based on ILA permits issued during that time period. It was found that only 2.5 percent of the granular resources for this period predicted in the 1987 forecast were used, and 5.5 percent of those predicted in the 1991 forecast were used (North of 60 Engineering Ltd, March 1995, pg. 48). It was noted that the speculative projects such as oil and gas development cause large discrepancies between the amount of gravel that is theoretically demanded and the amount of gravel that is actually used during a given period of time (Alpha Corporation, March 2007, pg. 10). The projected demand for the 20 year period of 1995-2015 was 4 million cubic metres (North of 60 Engineering, March 1995, pg. 10).

The most recent granular resource forecast was conducted in 2001 by North of 60 Engineering Ltd, for the twenty year period of 2000 to 2020 . North of 60 compared the forecasted demand for gravel between 1995 and 1999 to the actual demand for gravel, estimated through quarry licenses, and found that the actual demand was $50 \%$ higher than had been forecasted in the 1995 report. The forecasted demand for gravel for the 2000-2020 period was 5.37 million cubic metres, thirteen percent of which is demanded by communities, and the remainder by oil and gas exploration and development. The report stresses the fact that a demand database should be maintained and updated regarding the issuance of quarry 
licenses and the amount of materials extracted. This database will become important for monitoring rising demand due to oil and gas exploration and development, and will provide important information for the development of a gravel management plan for the region (McDougall, 2001).

\section{3- Historical Demand for Granular Resources}

Information about the actual demand for gravel in the Inuvialuit Settlement Region since the inception of the Inuvialuit Final Agreement in 1984 is difficult to obtain. Demand can be studied through the analysis of quarry licenses or permits that have been issued by governing bodies. However, data about quarry licenses is only publicly available for Inuvialuit private land, from the Inuvialuit Land Administration. In order to determine gravel demand on Crown land, Bob Gowan suggested that the information could be derived from data about the issuance of Land Use Permits for Crown land. Information about quarry permits is also unavailable for Commissioner's Land.

Another issue that hinders the accuracy of analyzing demand is that it is likely that gravel is taken from borrow sources without a permit or license. It is not realistic or feasible to have personnel at each borrow source to monitor activity and enforce regulations, it has been suggested by a number of respondents that gravel is taken without the knowledge of administrative bodies. It is also possible that only prominent users (such as oil and gas companies, or government departments) bother to apply for quarry licenses or permits because their construction of infrastructure using gravel is likely to be noticed. If a large user constructs infrastructure, such as an access road, or a pipeline, it will have gone through other regulatory processes as well, such as environmental assessments. Thus the user could not easily obtain 
gravel without the knowledge of the Crown or the Inuvialuit Land Administration. However, if a small user (for example, an Inuvialuit-owned company) extracts gravel for the construction of a small outbuilding or gravel pad on their own property, it is more likely to go unnoticed by the land administration, and may go unquestioned by the general public as it may be assumed that a quarry license has been obtained.

Taking the limitations of data regarding historical demands for gravel into consideration, the following is a discussion of the characteristics of demand for gravel in the Inuvialuit Settlement Region since 1984 rather than a numerical analysis of gravel usage. Available information about quarry activity can be viewed in Appendix D.

Overall, there are 104 records of quarry activity in the Inuvialuit Settlement Region between 1984 and 2007. Only six records of quarry activity were derived from information about Land Use Permits on Crown land, the remainder of activity occurred on Inuvialuit private land. The highest demand for granular material since 1984 occurred in 1985, when twenty permits were issued by the Inuvialuit Land Administration, primarily for use for oil and gas exploration. Companies including ESSO, Dome Petroleum, Chevron and Shell obtained gravel during this time period for the construction of infrastructure for oil and gas exploration. The Department of National Defence has also been a primary user of gravel in the ISR, using gravel for infrastructure at Distant Early Warning (DEW) and SRR sites.

Thirty-four percent of all permits obtained were for use by public entities including the territorial or municipal governments. Thirty-eight percent of permits were for users within the private sector, while thirteen percent were obtained by the Department of National Defence. 
The remaining forty-nine percent of permits were granted to unidentified users. The area from which gravel was most often taken was Tuktoyaktuk, making up forty-three percent of quarry permits. Fourteen percent of permits were issued for the Inuvik area, with the remaining permits were dispersed amongst the remaining communities or areas that are unidentified within the database.

Overall, there is not enough information to make conclusions about historical granular resource demand in the Inuvialuit Settlement Region. However, there are several trends that emerge when examining quarry permits that have been issued since 1984 that should be taken into consideration when developing a granular resource management plan. It is clear that demand for gravel increases with oil and gas exploration activity. This trend will likely repeat itself if the Mackenzie Gas Project is approved by the federal government. As well, the majority of demand for gravel from private and Crown land has been from private users. Hence, it is important to obtain information from private users when creating the twenty year demand forecasts that are required by the Inuvialuit Final Agreement. Finally, most demand has occurred in the Tuktoyaktuk region, indicating that Tuktoyaktuk is a definite area of priority for the sustainable management of granular resources.

\section{4- Current Demand Forecasts}

The most recent demand forecast for the Inuvialuit Settlement Region was seven years ago. In 2006, Indian and Northern Affairs Canada commissioned Alpha Corporation to review past granular resource forecasts and to present a methodology for completing a new forecast within the near future. Thus far, a template for obtaining and compiling granular resource demand information from all potential users has been developed (Appendix D). A list of 
contacts for obtaining demand information has also been compiled. At present, the logistics of data collection are being organized, including determining the best method of achieving a high response rate from potential users (Chaytor, Personal Communication, 2008). As such, lacking is an up-to-date granular resources demand forecast for all users, public and private, within the Inuvialuit Settlement Region.

In the spring of 2007, the Government of the Northwest Territories released the Territorial Granular Resources Strategy which includes forecasts for gravel demanded by departments of the Territorial government, for all communities within the Northwest Territories for three years, as well as long term speculation for public projects. The forecast was developed by an Interdepartmental Granular Acquisition Committee (IGAC) together with departments of Municipal and Community Affairs (MACA), Transportation (DOT), Public Works and Services (PWS) and the Northwest Territories Housing Corporation (NWTHC) (Interdepartmental Granular Acquisition Committee, NWT, May 2007, pg. 2). The forecast includes details about the amount of gravel required for projects occurring between 2007 and 2010 and some information about where the gravel may come from and how collaboration between projects could occur in order to minimize pit development costs.

The ideal demand forecast for the Inuvialuit Settlement Region would incorporate the existing forecast from the Territorial Granular Resources Strategy in addition to demand forecasts for federal and private users (ie// Inuvialuit companies, oil and gas developers). If such a forecast were developed, the entire demand and its characteristics for the region could be planned for during the creation of a granular resources management plan. 


\section{5- Current Demand for Gravel in the Inuvioluit Settlement Region}

Gravel demand by GNWT departments and MACA is directly correlated with community size and population. The forecasted demand for gravel by the Government of the Northwest Territories and Municipal and Community Affairs for each community is outlined in Table 6.1 below.

\begin{tabular}{|l|r|r|r|r|r|r|}
\hline \multicolumn{6}{|c|}{ GNWT Granular Demand Forecast $(\mathrm{m} 3)$} \\
\hline Community & $2007 / 2008$ & $2008 / 2009$ & $2009 / 2010$ & $\begin{array}{c}3 \text { Year } \\
\text { Demand }\end{array}$ & $\begin{array}{c}\text { Future } \\
\text { (Annual) }\end{array}$ & $\begin{array}{c}\text { Future } \\
\text { (Speculative) }\end{array}$ \\
\hline Aklavik & 13,330 & 18,430 & 13,230 & 44,990 & 9,230 & 11,000 \\
\hline Inuvik & 63,250 & 59,250 & 57,500 & 180,000 & 58,300 & 13,700 \\
\hline Paulatuk & 9,033 & 8,733 & 14,033 & 31,799 & 6,533 & 7,050 \\
\hline $\begin{array}{l}\text { Sachs } \\
\text { Harbour }\end{array}$ & 9,015 & 6,340 & 4,790 & 20,145 & 4,790 & 2,975 \\
\hline Tuktoyaktuk & 22,850 & 21,200 & 17,700 & 61,750 & 18,700 & 12,800 \\
\hline Ulukhaktok & 8,230 & 10,830 & 9,230 & 28,290 & 7,630 & 9,700 \\
\hline
\end{tabular}

Table 6.1- Forecasted Demand for Territorial and Municipal Users in Inuvialuit Settlement Region Communities

Source: Derived from the Territorial Granular Resource Forecast (Interdepartmental Granular Acquisition Committee, 2007)

Sachs Harbour, the ISR community with the smallest population has the lowest demand for gravel $\left(20,175 \mathrm{~m}^{3}\right)$, while Inuvik, the most populous community has the highest demand $\left(180,000 \mathrm{~m}^{3}\right)$ between 2007 and 2010. Inuvik, Sachs Harbour and Tuktoyaktuk are forecasted to have decreasing demands for gravel between 2007 and 2010. Meanwhile, Paulatuk, Ulukhaktok and Aklavik are forecasted to have unsteady demand over the same three year period. 
The most demanding use of gravel for each community is for operation and maintenance of infrastructure and for road resurfacing. Aklavik requires gravel for road erosion protection on a yearly basis, as well as gravel for its water treatment plant, an extension of the airstrip and for housing development. Inuvik will require gravel for housing development each year between 2007 and 2010, as well as for airport maintenance and the construction of a gym for Aurora College. The community of Paulatuk requires gravel for various capital plan projects which are unnamed in the forecast, as well as housing, and for a fuel storage site upgrade. Sachs Harbour requires gravel for the construction of an RCMP building, the water treatment plant, housing and for maintenance of the fuel tank farm. Tuktoyaktuk will also require gravel for its water treatment plant, as well as for unnamed capital plan projects and housing. Finally, Ulukhaktok has demand for gravel for its water treatment plant, capital projects and housing. Current demand for granular resources from users other than the Government of the Northwest Territories is undocumented at this time.

\section{6- Competing Demands for Granular Resources}

A 2007 report prepared for the Department of Indian Affairs and Northern Development identifies natural gas development as the most significant demand for granular resources in the Mackenzie Delta region. It is predicted that natural gas development may result in conflicts in demand between private industrial and community needs (Alpha Corporation, March 2007, pg. 6). There are two projects in particular that may place competing demands on granular resources within the ISR. The first is the already approved Mackenzie Gas Project and the potential Inuvik Tuktoyaktuk Highway. Both projects offer tremendous potential to contribute 
to economic growth for the region, however, they place intense demands on granular resources which are already scarce within the region.

\subsection{1-Mackenzie Gas Project}

The proposed Mackenzie Gas Project, if approved will add additional pressure on granular resources in the Inuvialuit Settlement Region. The timeline for the project according to Roy Wilson, the Inuvialuit Settlement Regional Liaison for Imperial Oil, is to have a certificate of public convenience in fall of 2008 , permitting the construction of the pipeline. If this certificate is obtained, construction is intended to begin in 2010 , lasting three years. The project will require the construction of infrastructure to support the production and transportation of natural gas from the Mackenzie Delta to Alberta. The major infrastructure required for the project includes three natural gas field production facilities which lie within the ISR (at Niglintgak (developed by Shell Canada), Taglu (Imperial Oil) and Parsons Lake (Conoco Phillips and Exxon Mobil)), a gathering pipeline system, a gas processing facility near Inuvik, and a natural gas liquids pipeline from the Inuvik area facility to Norman Wells, NWT.

Before construction for the project begins, the creation of some new infrastructure will be required. The Mackenzie Gas Project estimates that approximately 20 kilometres of new allweather roads will be required in order to provide access to the Inuvik-area processing facility and to the Norman Wells compressor station, as well as between barge landing sites, borrow source material sites, and camps and stockpile sites. Furthermore, a 20 kilometre road is also being considered for the Trail River area compressor station (MGP, January 2004, pg. 1). 
Barge landing sites will be required for equipment and materials that will arrive by barge and these sites will require access ramps and roads for the transportation equipment. Airstrips and helipads may be required at each of the main construction camps for the movement of supply and emergency purposes, and these pads will require granular resources.

The total amount of borrow material required for the Mackenzie Gas Project from Crown lands within the ISR is approximately 300,000 cubic metres for the gathering pipeline, and 1.6 million cubic metres for the Parsons Lake and Taglu anchor fields (Imperial Oil Resources Ventures Limited, 2006). Another 800,000 cubic metres of gravel will be required for the Niglintgak anchor field, and this gravel will be taken from Inuvialuit private lands. Other pipeline related infrastructure will require another 550,000 cubic metres of granular resources from private land. The total extracted amount of gravel required from the ISR for the Mackenzie Gas Project is over 3 million cubic metres. The demands and sources for gravel for the MGP within the ISR are summarized in Table 6.2. 


\begin{tabular}{|c|c|c|c|c|c|c|c|}
\hline $\begin{array}{l}\text { Eorrow } \\
\text { Site }\end{array}$ & Latitude & Longitude & $\begin{array}{c}\text { Quantity of } \\
\text { Extraction } \\
\left(\mathrm{m}^{2}\right)\end{array}$ & $\begin{array}{c}\text { Probable } \\
\text { Rosaves } \\
\left(\mathrm{m}^{3}\right)\end{array}$ & $\begin{array}{l}\text { Source } \\
\text { Type }\end{array}$ & $\begin{array}{c}\text { Expected } \\
\text { Yars in } \\
\text { Use }\end{array}$ & $\begin{array}{c}\text { Existing } \\
\text { Improvements }\end{array}$ \\
\hline $10 \mathrm{PP}$ & 092004 & -1345879 & 51000 & $780 \mathrm{000}$ & Granua & $2009-10$ & No \\
\hline 20221 & 0896 & -33.6807 & $8,0,0$ & 20001003 & Oronula & 200011 & No \\
\hline $20 \mathrm{mp}$ & 689274 & -1340469 & 15000 & 500000 & Grmula & $200 \%-1$ & 100 \\
\hline $202+$ & 18.003 & M3 $8 \times 5$ & 50000 & \multirow{2}{*}{10 mo oo } & Granda & $20081 \%$ & ves \\
\hline $2020 \mathrm{~PB}$ & 809747 & $-13,9026$ & 30,000 & & Granuar & 200011 & Ves \\
\hline $20038 \mathrm{P}$ & 68.4633 & $13,3,4$ & 13000 & som Note" & Guary & 200411 & No \\
\hline \multicolumn{8}{|c|}{ 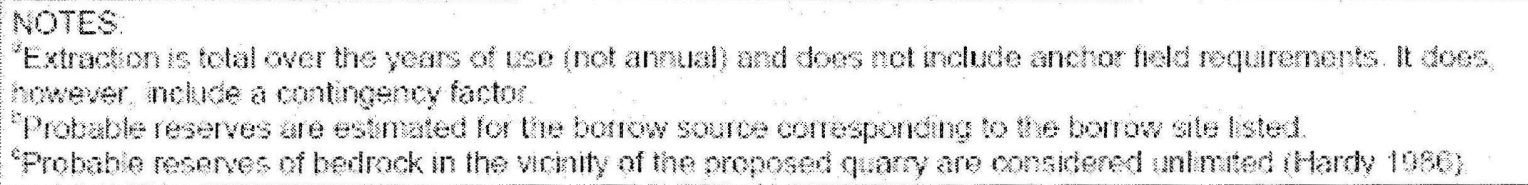 } \\
\hline
\end{tabular}

Table 6.2- Primary Borrow Sites for the Mackenzie Gas Project in the Inuvialuit Settlement Region

Source: Imperial Oil Resources Ventures Limited, 2007

It is expected that in locations with stable terrain, pit development and gravel extraction can take place in the summer. Therefore, Taglu and Parsons Lake will have construction year round. However if the terrain is thermally sensitive, work wll occur during the winter. Since the Niglintgak anchor field will be barge based, it will be largely constructed off site, and assembled after components are barged to the site (Wilson, 2007, Interview). Most gravel for infrastructure construction will be quarried during the witner, with the exception of around Parsons Lake, which has a gravel source nearby which will have a year round access road (Ibid). The development rate of the borrow sites will depend on the amount of ice content within the borrow sources. If there is high ice content in a source, the gravel may be excavated and stockpiled a year in advance and left to melt and drain over the summer for use in the following winter (Mackenzie Gas Project, March 2006, Online). 
According to Roy Wilson of Imperial Oil, if the communities (Inuvik and Tuktoyaktuk specifically) decide that they require gravel from the sources that the Mackenzie Gas Project has chosen as its primary borrow sources, the MGP will have to utilize secondary sources which have been prospected by the developers. These sources are less ideal than the primary sources, for reasons that are undisclosed, and their characteristics such as quantity and quality of the gravel are also undisclosed by the Mackenzie Gas Project.

The Mackenzie Gas Project has reclamation plans in place for the quarries that will be utilized to construct the pipeline and related infrastructure, and will restore the quarries to the standards of the Inuvialuit Final Agreement. When the gas extraction portion of the project is complete, all related infrastructure must be removed, unless a community can utilize it (for example, a barge landing site may be of use to a community). However, the pipeline will remain since natural reclamation will have begun over the approximate twenty year lifetime of the project and hence it would be more destructive to rip it back up. Gravel used for the project other than beneath the pipeline will be cleaned up and made available to communities. It is estimated that fifty percent of the gravel used for the project will be usable by communities again in thirty years. Because of this, some of the gravel used for the project could be considered "borrowed" or "leased" since it will become available for use again at a later date (Wilson, 2007, Interview).

The Mackenzie Gas Project will submit permit applications for granular resources in 2009, should the project be approved. As such, it would be beneficial for the Inuvialuit Settlement Region to have a full demand forecast complete so that community needs are 
known before granular resources are made available for the MGP. This would be in keeping with the Inuvialuit Final Agreement priorities, ensuring that public needs are met (first priority) before private needs are considered (third priority).

\subsection{2-Inuvik-Tuktoyaktuk Road}

In 1994, the Northwest Territories Transportation Strategy identified a road corridor between Inuvik and Tuktoyaktuk as infrastructure that would be necessary for resource and economic development in the Inuvialuit Settlement Region. Currently, the only access to Tuktoyaktuk is by seasonal ice road along the Mackenzie River from Inuvik, which operates for three to four months each year, and by air (GNWT DOT, 1999a, pg ii). The prospect of an all weather road has been discussed since the late 1960s, and the first route plan was developed in 1974 when oil and gas exploration was occurring at Parsons Lake, south of Tuktoyaktuk (Ibid, pg 2-1). Oil and gas development did not advance in the 1970 s, and interest in the development of the road rose and fell throughout the 1980 s with economic and political changes. However, in 1997 the Inuvik Tuktoyaktuk Highway Steering Committee was formed, and in 1998 the Department of Transportation established a Stakeholder Committee, which confirmed that a 140 kilometre route origninally proposed by Public Works Canada in 1977 would be the ideal route for the Inuvik Tuktoyaktuk Highway (Ibid, pg. 2-2). The proposed route can be observed in Figure 6.1, along with the existing ice road. 

During community consultations which took place in January of 1999, one of the concerns expressed by both community individuals and elders with traditional knowledge was the issue of where gravel would be obtained from for the project, and how much in royalties would be paid to the Inuvialuit and by whom for the use of granular resources. The importance of careful planning of where aggregates would come from for the road and associated infrastructure was also emphasized during community consultations in Yellowknife (GNWT DOT, 1999a, pg vi).

The executive report for the Inuvik Tuktoyaktuk Highway, published in 1999 recognized that there is a lack of borrow sources with good potential within close proximity to the proposed highway route. The report raises concerns about the poor quality of the granular resources in the area, and their distance from the proposed route, as well as the massive ice deposits within the borrow sources and the presence of silt within the deposits (GNWT DOT, 1999a, 3-36).

There have been two design plans proposed for the highway-one designed for travel speeds of 80 kilometres per hour, and one designed for speeds of up to 60 kilometres per hour. Both roads would consist of a roadtop of 8.4 metres wide, with a minimum of 1.2 metres of fill underneath. The $80 \mathrm{~km} / \mathrm{h}$ option would require more general fill and crushed gravel than the $60 \mathrm{~km} / \mathrm{h}$ option (GNWT DOT, 1999a, pg. 2-5). The estimated granular resource requirement for the Inuvik Tuktoyaktuk highway is $3,300,000$ cubic metres, and the requirements for the highway were estimated using the dimensions in the cross-section presented in Figure 6.2: 


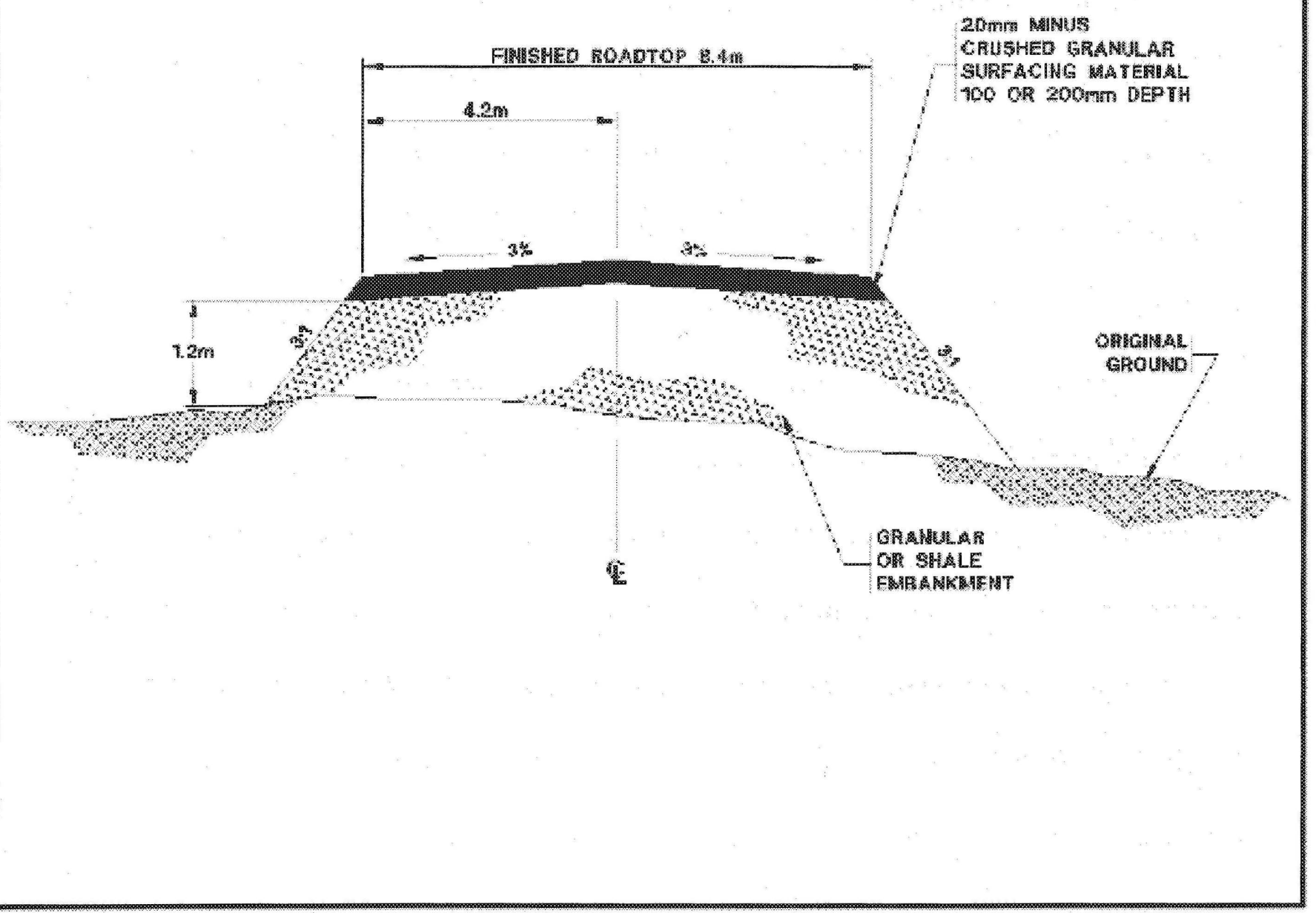

Figure 6.2- Gravel Requirements for the Inuvik Tuktoyaktuk Road Source: GNWT DOT Highways and Engineering Division, October 1999, pg. 4

\section{7-Clmate Change and Demand}

If there is an increase in atmospheric temperature by 6.5 degrees Celsius by 2100 las discussed in Chapter 2, Section 4), the thaw depth of the active layer could increase by up to 70 centimetres. Therefore, an additional 70 centimetres of gravel would be required underneath 
newly constructed infrastructure in addition to the current amount of gravel used in order to create a thick enough non-frost susceptible layer.

Indian and Northern Affairs Canada has commissioned North of 60 Engineering Ltd. to create a granular resource estimating tool which is available online (http://www.grancalc.ca). This tool can be implemented to project the additional demand that climate change may place on granular resources for the construction of infrastructure. In order to estimate the amount of gravel required for a project, measurements of a gravel pad or layer can be input into the estimating tool. In order to demonstrate the additional demands that will be placed on granular resources due to climate change, the case of the potential Inuvik Tuktoyaktuk Highway was selected. Engineering reports detailing the dimensions of the highway have been published by the GNWT Department of Transportation (March 1999) and these dimensions were entered into the estimating tool. For the scenario of a 60 kilometre/hour, 140 kilometre long highway from Inuvik to Tuktoyaktuk, with a roadtop width of 8.4 metres, and an embankment fill (road depth) of 1.2 metres plus surface fill of 10 centimetres, the amount of granular resources required is calculated by the estimating tool to be $2,559,480$ cubic metres. If the embankment fill is increased by 70 centimetres in order to prevent road settlement and heaving due to climate change, the amount of gravel required for the project increases to $4,532,220$ cubic metres.

In addition to increased amounts of gravel required for the construction of new infrastructure, granular resources will also be required to diminish the impacts of climate change on existing infrastructure, and to repair or replace that which is damaged or destroyed 
because of changes in the permafrost due to increased temperatures. Specific estimates of how much gravel will be required to protect infrastructure from failure are unavailable from literature. However, Neil MacLeod of EBA Engineering indicated that the requirement for gravel is a function of the soil and ground ice conditions in the area that is impacted by climate change, as well as the tolerance of infrastructure to permafrost degradation (MacLeod, 2008, Interview). There are no studies that suggest how much extra granular material will be required to minimize the impacts of climate change on infrastructure in the Inuvialuit Settlement Region, however, it is suggested that the amount of gravel used for the construction of new projects has already increased by fifteen to twenty percent to prevent infrastructure failure due to future climate change (bid). 


\section{1- Supply Inventories}

The location and characteristics of available granular resources in a geographic region can be accounted for in a supply inventory. A gravel supply inventory includes information about the location, setting, owner, continuity, amount, and type of gravel, as well as constraints to developing the borrow source and the accessibility of the source.

\subsection{1- Granular Material Quality}

Within the inventory, gravel is classified into one of five standard categories of granular resource quality, which were developed by Indian and Northern Affairs Canada in 1983:

Class 1- Excellent quality sands and gravels suitable for use as high quality surfacing materials, or as high quality asphalt or concrete aggregate, requiring minimal processing

Class 2- Good quality well-graded sands and gravels with limited silt, suitable as a good quality base or structure-supporting fill

Class 3- Fair quality material, of poorly-graded sands and gravel, used for fair quality general fill for roads, foundation pads, or yards

Class 4- Poor quality, silty, poorly-graded sand with little gravel content, may be used as general fill, not supporting structures 
Class 5- Bedrock of fair to good quality, potentially excellent construction material for general fill or concrete aggregate, if quarried and processed

(EBA Engineering Consultants, Ltd. (a), 1987)

The estimated amount of gravel in each source is categorized into certainty levels: proven, probable and prospective. The amount of proven gravel within a source is a volume that has been estimated based on ground truthing methods, including boreholes and test pitting which has been carried out extensively at the site. The probable amount of gravel is that which has been estimated based on less concrete evidence, such as airphoto interpretation, topography, landform characteristics, and limited ground sampling. Prospective volume refers to the amount of gravel that has been estimated to be in a source based on limited evidence, and without any ground truthing (EBA Engineering Consultants, Ltd. (a), Ltd., 1987). Using these categories, the amount of gravel that is potentially available to communities is identified, and the sources that require more exploration are noted.

\subsection{2- Access to Gravel}

A gravel inventory also indicates how the gravel can be accessed seasonally. Gravel is acquired by several different routes and methods of transportation in the Inuvialuit Settlement Region, including all-season roads, tundra roads, ice roads, and barges on rivers, lakes or the ocean. Dedicated access roads to sources of gravel are expensive to build and difficult to maintain due to heavy loads of the hauling equipment, and therefore tundra and ice roads provide viable alternatives (Nuna Logistics, 2003, Online). Ice roads are those constructed 
across frozen rivers or lakes. Auger trucks are used to drill holes through the ice, causing flooding to occur, and the water freezes adding thickness to the ice. Generally, the thickness of an ice road begins at approximately half a metre and peaks at two metres during the winter (Coneco Equipment, 2004, Online). Tundra roads are built across the land; once there is a significant amount of snow overlying the tundra, the snow is compacted creating a roadway.

If gravel is located next to a waterway, extracting equipment can be delivered to the site and gravel can be hauled back to a community by barge. The use of a barge for transportation of equipment and gravel usually requires the construction of a dock for the barge, and access roads from the dock to the gravel source (EBA Engineering Consultants, Ltd. (e), Ltd., 1987). Both of these require granular resources for their construction, and hence, if the pit has only a small amount of gravel to begin with, it is not worthwhile to use the resources to construct infrastructure for barge accessibility.

\subsection{3- Constraints to Pit Development}

Figure 7.1 depicts a hypothetical granular deposit within the Inuvialuit Settlement Region, and the characteristics of a typical deposit. There are many factors that can make difficult or prevent the development of a gravel pit. These constraining factors may be physical in nature, such as the existence of massive ground ice within the source, a large amount of overburden over the gravel requiring extra labour to remove compared to other sources with little overburden, or location within a lake, river or ocean environment, making it difficult to carry out extraction, stockpiling and hauling processes. Some sources of gravel may be directly adjacent to a river or lake, and it is recommended that pit development be restricted to at least 
thirty metres away from such water bodies to prevent disturbance of the ecosystem as well as to avoid flooding of the pit. As well, some granular resources lie in riverbeds, which can be extracted through dredging. However, this activity is only permitted after clearance from the Department of Fisheries and Oceans and through the Northern Inland Waters Act, if the activity will have no negative impacts on fish within the river (INAC, 1982, pg. 13). Most physical constraints can be worked around during pit development, but add cost to and decrease efficiency of the operation.

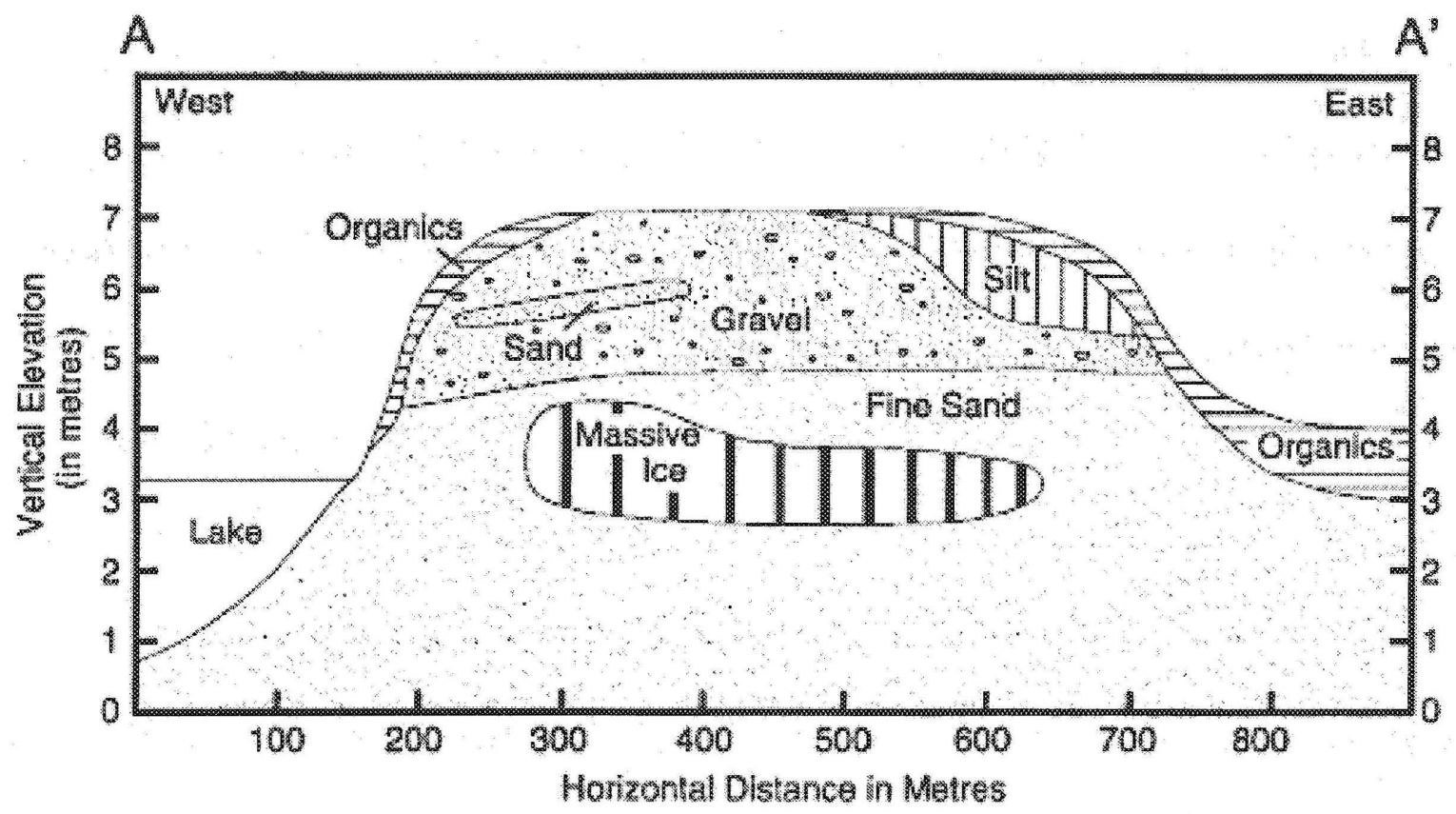

Figure 7.1-Characteristics of a Generic Granular Resource Deposit in the Inuvialuit Settlement Region Source: Thompson, March 1994

Other constraints to development are related to the environment. Such factors include the land's significance as a fish or wildlife habitat or breeding ground, the presence of an at-risk species, or the location of a bird sanctuary. The 1994 Migratory Birds Convention Act and 
Regulations and the Migratory Birds Sanctuary Regulations prohibit activity that may harm birds and their habitats and breeding grounds (INAC, 4 July 2001, Online). Likewise, the Wildlife Act (NWT) states that no person shall "engage in any activity that is likely to result in a significant disturbance to a substantial number of wildlife animals" without a permit (INAC (d),

21 February 2005, Online). Environmental constraints such as these prevent gravel sources from being developed, because of the significance of wildlife to traditional Inuit harvesting activities as well as species preservation efforts by the territorial and federal governments.

\section{2- Historical Supply Inventories in the Inuvialuit Settlement Region}

It has been noted that the availability of information about granular resource supply is a function of demand for the resources (Gowan, Personal Communication, 2008). In 1987, EBA Engineering Consultants, Ltd. concluded that communities adjacent to oil and gas exploration (Inuvik and Tuktoyaktuk) may have greater demand for gravel, and therefore, potential borrow sources have been thoroughly investigated in those areas. However, Ulukhaktok, Sachs Harbour and Paulatuk, which are generally unassociated with oil and gas exploration and development have far less information about the location and characteristics of nearby borrow sources. Historically, in communities where gravel is in less demand, information about the gravel supply is limited to the near vicinity of the community. Contrarily, in communities where gravel is required beyond normal community consumption, information is available about gravel further afield, because private companies have carried out reconnaissance and exploration. 
In 1987, Indian and Northern Affairs Canada on behalf of the Inuvialuit Land Administration commissioned EBA Engineering Consultants, Ltd. to conduct supply inventories and a twenty year demand forecasts for the six ISR communities. The inventories were based upon all available information - site investigations, airphotos, and ground truthing in some cases. The 1987 report is the only time the granular resource potential for all communities has been inventoried since the implementation of the Inuvialuit Final Agreement. The information about granular resources obtained from these inventories serves as the basis of the existing Inuvialuit Settlement Region supply inventory.

Further reports have been compiled about the supply of granular resources in the ISR since the 1987 EBA reports. One report was presented to Indian and Northern Affairs Canada (INAC) in 1991 by Hardy BBT Limited about granular resource potential in the Mackenzie Delta (Tuktoyaktuk, Inuvik and Aklavik) only, drawing upon information from the 1987 EBA reports as well as more recent information from investigations for the gas pipeline and a potential Mackenzie Highway, and from reports from the Geological Survey of Canada. In the same year another study was commissioned by INAC and conducted by EBA Engineering Consultants Ltd., re-evaluating the granular resource potential around Paulatuk. In this report, assessments of gravel at sources $87-\mathrm{P}-12$ and $87-\mathrm{P}-23$ were carried out because the former had just been opened for development by the GNWT Department of Transportation and the latter was being used as a primary source of gravel and was becoming depleted. Finally, in 1993, French Arctic Consultants Limited completed two reports in which the granular resources surrounding Ulukhaktok and Sachs Harbour were mapped. 


\section{3- Current Supply Inventory}

\subsection{1- Development of the Supply Inventory}

The current supply inventory that is used by land managers for Inuvialuit private lands and federal lands is based on the 1987 supply inventories completed by EBA Engineering Consultants (Harlow, 2008, Interview). When a quarry license or concession is issued by the rightful land owner of the granular resources, the amount of gravel allotted to the user by the permit is deducted from the supply inventory. The amount of material leaving pits on private land is monitored by an environmental monitor who is hired at the expense of the user to ensure that no more than the appropriate amount of gravel allotted by the permit is extracted (Romaine, 2007, Interview).

During conversation about the supply inventory for the Inuvialuit Land Administration, Todd Romaine, Chief Land Administrator suggested that the inventory is likely inaccurate. This is due to the fact that gravel is probably being extracted by some users from pits without the acquisition of a quarry license beforehand. As such, it is impossible to track how much gravel is being removed from each source over time. This scenario is suggested because between 2000 and 2007 there have only been licenses issued for nine projects, when in all likelihood, there have been more than nine projects requiring granular resources from Inuvialuit private lands. The nine licenses issued were for users such as Petro Canada, E. Grubens Transport (a major Inuvialuit-owned company) and the Hamlet of Tuktoyaktuk. It may be the case that smaller users may not bother to apply for quarry licenses as the quarries are not monitored. Therefore, the recoverable volumes of granular material indicated in the supply inventory are likely lower 
than what the inventory suggests and as such available gravel supply may be overestimated for communities.

\subsection{2-Present Constraints to Community Gravel Supplies}

\subsubsection{1-Ground ice}

The existence of massive ice within a gravel deposit often makes it undesirable to develop, because it must be either avoided and preserved or allowed to thaw out. When ground ice is exposed to the atmosphere due to excavation, it will melt, and the water resulting from the melting will make the surrounding ground muddy and sticky. This in turn makes the gravel difficult to separate from silt and soil, making it necessary to dry the wet granular material before it can be used (Wainman, 2007, Interview).

There are two methods of coping with ice in a borrow source-removal of surrounding gravel or preservation of the ice. Kurt Wainman, president of Northwind Industries in Inuvik suggests that removing gravel around the ground ice slows down the construction process, requiring extra time and labour. If ground ice exists within a source, a layer of gravel surrounding the ice can be removed, and the newly exposed ice is able to thaw out. The procedure of removal and thawing continues as the pit is dug deeper. However, each time the ground ice is exposed it can take up to five years to melt. Despite the tedium of allowing ground ice to thaw out, this method ensures that the maximum amount of gravel is extracted from the source in areas where gravel is in short supply (Wainman, 2007, Interview).

Another method of coping with ground ice in a borrow source is to preserve it so that it is not able to thaw, ultimately preventing water from entering the surrounding granular 
material. In order to do so, it is suggested that a minimum of 150 centimetres of gravel is left surrounding the ground ice, in order to insulate it and prevent it from thawing (EBA Engineering Consultants, Ltd. (e), April 1987). Although this method preserves the quality of the gravel within the source, it constrains the maximum amount of gravel that can be removed from the source when supplies may be very limited for a community.

The presence of ground ice has been identified as a significant constraint to sustainable pit management. Mardy Semmler, Land Manager for the Gwich'in Tribal council indicates that without personnel to monitor the pits as users extract gravel, if the user comes across ground ice it will be avoided, and a new area will be excavated where gravel is easier to extract (Semmler, 2008, Interview). This creates a larger footprint than originally anticipated when the quarry license was issued (Wainman, 2007, Interview). Likewise, when ice is uncovered by a user while quarrying, often it is not covered back up, allowing it to melt during the summer, making the gravel undesirable to the next pit user (Semmler, 2008, Interview).

\subsubsection{2- Granular Material Quality}

The construction and maintenance of infrastructure requires gravel of reasonable quality. However, the distribution of quality granular resources in the Inuvialuit Settlement Region is uneven, leaving some communities with access to resources suitable for infrastructure construction and maintenance while others have access to only poor quality material. Because of this, although gravel may exist within close proximity to a community, developers may need to travel further afield to obtain gravel of an appropriate grade, ultimately increasing the costs of acquiring gravel as a user. 
It is estimated that approximately seventy-five percent of granular resource requirements within the Northwest Territories are for general fill, of low quality (Class 4). Approximately fifteen percent of granular resource demand is for fair quality gravel (Class 3 ), five percent is for good quality material (Class 2), and five percent of demand is for high quality material (Class 1) (MacLeod, 2008, Interview). Neil MacLeod, of EBA Engineering Consultants, Ltd. proposes that a user will select a borrow source to extract from based on quality and distance, choosing the closest source of the most suitable material for the project.

\subsubsection{3-Accessibility}

The accessibility of granular resources varies by location and proximity to a community. EBA Engineering Consultants, Ltd. (1987 (a)) suggest that access to granular resources is influenced by two factors: cost and environmental protection. Those pits that are nearer to communities and have large volumes of recoverable material are more likely to be worthy of construction of an all season road for access. Because the construction of all-season roads is not economically feasible for gravel pits that lie outside community limits, most gravel is accessed by routes that are impacted by seasonality. The creation and operating season of tundra and ice roads is influenced by atmospheric temperature. Likewise, the season during which gravel can be accessed by barge is also dependent on temperature, and when waterways are free of ice. Therefore, atmospheric temperature dictates when most gravel can be accessed in the Inuvialuit Settlement Region.

Before a project, such as the construction of any road is carried out in the Inuvialuit Settlement Region, it must be reviewed by the Environmental Impact Screening Committee 
(EISC). The project is reviewed for potential environmental impacts, such as conflict with wildlife management plans or community conservation plans, or causing habitat loss and disturbance to significant species including those that are traditionally harvested by the Inuvialuit or are keystone species. The project must also fall within territorial or federal air and water quality standards (Indian and Northern Affairs Canada, 2001). Therefore, the construction of roads for access to granular resources is only possible if it does not interfere with wildlife or have significant negative impacts on the environment. As such, although a source of gravel may exist within close proximity of a community, access may be restricted due to environmental impact.

Having only seasonal access to aggregates creates vulnerabilities for Inuvialuit communities. A lack of year-round gravel supply is a major concern for Aklavik. According to Mardy Semmler, Land Manager of the Gwich'in Tribal Council, Aklavik flooded in 2006, washing out roads and gravel pads such that gravel was required to repair and rebuild some infrastructure. However, at the time the community had no stockpile, and there were no nearby sources that were accessible during the spring. As a result, the community resorted to hauling gravel on barges from the Inuvik area in order to rebuild infrastructure (Semmler, 2008, Interview).

\subsection{3- Current Community Gravel Supplies}

Compared to other areas in Canada, the Northwest Territories and Nunavut rely heavily on granular resources that are very difficult to access. The neigbouring Yukon Territory has excess gravel which is often exported to Alaska. However, granular resource borrow sites 
surrounding the Inuvialuit Settlement Region communities are nearly exhausted, and there are economic constraints to developing sources further afield (Romaine, 2007, Interview).

\section{Aklavik}

Aklavik has no sources of gravel within fifteen kilometers of the community. The nearest borrow sources are located on Crown land and are between 15 and 20 kilometres away. Both sources (468 and 469) are accessible only during the winter, and both contain gravel of extremely poor quality (Class 5). The nearest gravel of fair quality (Class 3 ) is located between 20.1 and 30 kilometres of Aklavik, at two different locations (Pits 455 and 467) on Crown land. Both of these sources can be developed without constraints, and together have a recoverable volume of 3.5 million cubic metres. Two of the pits on Crown land within 30 kilometres of Aklavik, that were accessible year round by winter road and barge have been completely depleted of granular material. Two more sources of extremely poor quality material lie over fifty kilometers from the community, and despite having 8 million cubic metres of material, are constrained by wildlife habitat protection and lack of accessibility.

Overall, Aklavik has very poor access to granular resources, and this access is limited to the winter season. Even then, the materials are of a quality useful for general fill at best, and not for supporting infrastructure such as housing or for finishing roads.

Inuvik

There are only three sources of gravel within ten kilometers of Inuvik, and one of them is nearly exhausted of material (1400). The pit (1402) with the greatest amount of gravel within 
close proximity of the community belongs to Transport Canada, and as such is reserved for projects that are supported by Transport Canada. The remaining pit (1401A) lies on Crown land and does contain over one million cubic metres of recoverable gravel. However, this source lies in an area of significance for wildlife, and is only of fair quality and accessible only during the winter. Pit 1400, which is almost exhausted was the nearest source of gravel on private land and accessible year round.

There are three sources of gravel between 15.1 and 20 kilometres of the community, and two (1403 and 1404) are accessible year round by permanent access roads and have no constraints to development. The total recoverable volume between these two pits is 2.5 million cubic metres, however the gravel is of poor quality. One of the sources $(2.46)$ located within 15.1 and 20 kilometres of Inuvik has been completely depleted. Another (R29) is accessible year round by winter road and barge, and contains 20 million cubic metres of granular material, but it is also of poor quality.

The largest source (2.43) of granular material for Inuvik lies between 30.1 and 40 kilometres of the community and contains 180 million cubic metres of gravel, of Class 4 quality. It is accessible only during the winter by tundra or ice roads and has no constraints to development. The nearest sources of good quality (Class 2) gravel lie between 60.1 and 90 kilometres of the community and all are constrained by environmental factors. Two are located in areas identified as significant by the International Biological Program, another is located in a fish and wildlife habitat, while the final one has development constraints due to the presence of massive ice. The closest source of good quality developable granular material is at the $\mathrm{Ya} Y \mathrm{Ya}$ Lakes site, approximately 100 kilometres from Inuvik. This site contains nearly 13 million cubic 
metres of recoverable Class 2 material, but is only accessible during the winter by tundra or ice roads.

In general, over fifty percent of the 34 potential borrow sources for Inuvik have constraints to development as they are in areas of environmental significance or wildlife habitats. Another fifteen percent of the borrow sources have physical constraints to development. Although there is approximately 448 million cubic metres of granular potential for extraction, only half of it is available for development without environmental or physical constraints.

\section{Paulatuk}

There are four sources (87-P-11, 87-P-12, 87-P-21, 87-P-22) of granular material within 10 kilometres of Paulatuk. All of the sources are on private land and are accessible by winter road only. These four sources have a total recoverable volume of $3,950,000$ cubic metres of gravel. However, each source has constraints to development Both 87-P-12 and 87-P-21 have poor accessibility, while 87-P-11 and 87-P-22 are wet because they are low lying or on the coast. The highest quality of gravel within 10 kilometres of the community is located at source 87-P-12, and is Class 2 (good quality)with a volume of one million cubic metres. Meanwhile, source $87-\mathrm{P}-11$ and $87-\mathrm{P}-21$ contain Class 3 (fair quality) materials and 87-P-22 has Class 4 (poor quality) gravel.

Between 10.1 and 15 kilometres of Paulatuk there are four sources (87-P-9, 87-P-10, 87P-13 and 87-P-20) that contain a total of 8.9 million cubic metres of gravel. 87-P-9 lies on Crown land, while the other three pits lie on private land, and all are accessible during the 
winter only by tundra or ice road. Pit $87-\mathrm{P}-20$ is the closest borrow source to the community with no constraints to development, and contains Class 3 granular material. The pit, despite a large recoverable volume ( 5 million cubic metres) has Class 4 granular material and its development is constrained by poor accessibility. Source 87-P-10 is also poorly accessible and $87-\mathrm{P}-13$ is relatively thin.

There are eight borrow sources between 15.1 and 20 kilometres of the community, with a combined recoverable volume of 16.5 million cubic metres. Three of these pits have no constraints to development (87-P-1, 87-P-14, 87-P-19). 87-P-19 contains Class 2 material, and 87-P-15 and 87-P-19 have Class 3 material. The remaining pits within 15.1 and 20 kilometres of Paulatuk are constrained by poor accessibility, poor material quality, presence of ground ice, or by being thinly distributed.

Three sources (88-P-3, 87-P-16 and 87-P-17) lie at distances greater than 20 kilometres from Paulatuk. Source 88-P-3, containing Class 2 material could be developed without constraints, however, is not continuously distributed and is only accessible during the winter. Pit 87-P-17 has been depleted and contains no resources, and pit 87-P-16 is thinly dispersed and contains ground ice.

Overall, there are no sources of granular material within ten kilometers of Paulatuk that have no constraints to development. The nearest source that is unconstrained is approximately 15 kilometres from the community, and contains Class 3 (fair quality) materials. There are two other sources without constraints between 15.1 and 20 kilometres from the community, containing Class 2 and 3 materials, and one source more than 20 kilometres away with Class 2 
materials. Paulatuk has no summer access to granular materials, and all but one identified sources of gravellie on Inuvialuit private land.

\section{Sachs Harbour}

There is a total of over 13.6 million cubic metres of recoverable granular material within 20 kilometres of Sachs Harbour, and all of this material has been identified as Class 3 (fair quality) material. All sources of gravel that have been identified in the supply inventory lie on Inuvialuit private land.

Within 10 kilometres of the community, there are ten borrow sources. Six of these sources are accessible year round, four by all-season roads, two by ice road in the winter and barge in the summer. Four of the sources are accessible in the winter only by tundra road. Of the ten sources, only two (87-SH-1 and $87-\mathrm{SH}-2$ ) have no constraints to development. Three of the sources (87-SH-3, 87-SH-5 and 87-SH-6) have small volumes, while $87-\mathrm{SH}-4$ is depleted. Four of the sources are difficult to develop and extract from due to their proximity to water bodies. There are over 7 million cubic metres of Class 3 granular material within 10 kilometres of Sachs Harbour, only 200,000 cubic metres of which have no constraints to development.

Further from the community, between 10.1 and 15 kilometres, there are two more sources of gravel on private lands (87-SH-7 and 87-SH-11), 87-5H-7 is accessible year round, but its development is constrained by its coastal location. Source $87-\mathrm{SH}-11$ is the largest source of gravel in the Sachs Harbour area (6.5 million cubic metres), however is only accessible during the winter, and is constrained by its location within a riverine environment. 
There is one source of gravel 19 kilometres away from the community that is accessible year-round by tundra road in the winter and barge in the summer. However, constraints to its development have not been identified, and as such it may not be a viable source of gravel for Sachs Harbour.

Overall, the sources of gravel accessible year round to Sachs Harbour are largely depleted. As such, the community may have to develop borrow sources that are only accessible during the winter. The development of most of these sources may be difficult as they are located in river or coastal environments.

\section{Tuktovaktuk}

Six sources of gravel lie within 10 kilometres of Tuktoyaktuk, all on Inuvialuit private land. Four of the sources $(158,159,160 / 161$, and 162) are accessible year round, by tundra and ice road in the winter and by barge in the summer. Pit 156 is only accessible by barge in the summer, and 181 is only accessible in the winter by tundra or ice road. There is a total recoverable volume of approximately 13.8 million cubic metres of granular material within 10 kilometres of Tuktoyaktuk, but all of the sources have constraining factors to their development. Four of the six sources contain ground ice, making them difficult to excavate. The constraining factors to development of the six nearest sources to Tuktoyaktuk include location in an environmentally sensitive area (156), overburden (160/161, 159), and location in a fish habitat (162). The gravel found within 10 kilometres of the community is primarily Class 3 (fair quality). 
The two pits located between 10.1 and 15 kilometres from Tuktoyaktuk also have constraints to development, including being located in an environmentally sensitive area (157) and having major ground ice content (183). There is one source (169) located approximately 17 kilometres from the community that contains 3 million cubic metres of primarily Class 2 (good quality) gravel. This particular source is accessible only during the winter by tundra or ice road, however, there are no identified constraints to developing and extracting the pit, nor has ground ice been discovered at this location.

The nearest sources of high quality gravel (Class 1) are located between 30.1 and 40 kilometres from Tuktoyaktuk. Access to both of these pits (166 and 304) is unconstrained, however, there is only a total recoverable volume of 176,000 cubic metres of gravel. The Parsons Lake site, approximately 60 kilometres from the community contains ten separate pits of gravel of good and fair quality. The major constraints to development of these sites can potentially be overcome as they are physical constraints-excess overburden and ground ice. Furthermore, three of these sources are accessible year round by winter roads and barge.

There is a total of nearly 800 million cubic metres of recoverable gravel in the eighty four pits that lie within 100 kilometres of Tuktoyaktuk. However, only 162 million cubic metres of this potential is unconstrained. The best quality gravel available to the community is located more than twenty kilometers away, and is only accessible during the winter season. Furthermore, five of the eighty four pits for Tuktoyaktuk have been completely depleted. 


\section{Ulukhaktok}

The current amount of gravel available to Ulukhaktok is 3.6 million cubic metres, and all of this gravel lies on Inuvialuit private land. There are four sources $(87-\mathrm{H}-6,87-\mathrm{H}-7,87-\mathrm{H}-8$, and 87-H-10) within ten kilometers of the community, with a recoverable volume of 650,000 cubic metres. Three of the sources are accessible by all-season roads $(87-\mathrm{H}-6,87-\mathrm{H}-7$, and $87-\mathrm{H}-8)$, while one $(87-\mathrm{H}-10)$ is accessible during the winter by winter road and by barge during the summer months. The amount of ground ice within any of the sources lying in close proximity to Ulukhaktok is unknown. However, $87-\mathrm{H}-7$ is difficult to access, and $87-\mathrm{H}-8$ is located underneath the town and therefore not ideal for development. When taking into account the constraints to development of $87-\mathrm{H}-7$ and $87-\mathrm{H}-8$, there is only 275,000 cubic metres of gravel available to the town within ten kilometers. Both of these sources consist of Class 3 (fair quality) granular material. The only source of a higher grade material is at $87-\mathrm{H}-7$, which is constrained by difficult accessibility.

There are five more sources of gravel $(87-\mathrm{H}-2,87-\mathrm{H}-4,87-\mathrm{H}-5,87-\mathrm{H}-11$, and $87-\mathrm{H}-12)$ that lie within 10.1 and 15 kilometres of Ulukhaktok, with a total recoverable volume almost 2 million cubic metres. Four of the five sources are accessible in the winter, and one is accessible year-round by an all-season road $(87-\mathrm{H}-5)$. One of the sources is inaccessible during the summer months $(87-\mathrm{H}-2)$, while three are accessible by barge, and one by an all-season road. However, $87-\mathrm{H}-5$, likely due to its easy accessibility is the most substantially depleted borrow source of any in the vicinity of Ulukhaktok. All of the deposits within 10.1 and 15 kilometres of the community are discontinuously distributed, making them more difficult and expensive to develop. 
Two sources of gravel lie at distances of approximately 16 kilometres away from Ulukhaktok (87-H-1 and 87-H-12). Both sources are only accessible during the winter by tundra or ice road, and are inaccessible during the summer. A total of one million cubic metres of gravel exists within the two sources, and no constraints to development have been identified.

Overall, there are two sources of gravel $(87-\mathrm{H}-6$ and $87-\mathrm{H}-10)$ in the near vicinity of Ulukhaktok that are accessible year-round, continuously distributed and have no identified constraints to development. The total amount of recoverable gravel in these two sources is 275,000 cubic metres. Further afield, between 10.1 and 15 kilometres away, there are two sources of gravel $(87-\mathrm{H}-4$ and $87-\mathrm{H}-12)$ that are accessible year-round, have no constraints to development, but are only semi-continuous in distribution, making them more expensive and labourious to develop. These two sources have a combined recoverable volume of 1.65 million cubic metres of gravel. The highest grade of gravel accessible by the community of Ulukhaktok is the Class 2 (good quality) gravel found at source $87-\mathrm{H}-4$, which is accessible year round and has no constraints to development, but is located approximately 13 kilometres from the community.

\section{4- Impacts of Climate Change on Supply}

\subsection{1-Shorter Hauling Season}

It is expected that the temperature increases that may be experienced in the Mackenzie Delta will produce milder winters which will shorten the ice road season (Natural Resources Canada, 2007, Online; Cohen, 2002, Online). The NWT Climate Change Impacts and Adaptation Report states that warming in the north has caused later freeze-up in the fall, 
thinner ice throughout the season and earlier spring thaw. These presumed climate change impacts have resulted in shorter winter road seasons, despite human efforts to preserve the roads with extra flooding and freezing (NWT ENR, 2008).

Data from between 1980 and 2007 (Figure 7.2), shows that there is a correlation between the number of days the Inuvik Tuktoyaktuk ice road is open per season and the average annual temperature in Inuvik. When the average annual air temperature rises, there is generally a corresponding decrease in the number of days for the ice road season that year. This trend was exemplified in the 1997/1998 El Nino year when the mean annual air temperature was $-4.6^{\circ} \mathrm{C}$, almost two degrees higher than the next highest temperature during the 1980-2007 timeframe. Likewise, when the temperature dropped, like in 1985/1986, the number of ice road days increased. Despite an average upwards trend in mean annual air temperature, the ice road season is also generally increasing. This may be attributed to the increasing efforts of ice road maintenance companies to preserve the ice road by carrying out more flooding because of increased demand for ice road use compared to the early 1980 s. 
Yearly Number of Ice Road Days (1980-1994, 1995-2007) and Annual Average Temperature $\left({ }^{\circ} \mathrm{C}\right)$ for the Inuvik-Tuktoyaktuk Ice Road

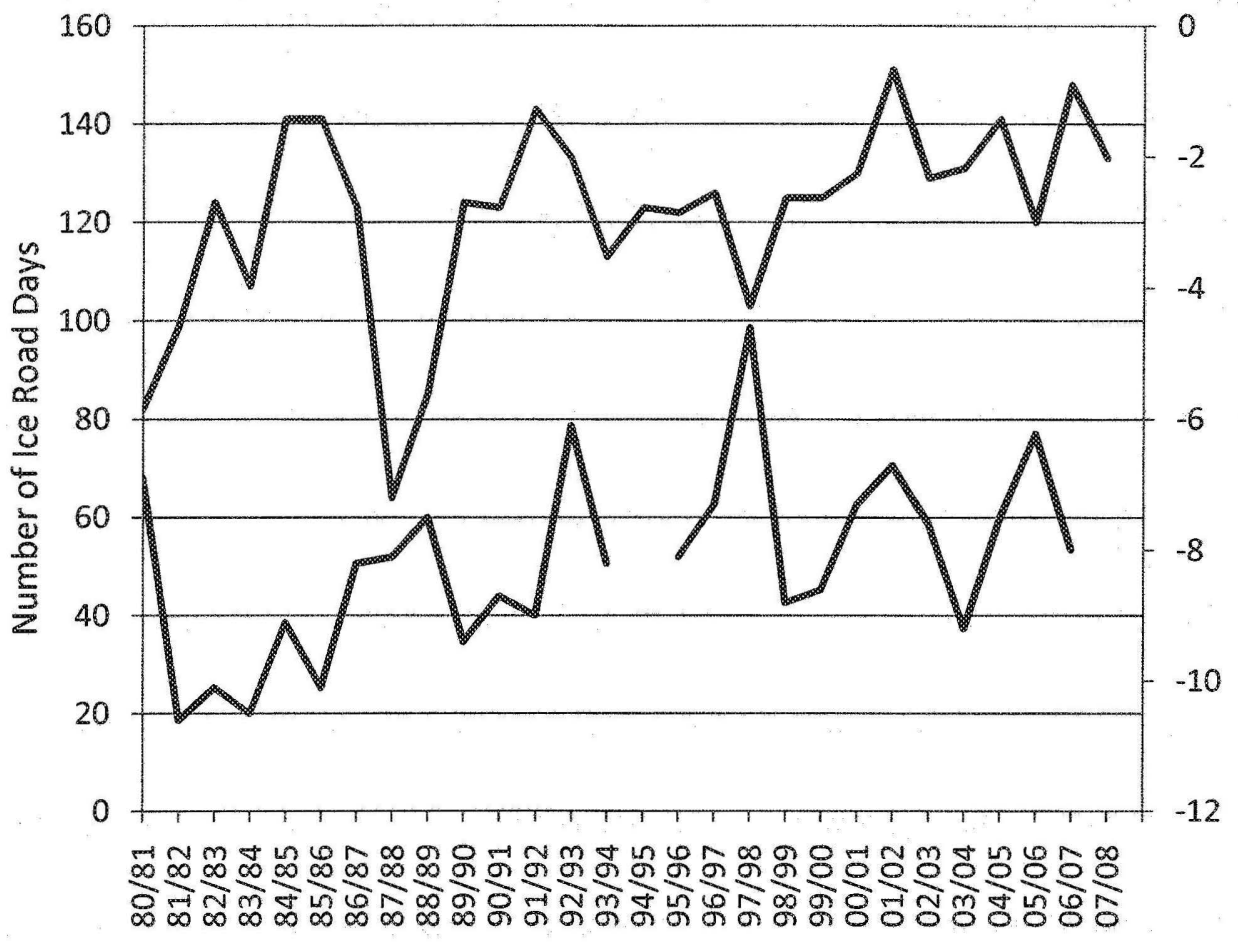

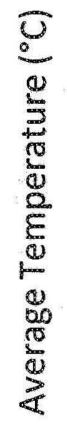

Number of Ice
Road Days
Annual Ave.
Temp $\left({ }^{\circ} \mathrm{C}\right)$

Figure 7.2-Ice Road Season ${ }^{1}$ and Average Annual Temperature ${ }^{2}$ for the Inuvik-Tuktoyaktuk Ice Road

Increasing temperatures have already had observable impacts on ice roads, such as the Tibbitt to Contwoyoto winter road which runs from Tibbit Lake (outside of Yellowknife) northwest for 600 kilometres to western Nunavut. The road is owned by diamond mining

${ }^{1}$ Source: NWT Department of Transportation. (2008) Mackenzie Delta Ice Roads (Inuvik Area). [Online] Available: http://www.dot.gov.nt.ca/_live/pages/roadreportsHistory/WinterRoad_MackenzieDeltaInuvikArea.pdf

${ }^{2}$ Source: Environment Canada. (1980-2005) Climate Data for Inuvik A Northwest Territories: Monthly Data Report. Station Latitude: $68^{\circ} 18.000^{\prime} \mathrm{N}$ Longitude: $133^{\circ} 28.800^{\prime}$ W Elevation: $68.30 \mathrm{~m}$, Environment Canada. (2006-2008) Climate Data for Inuvik AWOS A Northwest Territories. Station Latitude: $68^{\circ} 18.000^{\prime} \mathrm{N}$ Longitude: $133^{\circ} 28.800^{\prime}$ W Elevation: $68.30 \mathrm{~m}$ 
companies, and maintained by Nuna Logistics. In 2006, the air temperature at the beginning of the ice road season at Tibbitt Lake was $8^{\circ} \mathrm{C}$ higher than the normal average temperature for that time of year. The consequence was a winter road season 67 days shorter than average, and some portions of the road never thickened to a depth that could support the heaviest loads (Katz, 2007, pg. 94).

The implications of a shorter winter road season are negative for the granular resources industry. If the winter road season shortens, there will be pressure to move granular resources from their source to their demand points in a shorter period of time. This may be more costly for granular resource haulers, requiring more personnel and equipment to haul gravel during a shorter season, ultimately increasing the cost of acquiring gravel for the end user. There is also potential that the pace of hauling gravel will remain the same due to economic constraints and lack of personnel, thusly decreasing the supply of gravel available to those demanding it, making it an even more competitive resource. As well, if the thickness of the ice roads decreases, this will limit the weight of loads, decreasing the amount of gravel that can be hauled each trip. Although the ice road season will shorten with climate change, there will also be a longer ice free season, which will allow for a longer barge season (Natural Resources Canada, 2007, Online).

An issue of concern is the fact that the Northwest Territories Department of Public Works assesses the gravel demands of communities in the spring and summer, but budgeting for the acquisition of granular resource requirements does not reach the communities until January or February of the following year. Because of this, although the winter road season can begin in December, communities do not know whether winter roads will be required to reach 
certain borrow sources. Therefore, the hauling season for gravel for publicly-funded projects is often even shorter than the actual winter road season. If a warming climate makes the spring melt of winter roads occur even earlier than at present, the window for hauling may be too short to meet community demands. This in turn will place increased pressures on extractors and haulers to attempt to meet community demands over a shorter period of time (Semmler, 2008, Interview).

\subsection{2-Increasing Ground Ice Melt}

Mardy Semmler and Kurt Wainman expressed concern that climate change may cause ground ice in gravel deposits to melt faster if the pit is open and the ice is exposed to the atmosphere. This will cause the material to become muddy, sticky and therefore requiring drying before it is usable, making gravel unavailable for immediate use.

Climate warming may also increase the amount of granular material required to surround massive ice within a deposit in order to prevent it from melting while the pit is being developed. Just as infrastructure will require additional gravel to prevent permafrost thaw, so might ground ice. This in turn detracts from the total recoverable volume of a borrow source. Therefore, if the climate warms and causes increased ground ice melt, pits containing ground ice may become less desirable to develop due to the extra amount of effort required to preserve ground ice, ultimately decreasing the total amount of gravel available to communities for development. 


\section{5- Climate Change and Supply}

\section{Aklavik}

There are no gravel sources in the vicinity of Aklavik that are accessible by all-season roads, making the accessibility of all potential borrow sources vulnerable to climate change. The two sources ( 455 and 467) which are unconstrained for development are accessible during the winter only by tundra or ice road. These two pits are also the sources of the highest quality gravel (Class 3) in the Aklavik area, and are within a relatively reasonable distance (between 20 and 30 kilometres) of the community. The only sources that are accessible year round by winter road and barge are already constrained by poor quality and wildlife.

Inuvik

The community of Inuvik's supply of good and high quality of gravel will be impacted by climate change. These sources lie over 40 kilometres from the community and are accessible only by winter road. There are two sources of gravel that can be reached by all-season roads, however they are of poor quality. The primary source of good quality (Class 2) gravel, Ya Ya Lakes, is accessible by winter road only at a distance of approximately 100 kilometres. This source also contains massive ground ice, and its melting could create further obstacles to obtaining gravel. As such, there will be greater pressure to haul more gravel during a shorter period of time in order to meet community needs for good quality gravel for Inuvik. 


\section{Paulatuk}

The supply of gravel for the community of Paulatuk will be influenced by climate change through a shorter hauling season. All of the sources of granular material surrounding Paulatuk are accessible only during the winter by tundra or ice roads. Without summer access to granular resources, if temperatures warm due to climate change the community may have difficulties accessing gravel because of a shorter hauling season.

\section{Sachs Harbour}

The community of Sachs Harbour has year-round access to eight out of its thirteen sources of granular material. Over the short term, the community's gravel supply may not be impacted by climate change as the gravel will be accessible year round. However, the most plentiful source of gravel is located further afield, and is only accessible by winter roads. Once the borrow sources within close proximity of the community are depleted, climate change may impact the accessibility of this source, 13 kilometres away.

\section{Tuktoyaktuk}

The accessibility of good quality gravel for Tuktoyaktuk may be influenced by climate change. The nearest source of unconstrained good quality (Class 2) gravel is located approximately twenty kilometers from the community and is only accessible during the winter. The situation is the same for the nearest source of Class 1 gravel which is located 35 kilometres from Tuktoyaktuk. Most of the gravel sources with year round access have constraints to pit development, and as such do not provide viable alternatives for gravel extraction in the face of 
climate change. Two of the Parsons Lake sources are accessible year round, but have significant amounts of ground ice which may make development of the pit and extraction difficult if a warmer climate causes the ice to melt at a faster rate than normal. Overall, the community of Tuktoyaktuk is likely to experience stresses related to obtaining gravel to meet the community's needs for the upcoming year over a shorter hauling season.

\section{Ulukhaktok}

Ulukhaktok has one gravel pit $(87-\mathrm{H}-6)$ within ten kilometers of the community that has no constraints to development and is accessible by an all season road. Within the same distance is another pit $(87-\mathrm{H}-10)$ that is also unconstrained and accessible year round by winter road and barge. Therefore, two of the four pits, consisting of 275,000 cubic metres of material and located within ten kilometers of the community may have no constraints to accessibility due to climate change.

There are two other pits $(87-\mathrm{H}-4$ and $87-\mathrm{H}-12)$ that are also accessible year round and without constraints to development. These sources may also remain feasible for extraction in the face of climate change due to their year round accessibility, and contain a total volume of 1.65 million cubic metres of material. Source $87-\mathrm{H}-4$ contains material of good quality (Class 2).

Overall, it appears that Ulukhaktok may have over 1.9 million cubic metres of gravel within 15 kilometres of the community that will not be impacted by climate change and have no constraints to development. 


\section{1- The Implications of Climate Change for the Avallability of Granular Resources in the ISR}

The Inuvialuit Settlement Region is experiencing environmental change; the Arctic is warming at twice the rate of the rest of the globe. Specifically, the Mackenzie District, in which much of the ISR lies experienced a temperature increase of 2 degrees Celsius between 1948 and 2005, whereas the rest of the Canadian Arctic experienced only a 1.2 degree increase. The prognosis for the Arctic suggests that climate change is occurring and that the temperatures in the Inuvialuit Settlement Region are likely to continue to increase in years to come. With climate change will come change to the dynamics of demand and supply of granular resources on which communities depend for infrastructure construction and maintenance.

\subsection{1-Climate Change and Demand for Granular Resources}

The amount of gravel used for the construction of new infrastructure has already increased by fifteen to twenty percent (MacLeod, Interview, 2008), and will continue to do so as the active layer thickens and air temperatures increase due to climate change. If atmospheric temperatures increase by 6.5 degrees by 2100 as has been predicted, the active layer could thaw up to 70 centimetres in the Inuvialuit Settlement Region, making it necessary to increase the thickness of gravel pads beneath infrastructure by this depth as well. For projects such as the proposed Inuvik-Tuktoyaktuk highway, increasing temperatures could double granular resource requirements in order to abate and mitigate climate change related infrastructure failure. Currently, there is not sufficient information to determine whether regional demand for gravel, including increased demand due to climate change and economic development, will exceed the amount of gravel that is available to the communities. 


\subsection{2- Climate Change and Supply of Granular Resources}

Although there is a significant quantity of gravel within the Inuvialuit Settlement Region, the extraction of much of it is not feasible. Currently, some granular resource borrow sources are inaccessible to communities due to seasonal access, large amounts of ground ice, and the presence of environmentally-significant factors (wildlife, breeding grounds). Furthermore, it is difficult for communities (specifically, Aklavik and Tuktoyaktuk) to access granular resources of high quality. The inaccessibility of gravel will be significantly exacerbated by climate change.

The gravel supply will be limited by shorter ice and tundra road seasons, decreasing the amount of gravel that communities can haul to meet summer construction needs. Likewise, the melting of ice within the gravel sources will make it more difficult to extract, and ultimately result in less available material. Aklavik and Paulatuk will be the communities most impacted by climate change in terms of gravel accessibility, each having no unconstrained year-round access to gravel sources. Meanwhile, Inuvik and Tuktoyaktuk, the two communities demanding the most gravel may have difficulty accessing gravel of good quality for infrastructure construction. Sources of higher quality gravel for these communities are only accessible during the winter, and climate change will add pressure to move more gravel in a shorter period of time. Sachs Harbour and Ulukhaktok are the two communities with the least gravel demands, and have sources that will likely not be impacted by climate change as they are accessible year-round. Overall, Aklavik, Paulatuk, Inuvik and Tuktoyaktuk are the Inuvialuit Settlement Region communities most likely to experience shortfalls in gravel supply due to climate change. 


\section{2-Towards a Granular Resource Management Plan}

Without an established granular resource management plan for land managers of the three jurisdictions within the Inuvialuit Settlement Region to follow, the resource cannot be managed in a sustainable way. With uncertainty about the future demand for gravel, as well as the amount of gravel that is available, it is evident that a granular resources management plan must be put into place in the region. Thus far, there have been no studies focusing on the management of granular resources in the face of climate change. The following are recommendations based upon the research for this paper and discussions with stakeholders in the region for the development and implementation of an ISR-wide granular resources management plan that considers potential vulnerability presented by climate change.

In accordance with the Memorandum of Understanding between INAC and ILA, a granular resources management plan working group will need to work together to create a management plan with the overall goal of sustainable granular resource management within the Inuvialuit Settlement Region. Based upon the findings of this research paper, that climate change may impact the supply of and demand for granular resources, an additional objective of managing gravel sustainably in light of a changing environment should be added.

The key elements to a granular resources management plan where sustainable management of gravel is the goal include an accurate supply inventory of resources within the region, an accurate demand forecast for gravel use by all potential users for the upcoming 20 years, and pit management plans for the most commonly utilized pits surrounding communities. Each of these elements will require significant dedicated man-hours by ILA and INAC, as well as investment in consulting services. 
In order to develop a more accurate supply inventory than currently exists, it is necessary to identify which pits are the most commonly used surrounding each community. This can be done by a combination of methods, including analyzing quarry permits to determine which pits are most commonly extracted from. However, it is recognized that gravel is often taken from pits without a permit, and thus, further consulting with the ISR communities will be required to determine where un-permitted gravel extraction is occurring. A series of community consultations with community organizations including each hamlet or town office and community corporations, may give an indication of which pits are the most vital to community infrastructure development. It can then be decided upon which pits are the most crucial to re-assess in terms of the amount of available gravel as well as constraints to development (specifically, physical constraints that require measurement such as ice content). Therefore, money and consultant efforts can be concentrated on the sources that are of the most importance to community wellbeing at present, and an accurate depiction of supply can be obtained for those pits.

Likewise, an accurate demand forecast is crucial to the development of a granular resources management plan. In order to obtain information about demand for the upcoming 20 years, it will be necessary to speak to any potential granular resource users in the region and acquire demand information. In the past responses to demand forecast inquiries have been low, and as such, efforts will have to be placed into stressing the importance of participation in demand forecasting as part of the region's granular resource management plan.

Furthermore, within the management plan climate change scenarios for granular resource demand could be built into the demand forecasts. Currently, for the creation of their 
demand forecasts for gravel requirements, the Government of the Northwest Territories refers to a table which suggests the amount of gravel required for the construction of different types of new infrastructure, including fire halls, gas stations, sewage lagoons, etc. (The Interdepartmental Granular Resource Acquisition Committee, 2007). It would be ideal if these figures could be recalculated to reflect the amount of gravel that would be required to construct infrastructure under a climate change scenario (for example, an increase in the depth of the active layer by 70 centimetres over the next 100 years), and be included in the granular resource management plan. Likewise, a separate table could be constructed to suggest how much gravel would be required to abate the impacts of climate change on existing infrastructure, for example, the amount of extra fill needed by each of the types of infrastructure listed in the original table. Once such a table is constructed, when demand surveys are being conducted the user can be asked whether their design plans take into account the prospect of climate change. If not, the demand value for granular resources estimated by the user can be recalculated to reflect a more realistic figure of resources required. Then, overall, land managers would be presented with two figures: demand without consideration of climate change, and potential demand if the climate does warm to the extent suggested by the climate scenario. This information could be used to allocate resources in a more sustainable manner, taking into account climate change as a potential cause for major demand of resources, which is especially necessary to do before approving licenses for other 
Finally, the granular resources management plan will require pit management plans for the most commonly used pits in the region (as identified when re-evaluating the supply inventory). Pit management plans can be developed by each pit's owner, and these will serve as rules that proponents must follow when extracting gravel from a pit. Each pit management plan should detail the order in which different areas of the pit should be extracted from, physical constraints that must be avoided (ground ice, etc.), what must be done with overburden, and how the pit should be restored upon completion of quarry operations.

The key to preventing community vulnerability related to infrastructure failure due to climate change is the development a management plan in order to ensure the sustainable allocation of granular resources. The development of a granular resources management plan has been seemingly avoided thus far for several reasons including high staff turnover and a lack of dedicated staff resources to developing a plan, a lack of coordination between the federal government and the Inuvialuit Land Administration, and a deficiency of critical information necessary for forming a granular resources management plan.

Such a management plan is a necessity due to the stresses faced by the region including climate change and competing demands for resources by the Mackenzie Gas Project and the potential Inuvik-Tuktoyaktuk highway. Furthermore, the Inuvialuit Land Administration must ensure that the principles of the Inuvialuit Final Agreement are adhered to when managing land and resources in the ISR, including ensuring the socio-economic well-being of the inuvialuit beneficiaries would include preserving the infrastructure on which they depend for survival and economic activity. As such, the development of a granular resources management plan is of 
the utmost importance in order to ensure that granular resources are managed in a manner that will allow for the sustenance and growth of Inuvialuit communities now and in the future. 


\section{Participant Informed Consent}

I agree to take part in the above Ryerson University research project. I have read the above Explanatory Statement. I am willing to:

be interviewed by the researcher

allow the interview to be recorded by pen or typing, and to be stored on a secure computer hard drive

answer questions at my will about gravel use, supply and demand in the Inuvialuit Settlement Region

I understand that any information I provide is confidential, and that no information that could lead to the identification of any individual will be disclosed in any reports on the project, or to any other party.

I also understand that my participation is voluntary, that I can choose not to participate in part or all of the project, and that I can withdraw freely at any stage of the project.

\section{Please tick the appropriate box}

- The information I provide can be used by the researchers WITH my name attached.

a The information I provide can be used by the researchers WITHOUT my name attached.

Name:

(please print)

Signature:

Date: 


\section{Questionnaire}

1. What is your role in the granular resources industry?

Granular Resources Management (Issuing Exploration Permits, Quarry Permits/Licenses, Monitoring Supply, Forecasting Demand)

Please Answer Questions in Section 1

Granular Resources Extraction, Processing, Hauling

Please Answer Questions in Section 2

Infrastructure Planning, Construction, Maintenance

Please Answer Questions in Section 3

Community Government

Please Answer Questions in Section 4 


\section{Questionnaire}

1. What is your role in the granular resources industry?

Granular Resources Management (Issuing Exploration Permits, Quarry Permits/Licenses, Monitoring Supply, Forecasting Demand)

Please Answer Questions in Section 1

_ Granular Resources Extraction, Processing, Hauling

Please Answer Questions in Section 2

Infrastructure Planning, Construction, Maintenance

Please Answer Questions in Section 3

Community Government

Please Answer Questions in Section 4 


\section{Section 2- Granular Resources Extraction, Processing, Hauling}

1. Please describe your role in the granular resources industry.

2. How are granular resources extracted and processed?

3. How does climate and weather factor into the extraction and processing of granular resources?

4. During what time of the year is the majority of extraction and processing carried out?

5. During what time of the year is the gravel hauled from its source to its destination?

6. What transport routes are used for hauling granular resources from source to destination?

7. Have you noticed any changes in the length of the granular resources extraction/processing season? If so, has the season become longer or shorter?

8. Have you noticed any changes in the length of time that ice roads can be used for hauling granular resources? If so, has the season become longer or shorter?

9. What impacts do you anticipate climate change to have on the extraction and processing of granular resources?

10. How does the melting of ground ice within granular deposits impact the extraction of granular resources?

11. What impacts do you anticipate climate change to have on the hauling of granular resources from their sources to communities?

12. What would these impacts mean for the supply of granular resources to Inuvialuit Settlement Region communities? Is there potential for shortfalls in supply? 
12. How do you think the prospect of climate change should factor into the management of granular resources?

13. Have there been any noted changes in demand for granular resources that may be on account of climate change and a changing physical environment?

14. Do you think that practically, climate change should become factor in granular resource forecasting? If so, how could this factor be implemented into the forecasts?

15. In the face of climate change, do you see granular resources management as an important issue for the Inuvialuit Settlement Region?

16. What are your concerns for granular resources in the Inuvialuit Settlement Region in the future, should climate warming continue? 


\section{Section 3- Infrastructure Plonning, Construction and Maintenance}

1. Please describe your role in the granular resources industry.

2. How are granular resources used in the construction of infrastructure in the Northwest Territories?

3. Where/who are granular resources obtained from for the projects that you work on?

4. Why are granular resources of particular importance for construction of infrastructure in the Northwest Territories?

5. What are the advantages of using granular resources as opposed to other technologies for insulating the permafrost from infrastructure?

6. Have there been times when granular resources have been difficult to obtain for a particular project?

7. What impacts of climate change have you observed on infrastructure?

8. What impacts could climate change have on infrastructure in the future?

9. Has the amount of gravel used in new construction projects (ie// roads, airstrips, building pads) increased due to climate change already? If so, by how much?

10. Have you noticed an increase in demand for granular resources for use in maintaining infrastructure that has been impacted by climate warming?

11. Do you have any specific figures on how much extra gravel will be required for projects such as roads, airstrips and building foundations for a specific increase in temperature in the NWT? (ie// $\mathrm{x} \%$ more gravel will be required with a $\mathrm{y}^{\circ} \mathrm{C}$ increase in ground-surface temperature) 
13. How would the granular resource extraction/processing/hauling industry have to adapt to climate change in order to meet the demands of communities?

14. Is it likely that the granular resource supply industry could adapt to the possible impacts of climate change (ie// shorter hauling season) in order to meet community demands? Or would community demands possibly go unmet?

15. In the face of climate change, do you see granular resources management as a major issue for the Inuvialuit Settlement Region?

16. What could be done in order to help your industry adapt to the potential impacts of climate change? 


\section{Section 4- Community Government}

1. What is your role within the community government?

2. What concerns do you have about granular resources within your community?

3. Do you sense that there is concern within the community about the supply of granular resources, and whether there will be enough to meet future demand?

4. What role do you think the community should have in granular resource management?

5. If a changing climate is going to place more demand on granular resources, how do you think the management of granular resources for your community should be altered?

6. Is granular resource management a high priority issue facing your community at the present? 
12. Do granular resources have the ability to continue to abate the impacts of climate change on infrastructure, or will there be a point when measures other than a thicker insulating layer will be required?

13. When planning and forecasting future infrastructure for communities, has increased requirements for granular resources due to climate change been factored into these plans? If so, how?

14. Do you think that climate change will exacerbate problems of obtaining granular resources for infrastructure construction and maintenance? If so, how?

15. In the face of climate change, do you see granular resources management as an important issue for the Inuvialuit Settlement Region? 


\begin{tabular}{|c|c|c|c|}
\hline $\begin{array}{l}\text { Stakeholder } \\
\text { Name }\end{array}$ & $\begin{array}{l}\text { Role Within the Granular } \\
\text { Resources Industry }\end{array}$ & $\begin{array}{l}\text { Concerns About Granular Resource } \\
\text { Management }\end{array}$ & $\begin{array}{l}\text { Concerns About Granular Resources } \\
\text { and Climate Change }\end{array}$ \\
\hline Eddie Dillon & $\begin{array}{l}\text { Director of Tuktoyaktuk } \\
\text { Community Corporation, } \\
\text { Former Mayor of the } \\
\text { Incorporated Hamlet of } \\
\text { Tuktoyaktuk }\end{array}$ & $\begin{array}{l}\text { *The IFA requires granular inventories and } \\
\text { demand forecasts to be carried out at certain } \\
\text { intervals, and this has not been done yet. } \\
\text { *Because inventories and forecasts are } \\
\text { incomplete, how do we know whether the } \\
\text { amount of gravel that is being used for the } \\
\text { Mackenzie Gas Project isn't taking away from } \\
\text { community demands? } \\
\text { *In writing, the inuvialuit Final Agreement } \\
\text { pays close attention to granular resources, } \\
\text { because it was realized that gravel was going } \\
\text { to become an important and scarce resources, } \\
\text { and yet, } 24 \text { years later the requirements of } \\
\text { the IFA are not being met. } \\
\text { *Completing up-to-date supply inventories } \\
\text { and demand forecasts should be a priority for } \\
\text { the inuvialuit Land Administration and Federal } \\
\text { Government, in the face of the Mackenzie Gas } \\
\text { Project } \\
\text { *Community members are uninformed about } \\
\text { the status of supply inventories and demand } \\
\text { forecasts that have been contracted by the } \\
\text { ILA or INAC, and do not know if they have } \\
\text { been completed or what the results are. }\end{array}$ & $\begin{array}{l}\text { *Climate change may put increased } \\
\text { demand on granular resources. }\end{array}$ \\
\hline Neil Macleod & $\begin{array}{l}\text { Engineer, EBA Engineering } \\
\text { Consultants, Ltd. }\end{array}$ & & $\begin{array}{l}\text { *The most obvious adverse impact } \\
\text { would be on requirements for access } \\
\text { roads and hauling from remove } \\
\text { granular resource sources. More fill } \\
\text { would be needed for gravel access } \\
\text { roads, and the winter road season } \\
\text { would be greatly reduced. } \\
\text { *Climate change will not have much } \\
\text { impact on the access to commuity pits } \\
\text { which can be accessed by all-weather } \\
\text { roads. } \\
\text { *Within the pit, warmer ground } \\
\text { temperatures and a deeper active } \\
\text { layer would make it easier and } \\
\text { somewhat less costly to operate. }\end{array}$ \\
\hline $\begin{array}{l}\text { Mardy } \\
\text { Semmler }\end{array}$ & $\begin{array}{l}\text { Lands Manager, Gwich'in } \\
\text { Tribal Coucil }\end{array}$ & $\begin{array}{l}\text { *No conclusive pit management plans are in } \\
\text { place, the federal government is allowing } \\
\text { users to open up sources and highgrade all } \\
\text { the quality material that is easy to access and } \\
\text { then allowing them to open up bigger } \\
\text { footprints of areas without utilizing the whole } \\
\text { source. }\end{array}$ & $\begin{array}{l}\text { *Climate change may cause ice lenses } \\
\text { in the sources to melt and if not } \\
\text { removed once the pit is open, may } \\
\text { cause the material to become muddy. } \\
\text { sticky and unusable. Therefore, } \\
\text { remediation must be monitored and } \\
\text { enforced when the user is done }\end{array}$ \\
\hline
\end{tabular}


* Quarry permits do not specify which area within the pit the user must extract gravel from, and therefore, a user will take gravel from only the top layer of the entire pit, making a large footprint. If an ice lense is encountered, the user will move to another area where it is easier to extract from.

* Often, users don't cover the ice back up and during the summer it melts, causing the material to become wet and unusable, and this is not monitored by the government. extracting.

* Communities such as Aklavik, that have only seasonal access to granular resources may not be prepared for climate change induced infrastructure failure. If there is no stockpile within the community, it may be very costly or impossible to obtain gravel until the following winter to repair the infrastructure.

* Climate change combined with untimely budgeting for community granular resource acqisition may make the hauling season very short, putting additional pressures on haulers to meet community demands in a short period of time. It is possible that some demands may go unmet.

* The government may need to change the timing of budgeting and contracting in order to obtain granular resources for community projects during shorter winter hauling seasons.

*If winter season is shorter, freeze up occurs later in the fall and earlier in the spring, making the hauling season shorter. in bad conditoin, but has heard that there is no good source of gravel nearby to repair it.

* Is concerned about whether there is enough gravel to construct the Inuvik Tuktoyaktuk Highway if it is approved.
* Climate change will put greater pressure on haulers to transport resources faster, likely causing a logistics crunch.

* Knows of a tanker that was stuck outside of Yellowknife because the winter road thawed sooner than expected.

* Has noticed that it rains more in the summers, and when it rains gravel cannot be extracted, and slows down the construction process.

* Has noticed the need for more gravel pads due to increased temperatures 


\begin{tabular}{|c|c|c|c|}
\hline & & & $\begin{array}{l}\text { * Has noticed that roads are being } \\
\text { impacted more by warmer } \\
\text { temperatures, sinking due to } \\
\text { permafrost melt and poor road } \\
\text { maintenance. Roads sink into the } \\
\text { tundra faster than they used to. }\end{array}$ \\
\hline Todd Romaine & $\begin{array}{l}\text { Chief Land Administrator, } \\
\text { Inuvialuit Land } \\
\text { Administration }\end{array}$ & $\begin{array}{l}\text { *Gravel is the most important issue of the } \\
\text { Inuvialuit Land Administration. Gravel is one } \\
\text { of the most problematic land resources to } \\
\text { manage, and no one seems to have a solid } \\
\text { handle on their management in the ISR. } \\
\text { *As part of a granular resource management } \\
\text { plan, the process of setup, monitoring, and } \\
\text { cleanup of a pit needs to be outlined and } \\
\text { followed by land administrators from } \\
\text { beginning to end. } \\
\text { *With the impending inuvik Tuktoyaktuk } \\
\text { Highway and the Mackenzie Gas Project, a } \\
\text { management plan needs to be developed as } \\
\text { soon as possible } \\
\text { *More appropriate land management from all } \\
\text { levels of government needs to occur, } \\
\text { monitoring how much gravel is taken and that } \\
\text { the terms of quarry licenses and land use } \\
\text { permits are met. } \\
\text { *Frequent staff turnover causes issues to be } \\
\text { put on the "back burner," including the } \\
\text { completion of a current demand forecast. }\end{array}$ & 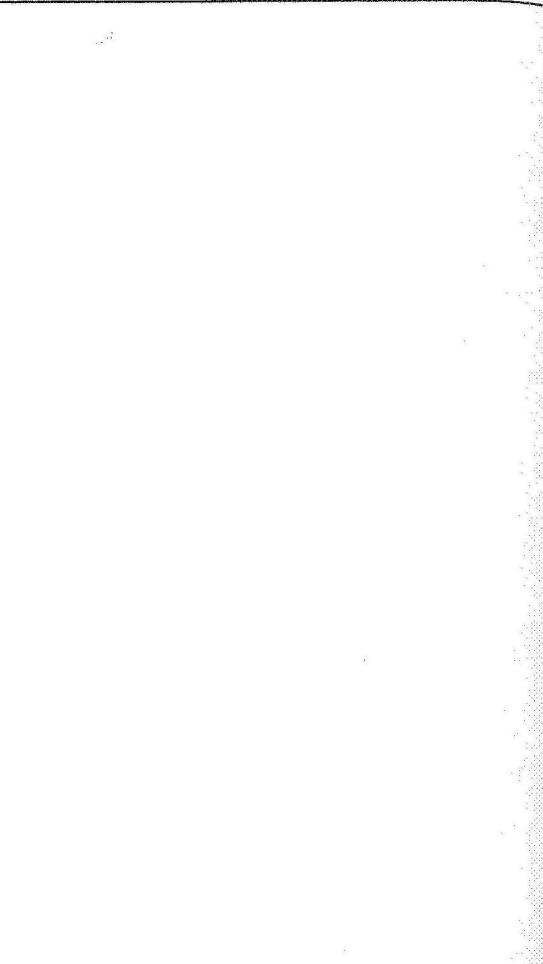 \\
\hline Kyle Sherwin & $\begin{array}{l}\text { Program Manager, } \\
\text { Environmental Projects, } \\
\text { Inuvialuit Land } \\
\text { Administration }\end{array}$ & $\begin{array}{l}\text { *Demand forecasts have not been conducted } \\
\text { as frequently as required by the Inuvialuit } \\
\text { Final Agreement } \\
\text { *inuvialuit Land Administration needs to start } \\
\text { tracking community gravel use better, people } \\
\text { often go to quarries and take gravel without } \\
\text { being permitted to. There is little monitoring } \\
\text { of unauthorized use. }\end{array}$ & $\begin{array}{l}\text { *Ice roads are used in the winter to } \\
\text { transport equipment to construction } \\
\text { sites/quarries, and gravel is also } \\
\text { hauled from the sites during the } \\
\text { winter. If temperatures increase, the } \\
\text { hauling season will get shorter. }\end{array}$ \\
\hline Susan Chaytor & $\begin{array}{l}\text { Consultant, Alpha } \\
\text { Corporation }\end{array}$ & $\begin{array}{l}\text { *Participation rate for demand surveys is low, } \\
\text { it is difficult to make contact with all gravel } \\
\text { users. }\end{array}$ & $\begin{array}{l}\text { *Climate change may have an impact } \\
\text { on the accessibility of granular } \\
\text { sources, and could cause increased } \\
\text { demand for granular resources. }\end{array}$ \\
\hline Fred Collins & $\begin{array}{l}\text { Projects and Geotechnical } \\
\text { Officer, GNWT Public } \\
\text { Works and Services }\end{array}$ & & $\begin{array}{l}\text { *Access to pits and quarries will be } \\
\text { impacted by climate change. }\end{array}$ \\
\hline
\end{tabular}




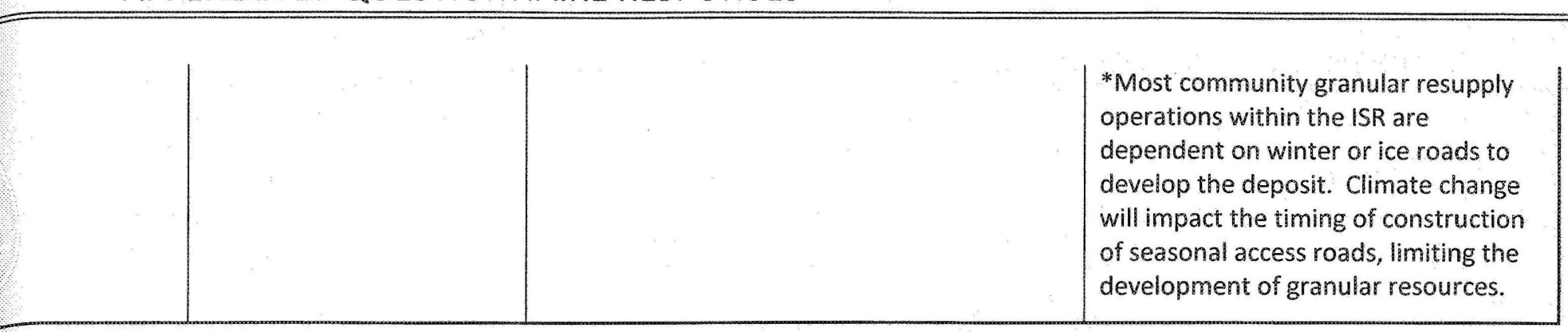




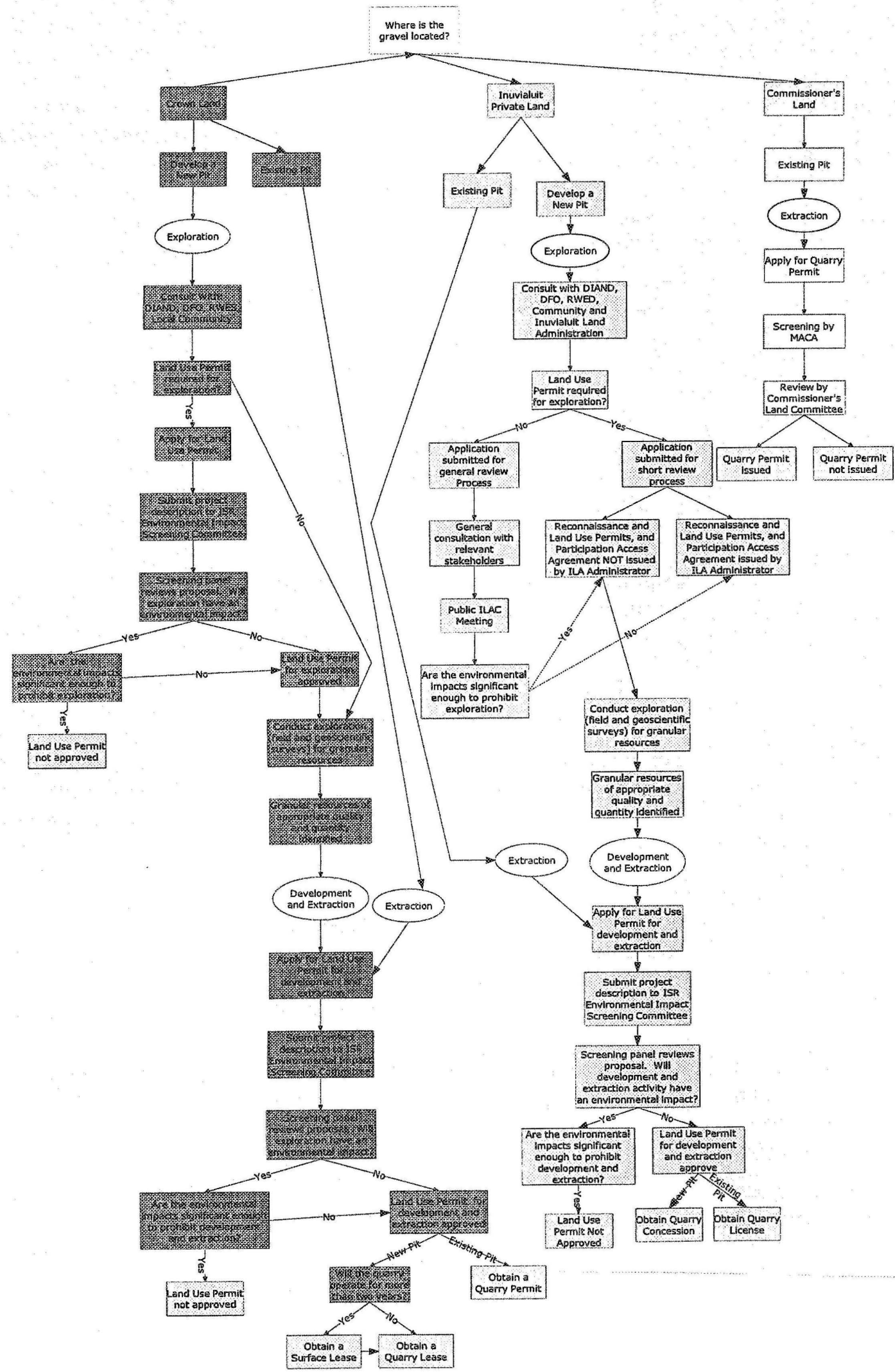

Derived from: Indian and Northern Affairs Canada. (21 February 2005)

A guide to mineral exploration and development in the NWT. [Online]

Available: http:// nwt-tno.inac-ainc.gc.ca/mpf/process/index_e.htm 


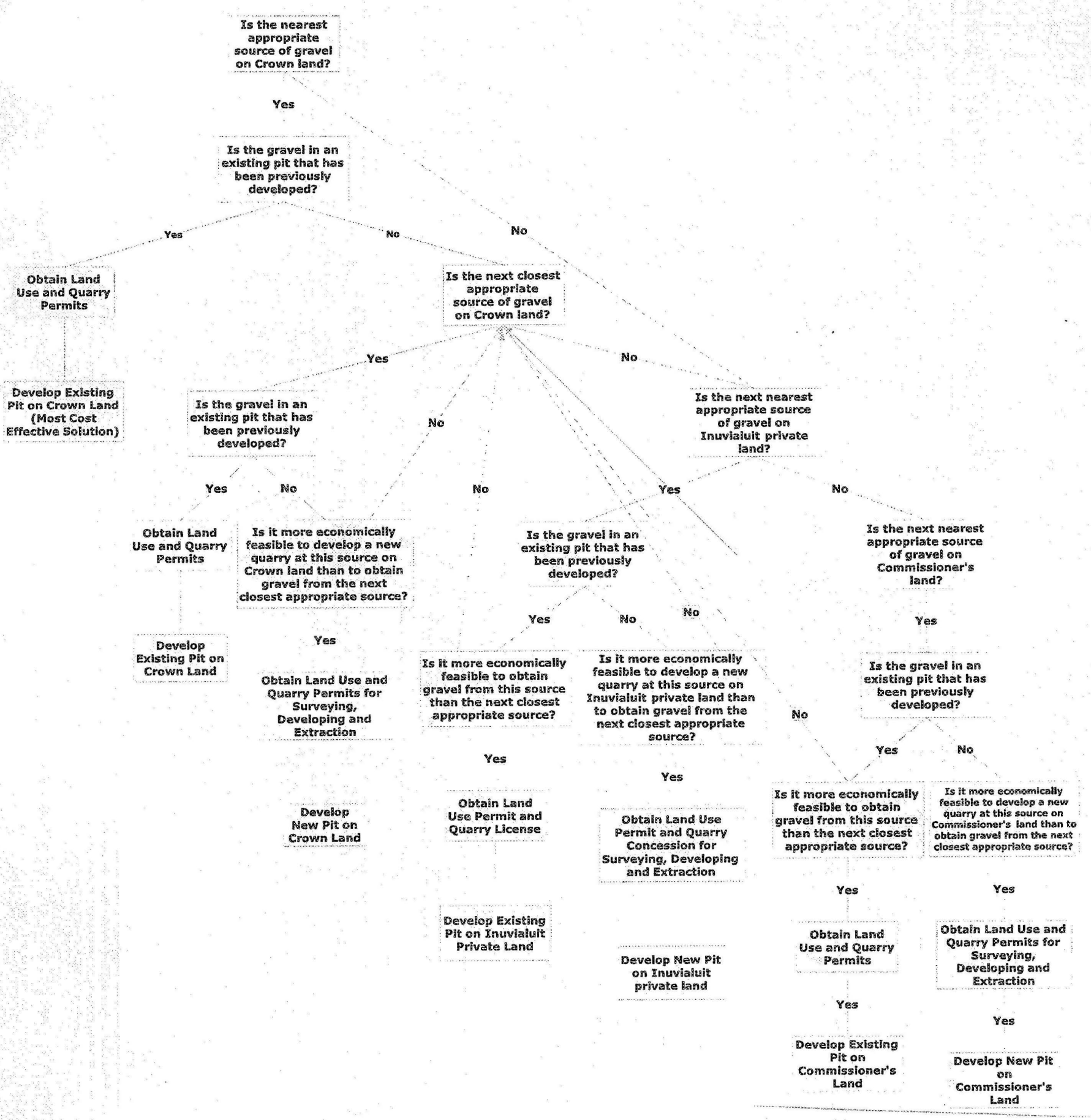




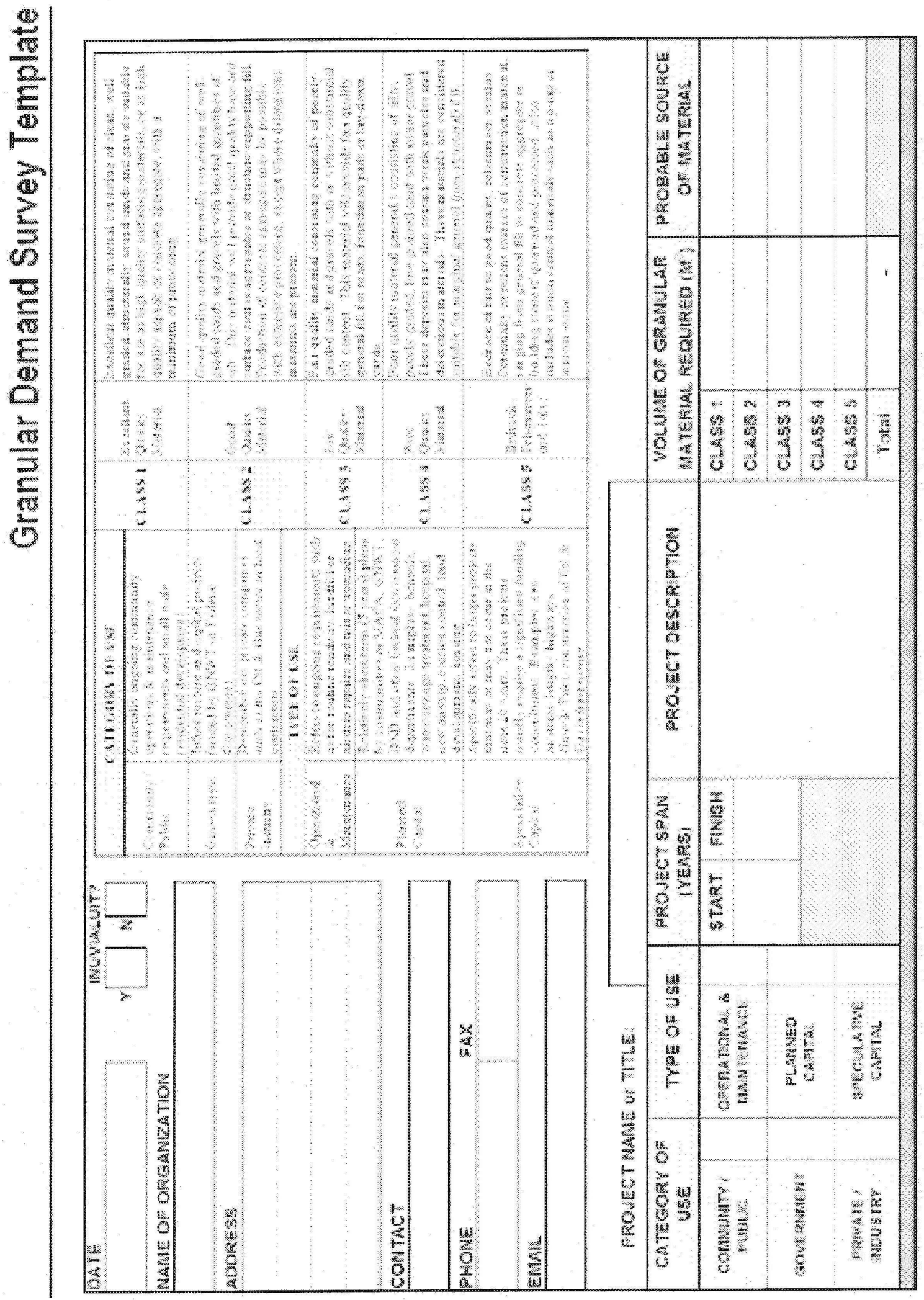

Figure 1- Gronular demand survey template for pending Inuviahuit Settlement Region demand survey. 
Table 1- Permits for quarrying activity within the Inuvialuit Settlement Region since the implementation of the Inuvialuit Final Agreement

\begin{tabular}{|c|c|c|c|c|c|c|c|}
\hline & Year & Owner & Permit Type & Community & Sponsor & Project & Category \\
\hline LA84SQ003 & 1984 & Private & Unknown & Sachs & AES & Building Pad & Public \\
\hline LA84SQ003 & 1984 & Private & Unknown & & Unknown & Unknown & Unknown \\
\hline LA85AQ016 & 1985 & Private & Unknown & Aklavik & GNWT-Aurora College & Unknown & Private \\
\hline LA851Q009 & 1985 & Private & Unknown & Tuk & Chevron & Oil Exploration & Private \\
\hline LA851Q009 & 1985 & Private & Unknown & Tuk & ESSO & Oll \& Gas Exploration & Private \\
\hline LA851Q009 & 1985 & Private & Unknown & Tuk & Dome Petroleum & Unknown & Private \\
\hline LA8510009 & 1985 & Private & Unknown & Tuk & Dome Petroleum & Unknown & Private \\
\hline$\angle A 851 Q 009$ & 1985 & Private & Unknown & Tuk & ESSO & Oil \& Gas Exploration & Private \\
\hline$\angle A 851 Q 010$ & 1985 & Private & Unknown & Inuvik & GNWT DOT & Unknown & Public \\
\hline LA851Q11 & 1985 & Private & Unknown & Tuk & Chevron & Oil \& Gas Exploration & Private \\
\hline LA85IQ84 & 1985 & Private & Unknown & Tuk & GNWT & Unknown & Public \\
\hline LA85SQ33 & 1985 & Private & Unknown & Sachs & AES & Pad for Fuel Tanks & Public \\
\hline LA85TQ015 & 1985 & Private & Unknown & Tuk & GNWT & Unknown & Public \\
\hline LA85TQ015 & 1985 & Private & Unknown & Tuk & E. Grubens Transport & Unknown & Private \\
\hline LA85TQ015 & 1985 & Private & Unknown & Tuk & Chevron & Oil \& Gas Exploration & Private \\
\hline LA85TQ015 & 1985 & Private & Unknown & Tuk & ESSO & Unknown & Private \\
\hline LA85TQ015 & 1985 & Private & Unknown & Tuk & E. Grubens Transport & Unknown & Private \\
\hline LA85TQ17 & 1985 & Private & Unknown & Tuk & Storrs \& Sons & Unknown & Private \\
\hline LA85TQ25 & 1985 & Private & Unknown & Tuk & GNWT & Road & Public \\
\hline LATQ26 & 1985 & Private & Unknown & Tuk & E. Grubens Transport & Road/Pad & Private \\
\hline LA85TQ98 & 1985 & Private & Unknown & Tuk & ESSO & Tuk Base & Private \\
\hline LA85TQ98 & 1985 & Private & Unknown & Tuk & ESSO & Surnmer Wells & Private \\
\hline LA86AQ103 & 1986 & Private & Unknown & Aklavik & Ministry of Transport & Slope Protection & Public \\
\hline LA861Q107 & 1986 & Private & Unknown & Tuk & Chevron & Oil \& Gas Exploration & Private \\
\hline ILA86IQ107 & 1986 & Private & Unknown & Tuk & Shell & Oil \& Gas Exploration & Private \\
\hline LA861Q107 & 1986 & Private & Unknown & Tuk & North Star & Stockpile & Private \\
\hline LA86PQ136 & 1986 & Private & Unknown & Paulatuk & Settlement Council & Road to New Water Lake & Public \\
\hline LA86TQ108 & 1986 & Private & Unknown & Tuk & ESSO & Hansen Exploration Well & Private \\
\hline LA86TQ109 & 1986 & Private & Unknown & Inuvik & ESSO & Exploration Well & Private \\
\hline LA86TQ111 & 1986 & Private & Unknown & Tuk & $\begin{array}{l}\text { Dept. of National } \\
\text { Defense }\end{array}$ & Bar-4 Airfield & Defense \\
\hline LA86TQ113 & 1986 & Private & Unknown & Tuk & $\begin{array}{l}\text { Dept. of National } \\
\text { Defense }\end{array}$ & Unknown & Defense \\
\hline LA86TQ114 & 1986 & Private & Unknown & Tuk & Storrs \& Sons & Unknown & Private \\
\hline LA86TQ156 & 1986 & Private & Unknown & Tuk & GNWT & Tuk Shoreline \& Reservoir & Public \\
\hline LA86TQ156 & 1986 & Private & Unknown & Tuk & E. Grubens Transport & Unknown & Private \\
\hline LA87SQ195 & 1986 & Private & Unknown & Sachs & MACA & Gravel Pad & Public \\
\hline LA881Q196 & 1988 & Private & Unknown & Tuk & North Star & Unknown & Private \\
\hline LA881Q199 & 1988 & Private & Unknown & Inuvik & GNWT & $\begin{array}{l}\text { Gravel Pad \& Road } \\
\text { Upgrade }\end{array}$ & Public \\
\hline A881Q199 & 1988 & Private & Unknown & Inuvik & E. Grubens Transport & Stockpile \& House Pads & Private \\
\hline$\angle A 881 Q 200$ & 1988 & Private & Unknown & Tuk & Beaudril & Tuk Base & Private \\
\hline$\angle A 881 Q 200$ & 1988 & Private & Unknown & Tuk & E. Grubens Transport & Stockpile & Private \\
\hline A88SQ212 & 1989 & Private & Unknown & Sachs & MACA & Sewage Facilities & Public \\
\hline A891Q288 & 1989 & Private & Unknown & Inuvik & E. Grubens Transport & Oil \& Gas Homeowners & Private \\
\hline A89PQ256 & 1989 & Private & Unknown & Paulatuk & Dept. of National & SRR Sites & Defense \\
\hline
\end{tabular}


Defense

\begin{tabular}{|c|c|c|c|c|c|c|c|}
\hline ILA89PQ286 & 1989 & Private & Unknown & Paulatuk & MACA & Unknown & Public \\
\hline ILA89TQ258 & 1989 & Private & Unknown & Tuk & $\begin{array}{l}\text { Dept. of National } \\
\text { Defense }\end{array}$ & Unknown & Defense \\
\hline ILA89TQ260 & 1989 & Private & Unknown & Tuk & $\begin{array}{l}\text { Dept. of National } \\
\text { Defense }\end{array}$ & Unknown & Defense \\
\hline LLA89TQ290 & 1989 & Private & Unknown & Tuk & $\begin{array}{l}\text { Dept. of National } \\
\text { Defense }\end{array}$ & SRR Sites & Defense \\
\hline ILA89TQ292 & 1989 & Private & Unknown & Tuk & $\begin{array}{l}\text { Dept. of National } \\
\text { Defense }\end{array}$ & SRR Sites & Defense \\
\hline ILA89TQ294 & 1989 & Private & Unknown & Tuk & E. Grubens Transport & Gravel Pads & Private \\
\hline ILA90|Q41 & 1990 & Private & Unknown & Inuvik & Hamlet of Tuk & Road \& Playground & Public \\
\hline ILA90IQ41 & 1990 & Private & Unknown & Inuvik & E. Grubens Transport & Building Pads & Private \\
\hline ILA90PQ25 & 1990 & Private & Unknown & Paulatuk & South Wind & Two Gravel Pads & Private \\
\hline ILA9OPQ26 & 1990 & Private & Unknown & Paulatuk & MACA & Water Supply & Public \\
\hline ILA93PX33 & 1990 & Private & Unknown & Paulatuk & MACA & Road Extension & Public \\
\hline ILA91PQ26 & 1991 & Private & Unknown & Paulatuk & $\begin{array}{l}\text { Dept. of National } \\
\text { Defense }\end{array}$ & Unknown & Defense \\
\hline ILA91PQ42 & 1991 & Private & Unknown & Paulatuk & GNWT & Airport Construction & Public \\
\hline ILA91SQ27 & 1991 & Private & Unknown & Sachs & MACA & Solid Waste Disposal Site & Public \\
\hline ILA91TO25 & 1991 & Private & Unknown & Tuk & $\begin{array}{l}\text { Dept. of National } \\
\text { Defense }\end{array}$ & Beach Tanks & Defense \\
\hline ILA91TQ28 & 1991 & Private & Unknown & Tuk & $\begin{array}{l}\text { Dept. of National } \\
\text { Defense }\end{array}$ & Beach Tanks & Defense \\
\hline ILA91TQ43 & 1991 & Private & Unknown & Tuk & $\begin{array}{l}\text { Dept. of National } \\
\text { Defense }\end{array}$ & Unknown & Defense \\
\hline ILA90PQ27 & 1992 & Private & Unknown & Paulatuk & GNWT & Runway Construction & Public \\
\hline ILA921Q10 & 1992 & Private & Unknown & Inuvik & E. Grubens Transport & Private & Private \\
\hline ILA92TQ2 & 1992 & Private & Unknown & Unknown & $\begin{array}{l}\text { Dept. of National } \\
\text { Defense }\end{array}$ & Unknown & Defense \\
\hline ILA93IQ5 & 1993 & Private & Unknown & Inuvik & E. Grubens Transport & Unknown & Private \\
\hline ILA93SQ51 & 1993 & Private & Unknown & Sachs & Hamlet of Tuk & Upgrade Road to Dump & Public \\
\hline ILA941006 & 1994 & Private & Unknown & Inuvik & E. Grubens Transport & & Private \\
\hline ILA951Q14 & 1995 & Private & Unknown & Inuvik & Unknown & Unknown & Public \\
\hline ILA95PQ27 & 1995 & Private & Unknown & Unknown & Unknown & Unknown & Public \\
\hline ILA95PQ42 & 1995 & Private & Unknown & Unknown & Unknown & Unknown & Public \\
\hline ILA96IQ07 & 1996 & Private & Unknown & Inuvik & Unknown & Unknown & Unknown \\
\hline ILA96SQ41 & 1996 & Private & Unknown & Sachs & Unknown & Unknown & Public \\
\hline ILA97HQ51 & 1997 & Private & Unknown & Holman & Unknown & Unknown & Public \\
\hline ILA97HQ51 & 1997 & Private & Unknown & Holman & Unknown & Unknown & Public \\
\hline ILA97PT07 & 1997 & Private & Unknown & Unknown & Unknown & Unknown & Public \\
\hline ILA97SQ23 & 1997 & Private & Unknown & Sachs & Unknown & Unknown & Unknown \\
\hline ILA97SQ40 & 1997 & Private & Unknown & Sachs & Unknown & Unknown & Unknown \\
\hline ILA97SQ45 & 1997 & Private & Unknown & Sachs & Unknown & Unknown & Unknown \\
\hline ILA981Q42 & 1998 & Private & Unknown & Inuvik & Unknown & Unknown & Private \\
\hline ILA981Q42 & 1998 & Private & Unknown & Inuvik & Unknown & Unknown & Private \\
\hline ILA981Q42 & 1998 & Private & Unknown & Inuvik & Unknown & Unknown & Private \\
\hline ILA981Q42 & 1998 & Private & Unknown & Inuvik & Unknown & Unknown & Private \\
\hline ILA98TQ06 & 1998 & Private & Unknown & Tuk & Unknown & Unknown & Public \\
\hline ILA98TTO2 & 1998 & Private & Unknown & Tuk & Unknown & Unknown & Defense. \\
\hline ILA99PQ33 & 1999 & Private & Unknown & Unknown & Unknown & Unknown & Unknown \\
\hline ILA99PQ39 & 1999 & Private & Unknown & Paulatuk & Unknown & Unknown & Public \\
\hline ILA99SQ46 & 1999 & Private & Unknown & Unknown & Unknown & Unknown & Public \\
\hline ILA99SQ46 & 1999 & Private & Unknown & Unknown & Unknown & Unknown & Public \\
\hline
\end{tabular}


APPENDIX D: DEMAND

\begin{tabular}{|c|c|c|c|c|c|c|c|}
\hline LA99SQ46 & 1999 & Private & Unknown & Unknown & Unknown & Unknown & Public \\
\hline 6199900002 & 1999 & Crown & Land Use Permit & Unknown & Unknown & Unknown & Unknown \\
\hline $61999 Q 0020$ & 1999 & Crown & Land Use Permit & Unknown & Unknown & Unknown & Unknown \\
\hline 6199900021 & 1999 & Crown & Land Use Permit & Unknown & Unknown & Unknown & Unknown \\
\hline LAOOPQ25 & 2000 & Private & Unknon & Paulatuk & Unknown & Unknown & Unknown \\
\hline LAOOTQO2 & 2000 & Private & Quarry License & Tuk & E. Grubens Transport & Unknown & Public \\
\hline$\angle A 011 Q 07$ & 2001 & Private & $\begin{array}{l}\text { Quarry } \\
\text { Concession }\end{array}$ & Tuk & Petro Canada & Unknown & Private \\
\hline LA011Q08 & 2001 & Private & Quarry License & Tuk & Unknown & Unknown & Public \\
\hline$\angle L A 011009$ & 2001 & Private & Quarry License & Tuk & Unknown & Unknown & Unknown \\
\hline LA01IQ24 & 2001 & Private & Quarry License & Inuvik & Petro Canada & Unknown & Private \\
\hline G2001Q0006 & 2001 & Crown & Land Use Permit & Unknown & Unknown & Unknown & Unknown \\
\hline ILAO2IQ24 & 2002 & Private & Quarry License & Inuvik & Petro Canada & Unknown & Private \\
\hline LLA02TX29 & 2002 & Private & Quarry License & Unknown & Inuvik Projects Inc. & Unknown & Unknown \\
\hline $62002 Q 0006$ & 2002 & Crown & Land Use Permit & Unknown & Unknown & Unknown & Unknown \\
\hline LA031Q007 & 2003 & Private & Quarry License & Tuk & Hamlet of Tuk & Unknown & Public \\
\hline$\angle A 031 Q 008$ & 2003 & Private & Quarry License & Tuk & Hamlet of Tuk & Unknown & Publc \\
\hline G2007E0006 & 2007 & Crown & Land Use Permit & Unknown & Unknown & Unknown & Unknown \\
\hline
\end{tabular}

Source:

ILA Licenses 1984-1999: MCDougall, James C. (June 2001) A granular resource demand forecast for the Inuvialuit Settlement Region.

ILA Licenses 2000-2003: Obtained from the Inuvialuit Land Administration through Todd Romaine.

Crown Land Use Permits: Obtained through a query using Indian and Northern Affairs Canada's SID (Spatial Information for DIAND) Viewer Online, of Land Use Permits issued for quarrying activity within the Inuvialuit Settlement Region. 
Aklavik Borrow Sources

\begin{tabular}{|c|c|c|c|c|c|c|c|c|}
\hline Source 10 & Ownership & $\begin{array}{l}\text { Recoverable } \\
\text { Volume }\left(\mathrm{m}^{3}\right)\end{array}$ & Winter Access & Summer Access & Constraints to Development & Ground lce & $\begin{array}{c}\text { Primary } \\
\text { Gravel Class }\end{array}$ & $\begin{array}{c}\text { Impacted By } \\
\text { Climate Change? }\end{array}$ \\
\hline \multicolumn{9}{|c|}{ Distance Between 15 and $20 \mathrm{~km}$} \\
\hline \multicolumn{2}{|c|}{469 Crown } & \multicolumn{2}{|c|}{$5,000,000$ Tundra/Ice Road } & None & Wildlife, Access, Poor Quality & Unknown & 5 & YES \\
\hline \multicolumn{2}{|c|}{ *468 Crown } & \multicolumn{2}{|c|}{$10,000,000$ Tundra/lce Road } & None & Accessibility & Unknown & 5 & YES \\
\hline \multicolumn{4}{|c|}{$15,000,000$} & & & & & \\
\hline \multicolumn{4}{|c|}{ Distance Between 20.1 and $30 \mathrm{~km}$} & + & & & & \\
\hline \multicolumn{2}{|c|}{$* 455$ Crown } & \multicolumn{2}{|c|}{500,000 Tundra/lce Road } & None & None & None & 3 & YES \\
\hline \multicolumn{2}{|c|}{ *456A Crown } & \multicolumn{2}{|c|}{ o Tundra/Ice Road } & Barge & Wildlife, Poor Quality, River Environment & None & $n / a$ & NO \\
\hline *457A & Crown & \multicolumn{2}{|c|}{ o Tundra/lce Road } & Barge & Wildlife, Poor Quality & \multicolumn{2}{|c|}{ Lenses, Inclu n/a } & YES \\
\hline 467 & Crown & $3,000,000$ & Tundra/lce Road & None & None & Unknown & 3 & YES \\
\hline & Total $=$ & $3,500,000$ & & & & & & \\
\hline \multicolumn{9}{|c|}{ Distance $>50 \mathrm{~km}$} \\
\hline \multicolumn{2}{|c|}{ *463 Private } & \multicolumn{2}{|c|}{$3,000,000$ Tundra/lce Road } & None & Low Quality & Unknown & 5 & YES \\
\hline \multicolumn{2}{|c|}{469 Crown } & \multicolumn{2}{|c|}{ 5,000,000 Tundra/lce Road } & None & Wildlife, Accessibility, Poor Quality & Unknown & 5 & YES \\
\hline & Total $=$ & $8,000,000$ & $\sin _{2}$ & & 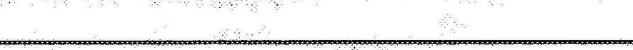 & 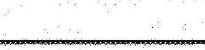 & & \\
\hline \multicolumn{9}{|c|}{ Denotes Sources That Have No Constraints to Development } \\
\hline
\end{tabular}




\begin{tabular}{|c|c|c|c|c|c|c|c|c|}
\hline Source 10 & Ownership & \begin{tabular}{|l|} 
Recoverable \\
Volume $(\mathrm{m} 3)$
\end{tabular} & Winter Access & $\begin{array}{l}\text { Summer } \\
\text { Access }\end{array}$ & Constraints to Development & Ground Ice & $\begin{array}{c}\text { Primary } \\
\text { Gravel } \\
\text { Class }\end{array}$ & $\begin{array}{c}\text { Impacted } \\
\text { By Climate } \\
\text { Change? }\end{array}$ \\
\hline \multicolumn{9}{|c|}{ Distance $<10 \mathrm{~km}$} \\
\hline \multicolumn{2}{|c|}{ 1401A Crown } & \multicolumn{2}{|c|}{$1,020,000$ Tundra/Ice Road } & None & Wildlife, Poor Quality & Massive, Excess & 3 & YES \\
\hline \multicolumn{2}{|c|}{ *1400 Private } & \multicolumn{2}{|c|}{ O Road } & Road. & Edge of Town, Nearly Depleted & Massive, Lenses & $n / a$ & YES \\
\hline \multicolumn{2}{|c|}{ *1402 Crown } & \multicolumn{2}{|c|}{$4,600,000$ Road } & Road & Transport Canada Pit & Unknown & 5 & NO \\
\hline \multicolumn{4}{|c|}{$\begin{array}{cc}\text { Total }=\quad 5,620,000 \\
\end{array}$} & & & & & \\
\hline \multicolumn{9}{|c|}{ Distance Between $15.1 \mathrm{~km}$ and $20 \mathrm{~km}$} \\
\hline \multicolumn{2}{|c|}{2.46 Crown } & \multicolumn{2}{|c|}{ O Tundra/lce Road } & None & None & Unknown & $n / a$ & YES \\
\hline \multicolumn{2}{|c|}{ *1403 Crown } & \multicolumn{2}{|c|}{$2,000,000$ Road } & Road & None & Unknown & 5 & NO \\
\hline \multicolumn{2}{|c|}{ *1404 Crown } & \multicolumn{2}{|c|}{500,000 Road } & Road & None & Unknown & 5 & NO \\
\hline \multicolumn{2}{|c|}{ *R29\&29 Crown } & \multicolumn{2}{|c|}{$20,000,000$ Tundra/lce Road } & Barge & None & Unknown & 5 & NO \\
\hline \multicolumn{4}{|c|}{ Total $=22,500,000$} & & & & & \\
\hline \multicolumn{9}{|c|}{ Distance Between 20.1 and $30 \mathrm{~km}$} \\
\hline \multicolumn{2}{|c|}{2.45 Crown } & \multicolumn{2}{|c|}{ O Tundra/lice Road } & None & Lake Environment & Unknown & $n / a$ & YES \\
\hline \multicolumn{2}{|c|}{ *DPW Pit Crown } & \multicolumn{2}{|c|}{$3,500,000$ Road } & Road & Current Quarry & Unknown & 5 & NO \\
\hline \multicolumn{2}{|c|}{ *1405A Crown } & \multicolumn{2}{|c|}{$13,000,000$ Tundra/Ice Road } & None & Wildlife, Poor Quality & Crystals & 4 & YES \\
\hline \multicolumn{2}{|c|}{ *1406 Crown } & \multicolumn{2}{|c|}{ 30,000 Tundra/Ice Road } & None & Wildife, Stream Environment & None & 3 & YES \\
\hline \multicolumn{4}{|c|}{$\begin{aligned} & \text { Total }= 16,530,000 \\
&\end{aligned}$} & & & & & \\
\hline \multicolumn{9}{|c|}{ Distance Between 30.1 and $40 \mathrm{~km}$} \\
\hline 2.43 & Private & $180,000,000$ & Tundra/lce Road & None & None & Unknown & 4 & YES \\
\hline 2.44 & Crown & $3,500,000$ & Tundra/lce Road & None & Unknown & Unknown & $n / a$ & YES \\
\hline & Total $=$ & $183,500,000$ & & & & & & \\
\hline Distance Betv & een 40.1 and & $50 \mathrm{~km}$ & & & & & & \\
\hline $323 A$ & Private & $46,010,000$ & Tundra/lce Road & None & International Biological Program Area & Excess & 2 & YES \\
\hline $324 A$ & Private & $47,180,000$ & Tundra/lce Road & None & International Biological Program Area & Unknown & 2 & YES \\
\hline & Total $=$ & $93,190,000$ & & & & & 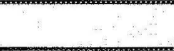 & \\
\hline Distance Betv & een 50.1 and & $60 \mathrm{~km}$ & & & & & & \\
\hline 316 & Private & 765,000 & Tundra/lce Road & None & Lake Environment & Excess, Massive & 3 & YES \\
\hline 317 & Private & $1,150,000$ & Tundra/lce Road & None & Environmentally Sensitive, Ice & Excess, Massive & 3 & YES \\
\hline 328 & Private & $53,000,000$ & Tundra/Ice Road & Barge & Wildlife, River Environment & Excess, Massive & 3 & YES \\
\hline 1407 & Private & 0 & Tundra/lce Road & Barge & Critical Wildlife, River Environment & Excess & $n / a$ & VES \\
\hline
\end{tabular}




Total $=64,765,000$

Distance Between 60.1 and $70 \mathrm{~km}$

\begin{tabular}{lrll}
315 Crown & $4,600,000$ Tundra/lce Road & None & Wildlife, Stream Environment \\
318 Crown & $1,500,000$ Tundra/lce Road & None & Environmentally Sensitive, Poor Quality \\
319 Crown & $1,150,000$ Tundra/lce Road & None & Wildlife, Ice, Poor Accessibility \\
320 Crown & $1,115,000$ Tundra/lce Road & None & Wildlife, Ice, Silt \\
321 Crown & 765,000 Tundra/lce Road & None & Poor Accessibility \\
\hline
\end{tabular}

Total $=9,130,000$

$\frac{\text { Distance Between } 70.1 \text { and } 80 \mathrm{~km}}{301 \text { Private }}$

*300A Private

3,000,000 Tundra/lce Road

600,000 Tundra/lce Road

Barge

Fish and Wildlife Habitat

Excess, Massive

Excess, Massive

Excess, Massive

Excess, Massive

Unknown

Barge

Poor Quality, Environmentally Sensitive

Excess, Massive

Excess

4 YES Total= $\quad 3,600,000$

Distance Between 80.1 and $90 \mathrm{~km}$

\begin{tabular}{|c|c|c|c|c|c|c|}
\hline 204. Private & 300,000 Tundra/lce Road & Barge & River Environment, Massive Ice & Massive & 2 & YES \\
\hline 302 Private & $1,140,000$ Tundra/lce Road & Barge & Fish and Wildlife Habitat & Massive, Excess & 2 & YES \\
\hline 303 Private & $21,500,000$ Tundra/lce Road & Barge & River Environment, Wildlife & Massive, Excess & 3 & YES \\
\hline
\end{tabular}
Total $=22,940,000$

Distance Between 90.1 and $100 \mathrm{~km}$

\begin{tabular}{|c|c|c|c|c|c|c|}
\hline \multicolumn{7}{|c|}{ Distance Between 90.1 and $100 \mathrm{~km}$} \\
\hline 222 Private & $7,500,000$ Tundra/lce Road & Barge & Overburden, Ice & Massive, Excess & 3 & YES \\
\hline Total $=$ & $7,500,000$ & & & & 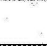 & \\
\hline \multicolumn{7}{|l|}{ Distance Over $100 \mathrm{~km}$} \\
\hline 214 Private & $6,250,000$ Tundra/lce Road & Barge & Waterfowl, River Environment & Massive & 3 & YES \\
\hline 215 Private & 65,000 Tundra/lce Road & Barge & Waterfowl, River Environment & Ice Rich Gravel & 3 & YES \\
\hline Ya Ya Lakes Private & $12,900,000$ Tundra/lce Road & None & Currently Developed, Massive Ice & Massive & 2 & YES \\
\hline
\end{tabular}

Denotes Sources That Have No Constraints to Development

* Denotes sources that were unable to be mapped 


\begin{tabular}{|c|c|c|c|c|c|c|c|c|}
\hline \multicolumn{9}{|c|}{ Paulatuk Borrow Sources } \\
\hline Source 10 & Ownership & $\begin{array}{l}\text { Recoverable } \\
\text { Volume }(\mathrm{m} 3)\end{array}$ & Winter Access & $\begin{array}{l}\text { Summer } \\
\text { Access }\end{array}$ & Constraints to Development & Ground lce & \begin{tabular}{|c|} 
Primary \\
Gravel Class
\end{tabular} & $\begin{array}{l}\text { Impacted By } \\
\text { Climate Change? }\end{array}$ \\
\hline \multicolumn{9}{|c|}{ Distance $<10 \mathrm{~km}$} \\
\hline $87-P-11$ & Private & $1,500,000$ & Tundra/lce Road & None & Low and wet & Unknown & 3 & YES \\
\hline $87-P-12$ & Private & $1,200,000$ & Tundra/lce Road & None & Poor Accessibility & Unknown & 2 & YES \\
\hline $87-p-21$ & Private & $1,000,000$ & Tundra/lce Road & None & Difficult Access & Unknown & 3 & YES \\
\hline 87. $P-22$ & Private & 250,000 & Tundra/lice Road & Possible & Coast Environment, Ice Rich & Unknown & 4 & YES \\
\hline \multicolumn{9}{|c|}{ Total $=3,950,000$} \\
\hline \multicolumn{9}{|c|}{ Distance Between 10.1 and $15 \mathrm{~km}$} \\
\hline $87-P-9$ & Crown & $5,000,000$ & Tundra/lce Road & None & Poor Access, Ice Rich & Unknown & 4 & YES \\
\hline $87-P-10$ & Private & 700,000 & Tundra/lce Road & None & Poor Access, Ice Rich & Unknown & 2 & YES \\
\hline $87-P-13$ & Private & $2,500,000$ & Tundra/lce Road & None & Relatively Thin & Unknown & 2 & YES \\
\hline $87-\mathrm{P}-20$ & Private & 700,000 & Tundra/lce Road & None & None & Unknown & 3 & YES \\
\hline \multicolumn{9}{|c|}{ Total $=8,900,000$} \\
\hline \multicolumn{9}{|c|}{ Distance Between 15.1 and $20 \mathrm{~km}$} \\
\hline $87-P-1$ & Private & $8,000,000$ & Tundra/lce Road & None & None & Unknown & 3 & YES \\
\hline $87 \cdot \mathrm{P}-2$ & Private & 700,000 & Tundra/lce Road & None & Poor Accessibility & Unknown & 3 & VES \\
\hline $87-P-4$ & Private & 500,000 & Tundra/Ice Road & None & Poor Quality, Ice Rich & Unknown & 2 & YES \\
\hline $87-P-6$ & Private & $1,200,000$ & Tundra/lce Road & None & Relatively Inaccessible & Unknown & 4 & YES \\
\hline $87-p-7$ & Private & $3,000,000$ & Tundra/Ice Road & None & Possibly Ice Rich & Unknown & 4 & YES \\
\hline $87-P-14$ & Private & $1,600,000$ & Tundra/Ice Road & None & None & Unknown & 3 & YES \\
\hline $87-P-15$ & Private & 300,000 & Tundra/lce Road & None & Very Thin & Unknown & 2 & VES \\
\hline $87-P-19$ & Private & $1,200,000$ & Tundra/lce Road & None & None & Unknown & 2 & YES \\
\hline \multicolumn{9}{|c|}{ Total $=16,500,000$} \\
\hline \multicolumn{9}{|c|}{ Distance $>20 \mathrm{~km}$} \\
\hline $88-P-3$ & Private & $1,300,000$ & Tundra/lce Road & None & None & Unknown & 2 & YES \\
\hline $87-P-16$ & Private & $1,500,000$ & Tundra/Ice Road & None & Thin, Ice Rich & Unknown & 2 & YES \\
\hline $87-P-17$ & Private & & Tundra/Ice Road & None & None & Unknown & 2 & YES \\
\hline \multicolumn{9}{|c|}{ Total $=2,800,000$} \\
\hline & 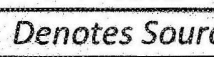 & cer That Hrion & & & & & & \\
\hline
\end{tabular}




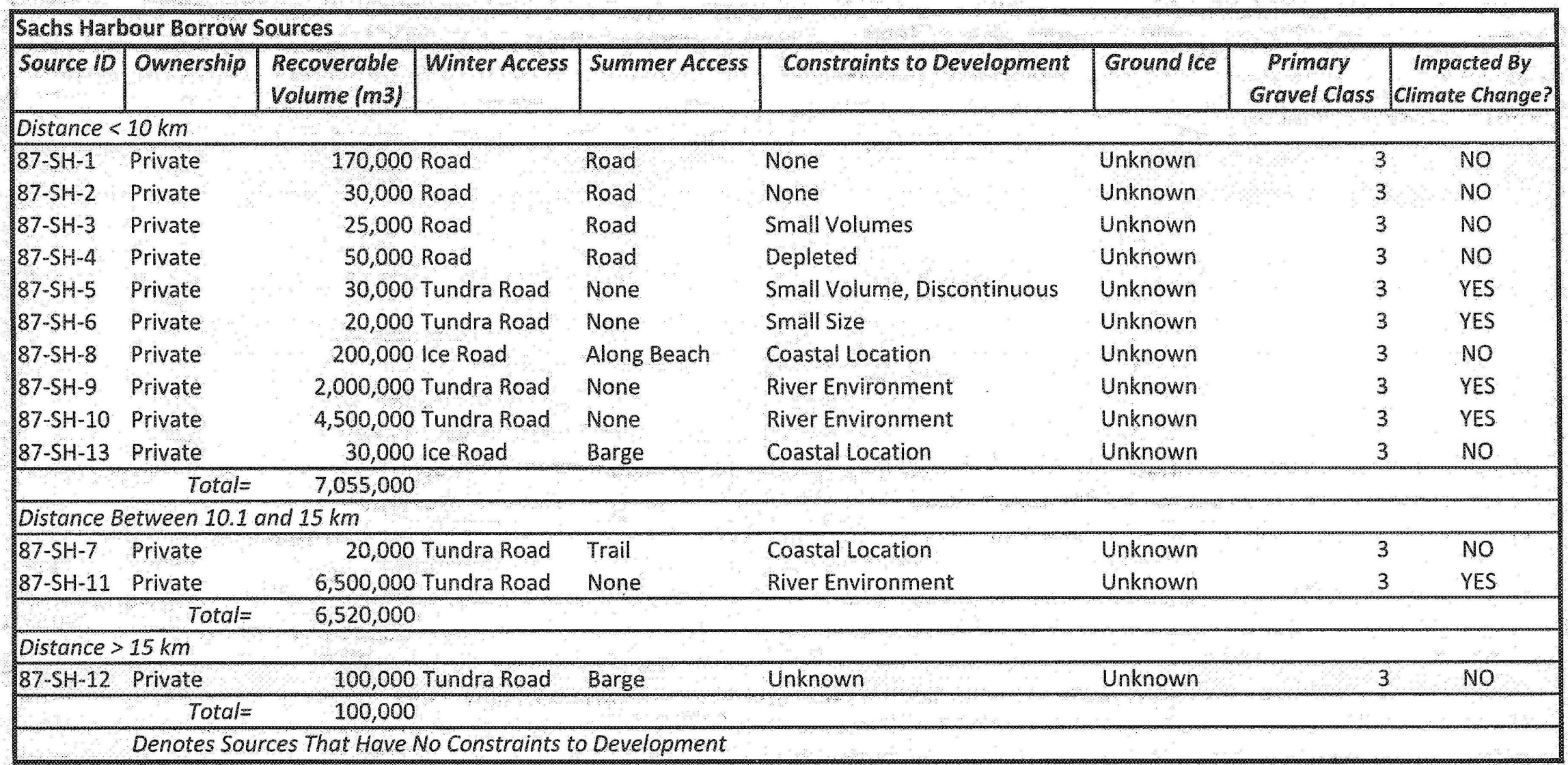


Tuktoyaktuk Borrow Sources

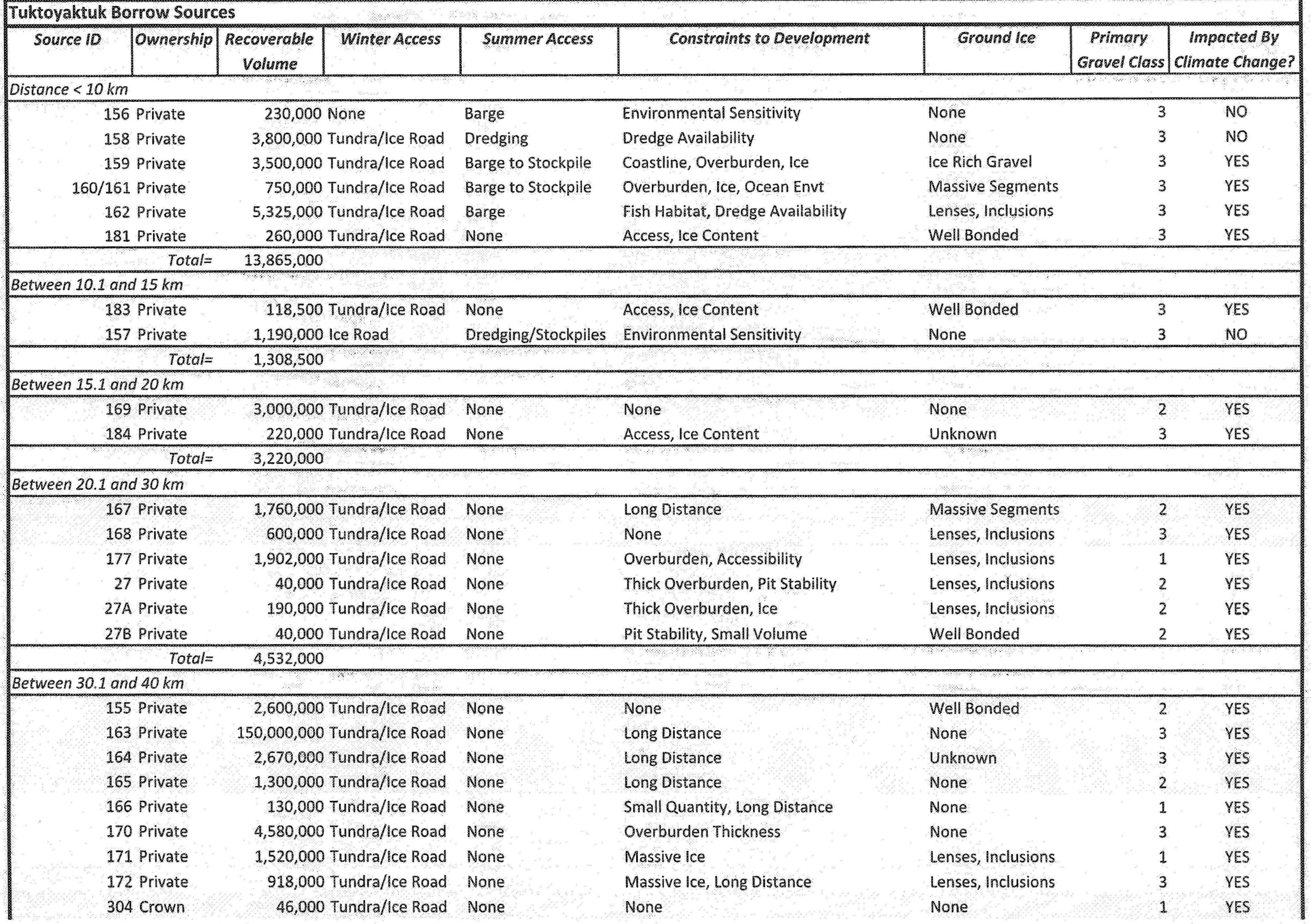




\begin{tabular}{|c|c|c|c|c|c|c|}
\hline Total $=$ & $163,764,000$ & & & & & \\
\hline \multicolumn{7}{|l|}{ Between 40.1 and $50 \mathrm{~km}$} \\
\hline 173 Private & 688,000 Tundra/lice Road & None & Massive Ice, Long Distance & Massive, Excess & 3 & YES \\
\hline 174 Private & 3,280,000 Tundra/lce Road & None & Massive Ice, Long Distance & Massive & 4 & YES \\
\hline 175 Private & 1,530,000 Tundra/lce Road & None & Massive Ice, Long Distance & Massive & 3 & YES \\
\hline 176 Private & $6,100,000$ Tundra/lce Road & None & Massive ice, Long Distance & Lenses, Inclusions & 1 & YES \\
\hline 211 Private & 940,000 Tundra/lce Road & None & Massive Ice, Long Distance & Lenses, Inclusions & 4 & YES \\
\hline 213 Crown & 300,000 Tundra/lce Road & Barge & River Environment & Unknown & 4 & NO \\
\hline 23 Private & 350,000 Tundra/lce Road & None & Long Distance, Thick Overburden & Massive, Lenses & 4 & YES \\
\hline $23 \mathrm{~A}$ Private & $1,900,000$ Tundra/lce Road & None & Long Distance, Thick Overburden, Ice & Lenses, Inclusions & 4 & YES \\
\hline 24A Private & 150,000 Tundra/lce Road & None & Terrain, lce & Lenses, Inclusions & 4 & YES \\
\hline 305 Private & 230,000 Tundra/lce Road & None & Massive Ice, Wildlife & Massive & 2 & YES \\
\hline 306 Private & 115,000 Tundra/lce Road & None & Long Distance, Wildlife & Lenses, Inclusions & 1 & YES \\
\hline${ }^{*} 151$ Crown & 380,000 Tundra/lce Road & Barge & Fish and Wildlife Habitat & Ice Rich Gravel & 1 & YES \\
\hline *211E Crown & 1,600,000 Tundra/lce Road & None & Poor Quality, Ground Ice & Massive, Excess & 4 & YES \\
\hline Total $=$ & $17,563,000$ & & & & & \\
\hline \multicolumn{7}{|l|}{ Between 50.1 and $60 \mathrm{~km}$} \\
\hline 206 Crown & 1,000,000 Tundra/lce Road & None & Overburden, Massive lce & Massive & 3 & YES \\
\hline 208A Crown & 450,000 Tundra/lce Road & None & Poor Quality & Unknown & 4 & YES \\
\hline 209 Crown & 1,000,000 Tundra/lee Road & None & Poor Quality, Lake Environment & Unknown & 4 & YES \\
\hline $210 A$ Crown & O Tundra/lce Road & None & Poor Quality, Overburden, Ground Ice & Massive & $n / a$ & YES \\
\hline 212 Crown & 190,000 Tundra/Ice Road & None & Overburden, Massive Ice & Massive & 4 & YES \\
\hline 307 Private & 115,000 Tundra/lce Road & None & Wildlife, Long Distance & Lenses, Inclusions & 4 & YES \\
\hline 308 crown & 15,000 Tundra/lce Road & None & Wildlife, Long Distance, Small Volume & None & 1 & YES \\
\hline 309 Crown & 1,500,000 Tundra/Ice Road & None & Wildlife, Long Distance & Massive & 2 & YES \\
\hline 310 A Private & 350,000 Tundra/lce Road & None & Poor Quality, Environmentall Sensitive & Massive & 4 & YES \\
\hline 216 Crown & $1,000,000$ Tundra/lce Road & None & Poor Quality, Ground Ice, Accessibility & Massive & 4 & YES \\
\hline *312 Private & $4,600,000$ Tundra/lce Road & Barge & Lake Environment, Wildlife & Massive, Excess & 1 & YES \\
\hline *313 Private & 38,000 Tundra/lce Road & Barge & Lake Environment, Wildlife & Massive, Excess & 3 & YES \\
\hline Total= & $10,258,000$ & & 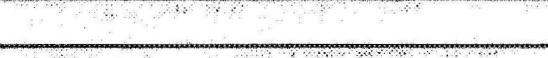 & $2+3$ & & \\
\hline \multicolumn{7}{|l|}{ Between 60.1 and $70 \mathrm{~km}$} \\
\hline 2.24 Crown & $12,000,000$ Tundra/lce Road & None & Lake Environment & Unknown & Unidentified & YES \\
\hline 205A Crown & o Tundra/lce Road & None & No Material & Unknown & $n / a$ & YES \\
\hline 207 Crown & 150,000 Tundra/lce Road & None & Lake Environment, Overburden & Massive & 3 & YES \\
\hline 217 Crown & $2,350,000$ Ice Road & None & Poor Quality, Ground Ice & Excess, Massive & 4 & YES \\
\hline 217E Crown & 0 ice Road & None & Poor Quality & Excess & $n / a$ & YES \\
\hline 218 Crown & o Tundra/lce Road & None & Poor Quality, Ground Ice & Excess, Massive & $n / a$ & YES \\
\hline
\end{tabular}


$218 \mathrm{~N}$ Crown

216 s Crown

219 Crown

311 Private

Parsons Lake 12 Private

Parsons Lake 10 Private

Parsons Lake 2 Private

Parsons Lake 3 Private

Parsons Lake 4 Private

Parsons Lake 5 Private

Parsons Lake 6 Private

Parsons Lake 7 Private

Parsons Lake 8 Private

Parsons Lake 9 Private
0 Tundra/lce Road None

1,700,000 Tundra/lce Road None

230,000 ice Road None

300,000 Tundra/lce Road Barge

1,000,000 Tundra/lce Road None

135,000 Tundra/lce Road None

230,000 Tundra/lce Road None

400,000 Tundra/lce Road None

150,000 Tundra/lce Road None

30,000 Tundra/lce Road Barge

7,500 Tundra/lce Road Barge

20,000 Tundra/lce Road None

75,000 Tundra/lce Road None

38,000 Tundra/lce Road None

Between 70.1 and $80 \mathrm{~km}$

2.34 Private $\quad 55,000,000$ Tundra/lce Road None

2.36 Private $\quad 300,000,000$ Tundra/lce Road None

2.37 Private $\quad 50,000,000$ Tundra/lce Road None

2.40 Private $\quad 40,000,000$ Tundra/lce Road None

760,000 Tundra/lce Road Barge Total $=445,760,000$

Between 80.1 and $90 \mathrm{~km}$

2.38 Private

$100,000,000$ Tundra/Ice Road None

201A Crown

20,000,000 Tundra/lce Road Barge

202A Crown

1,000,000 Tundra/Ice Road Barge

203A Crown

$7,000,000$ Tundra/lce Road Barge

314 Private

2,300,000 Tundra/lce Road None

325 Private

750,000 Tundra/lce Road Barge

$328 \mathrm{~A}$ Private

100,000 Tundra/lce Road Barge

Total $=131,150,000$

Distance $>90 \mathrm{~km}$

*152A Private

1,500,000 Tundra/lce Road Barge

1,750,000 Tundra/lce Road Barge

$3,250,000$

Total $=$

Poor Quality, Ground Ice

Poor Quality, Ground Ice

Fair Quality Material

Lake Environment, Wildlife

River Environment, Wildlife

Overburden, Ground Ice

High lce Content

River Environment, Ice Wedges

Overburden

Overburden, Ground Ice

Overburden, Ground Ice

Overburden, Ice Wedges

Overburden, Limited Volume

Overburden, Limited Volume

Lake Environment, Wildife

Wildlife

Wildlife

Wildlife

Lake Environment, Wildlife, Distance

Lake Environment, Wildlife

Lake Environment, Bird Sanctuary

Lake Environment, Bird Sanctuary

Lake Environment, Bird Sanctuary

Lake Environment, Wildlife

Lake Environment, Wildlife

Poor Quality, Environmentally Sensitive
Excess, Massive

Excess, Massive

Excess, Massive

None

Ice Lenses

Excess, Massive

Lenses, Inclusions

Lenses, Inclusions

Massive

Excess, Massive

Excess, Massive

Lenses, Inclusions

Lenses, Inclusions

Lenses, Inclusions

Denotes Sources That Have No Constraints to Development

* Denotes sources that were unable to be mapped 
Aklavik Borrow Sources

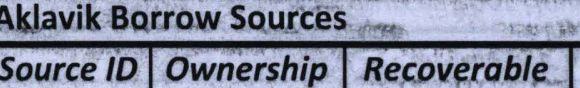

Distance Between 15 and $20 \mathrm{~km}$

469 Crown

*468 Crown

5,000,000 Tundra/Ice Road

$10,000,000$ Tundra/Ice Road

$15,000,000$

Distance Between 20.1 and $30 \mathrm{~km}$

*455 Crown

*456A Crown

*457A Crown

467 Crown Total =

Distance $>50 \mathrm{~km}$

*463 Private

469 Crown

Total $=$

000 Tundra/Ice Road

0 Tundra/lce Road

O Tundra/lce Road Barge

3,000,000 Tundra/Ice Road None

$3,500,000$

None

Wildlife, Access, Poor Quality

Accessibility

Constraints to Development

ment

tons

Ground Ice

T

Grav

\begin{tabular}{c|c|}
\hline Primary & $\begin{array}{c}\text { Impacted By } \\
\text { Gravel Class }\end{array}$ \\
\hline
\end{tabular}

Unknown

Unknown

(2)

None

Wildlife, Poor Quality, River Environment
Wildlife, Poor Quality

None

None

None

Lenses, Inclu $\mathrm{n} / \mathrm{a}$ Unknown

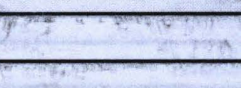

ristons

3,000,000 Tundra/lce Road Non
$5,000,000$ Tundra/Ice Road Non
$8,000,000$

None
None

Low Quality
Wildlife, Accessibility, Poor Quality

Denotes Sources That Have No Constraints to Development

* Denotes sources that were unable to be mapped 


\section{Constraints to Pit Development: Aklavik and Inuvik}

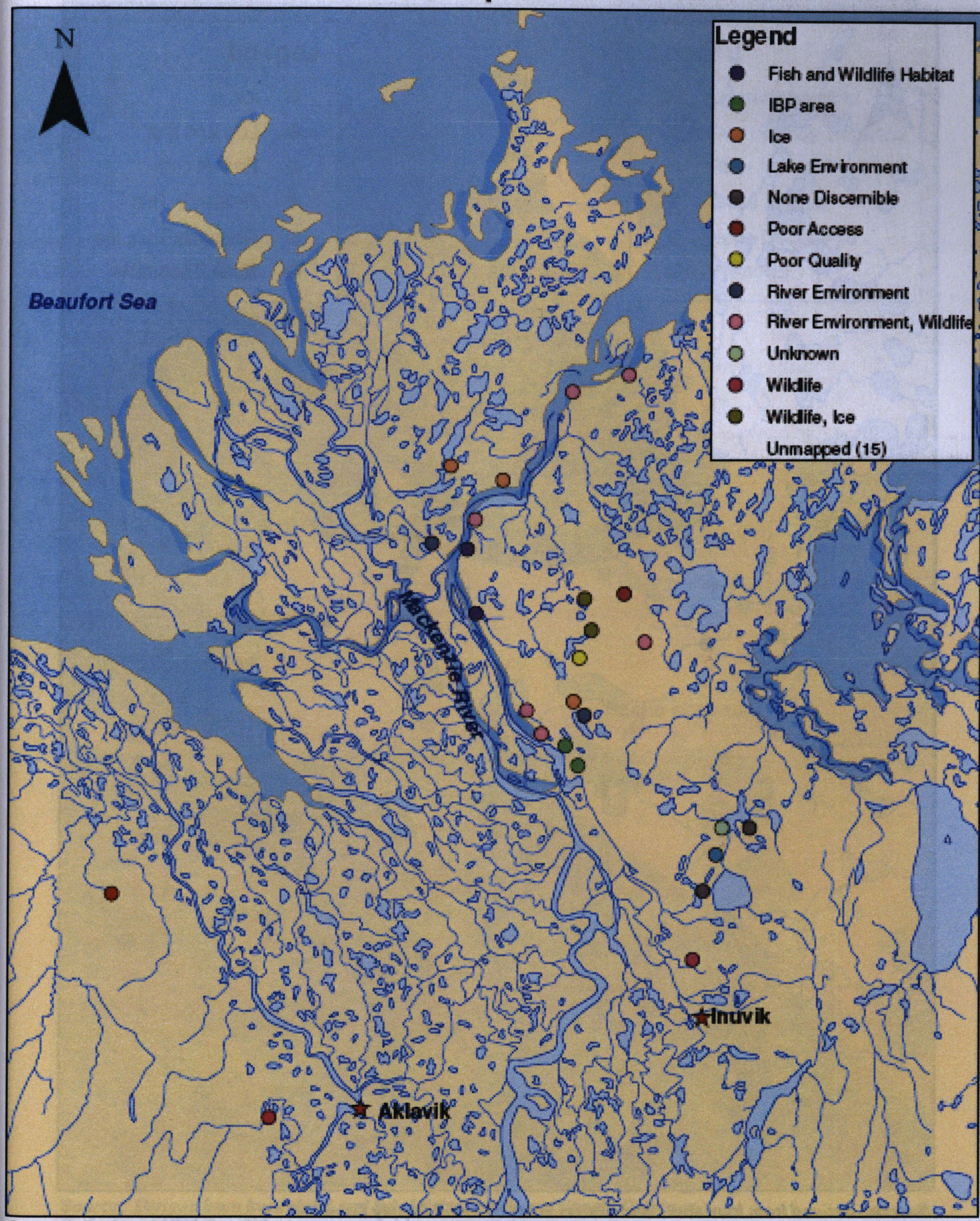


Constraints to Pit Development: Paulatuk

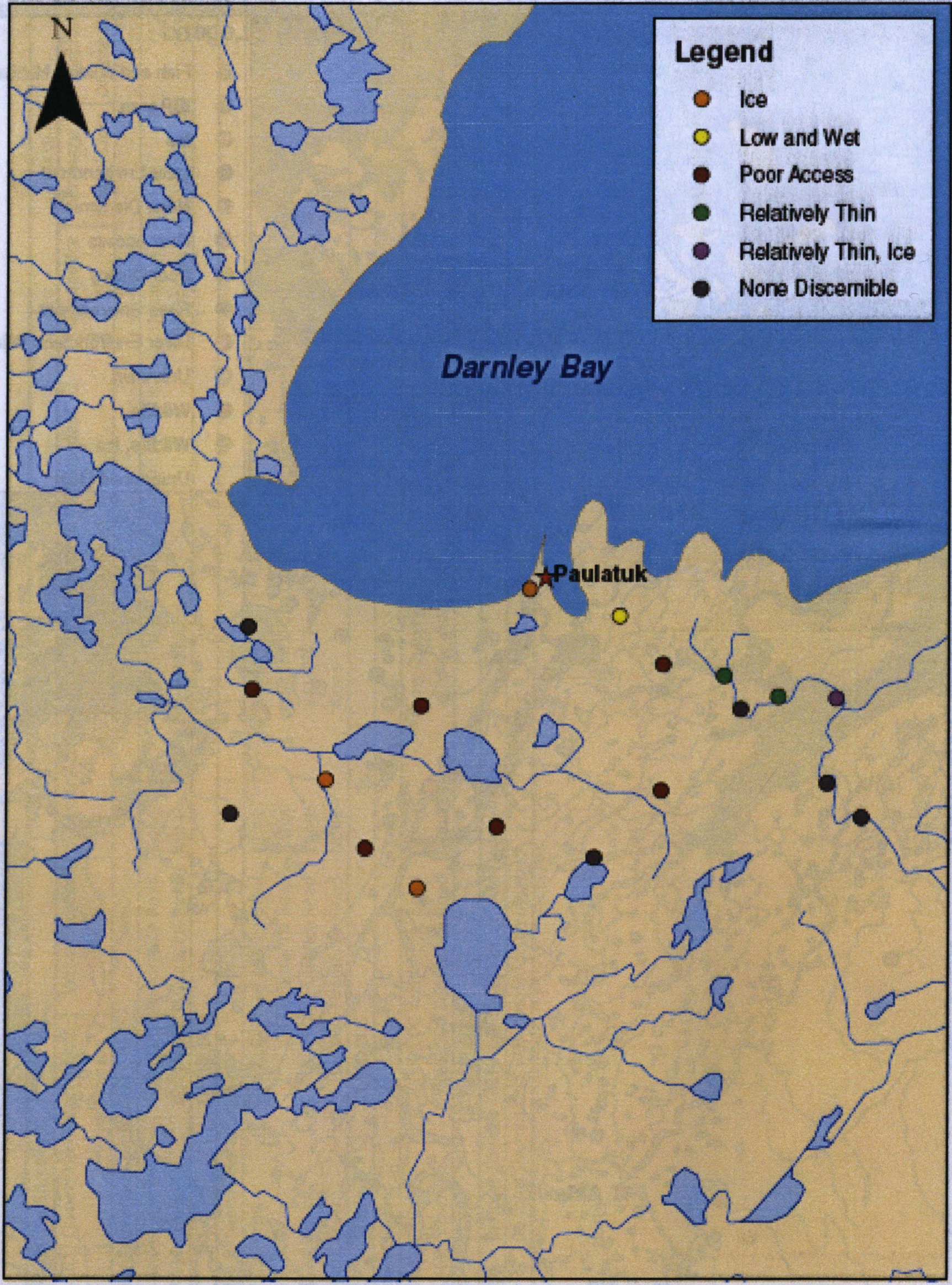

Source: Derived from Imuwialuit Land Adninistration Gravel Supply Database 


\section{Constraints to Pit Development: Sachs Harbour}

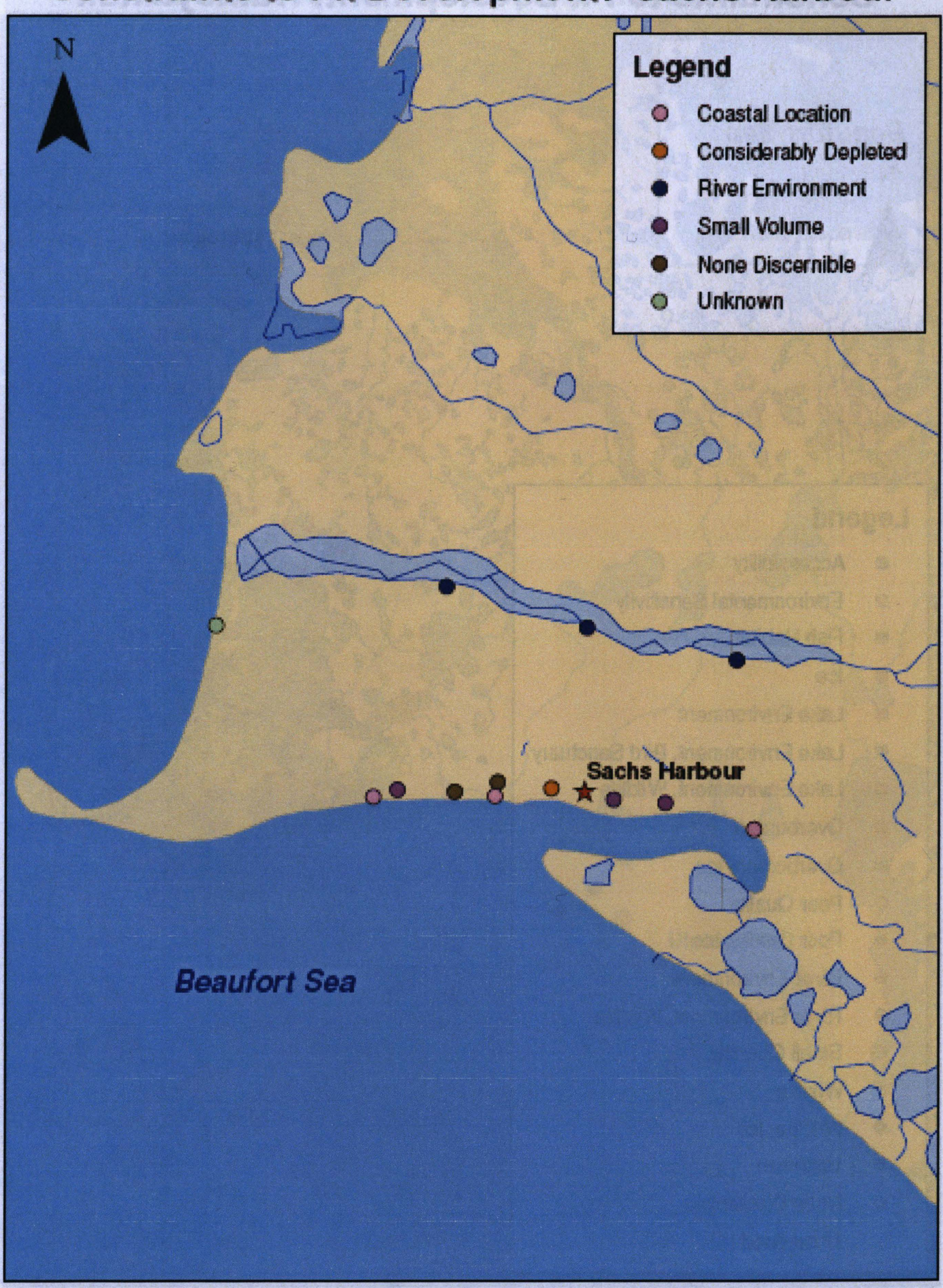

APPENDDX F: CONSTRAINT MAPS 


\section{Constraints to Pit Development: Tuktoyaktuk}

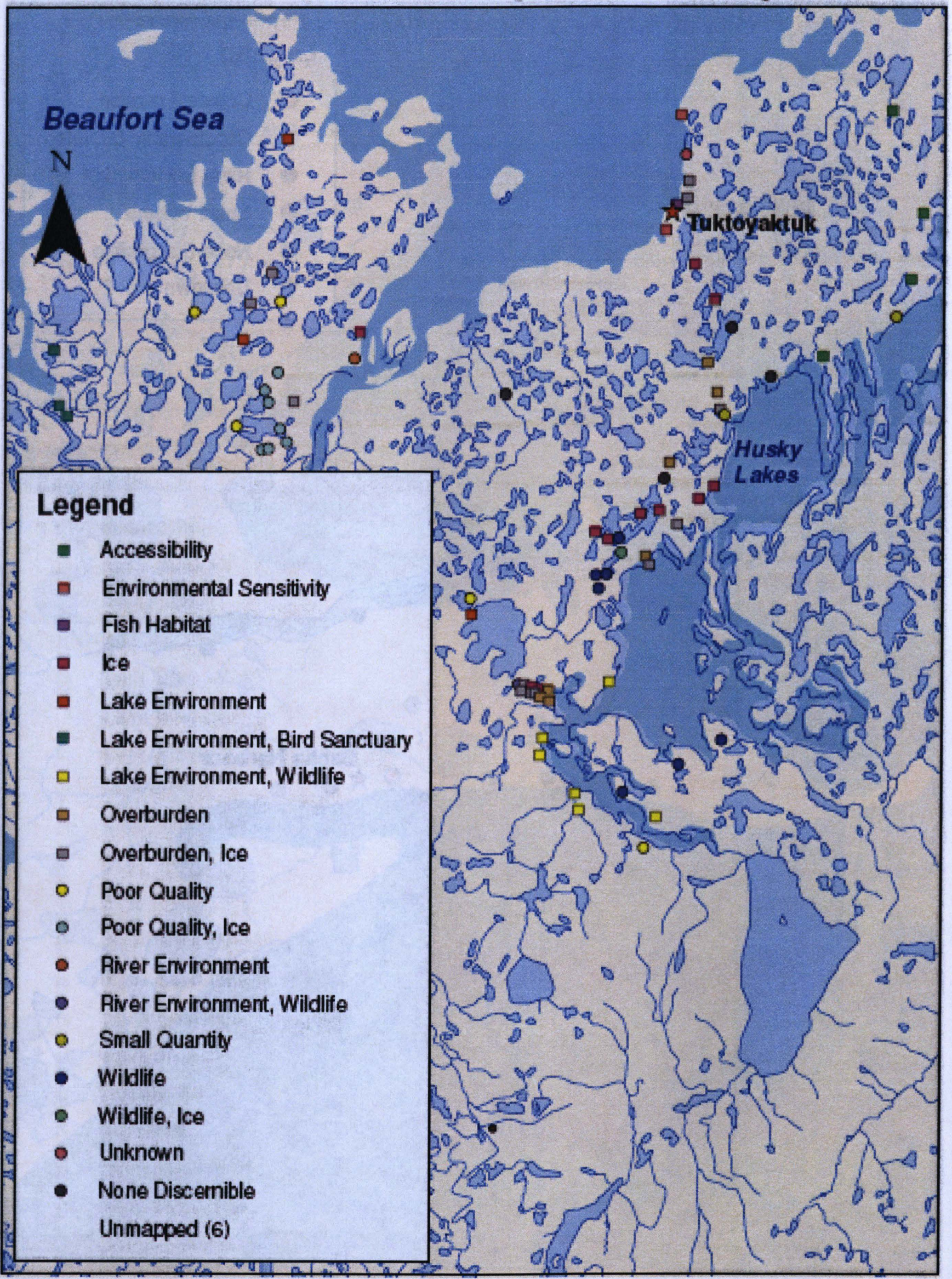

Source: Derived from Inuwaluit Land Adninistration Gravel Supply Database 


\section{Constraints to Pit Development: Ulukhaktok

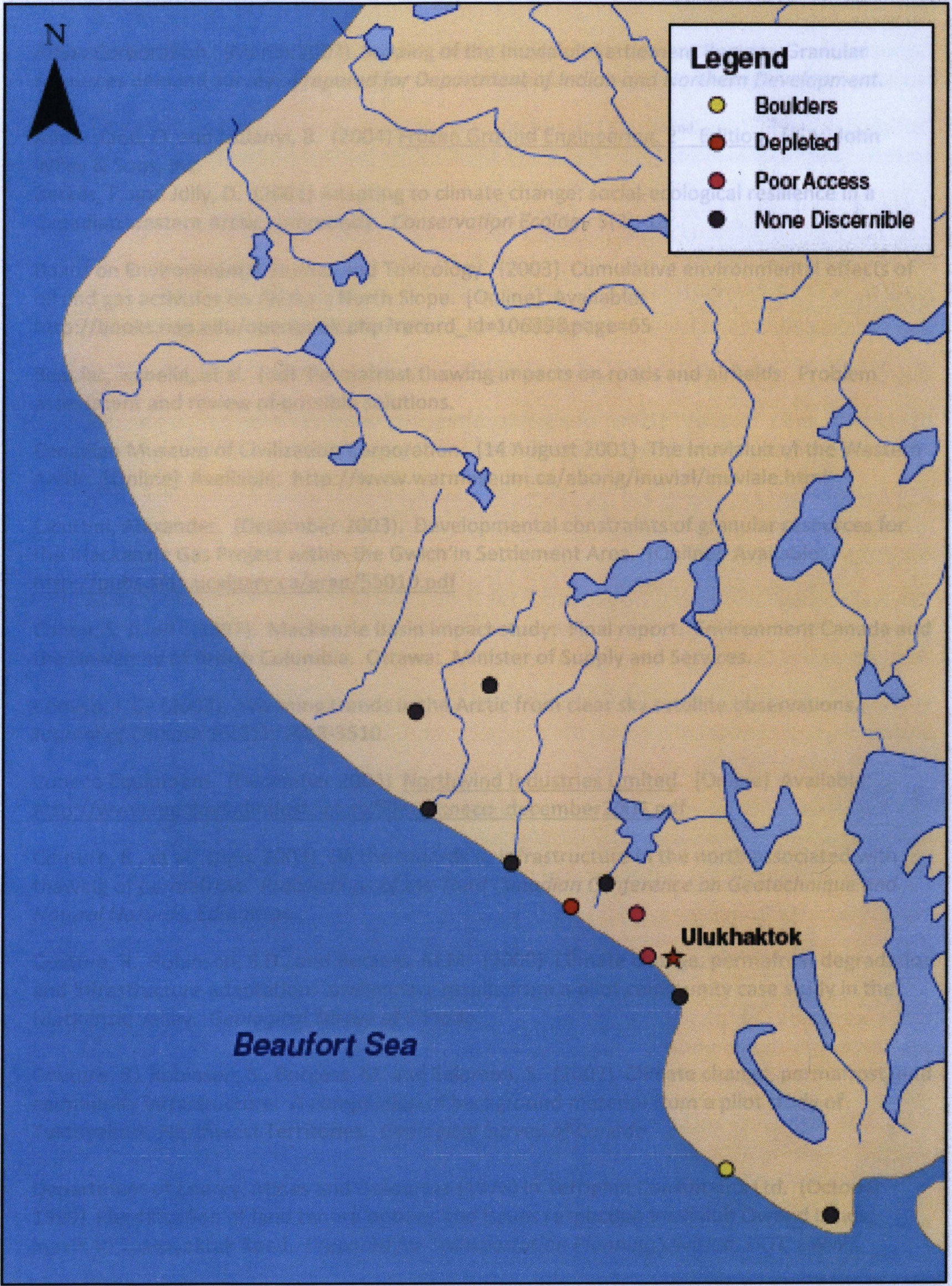

Source: Derived from Inuwaluit Land Adni istration Gravel Supply Database 

Alpha Corporation. (March 2007) Scoping of the Inuvialuit Settlement Region: Granular resources demand survey. Prepared for Department of Indian and Northern Development.

Andersland, O. and Ladanyi, B. (2004) Frozen Ground Engineering, $2^{\text {nd }}$ Edition. USA: John Wiley \& Sons, Inc.

Berkes, F. and Jolly, D. (2001) Adapting to climate change: social-ecological resilience in a Canadian western Arctic community. Conservation Ecology 5(2), 18

Board on Environmental Studies and Toxicology. (2003) Cumulative environmental effects of oil and gas activities on Alaska's North Slope. [Online] Available:

http://books.nap.edu/openbook.php?record_id $=10639 \&$ page $=65$

Beaulac, Isabelle, et al. (nd) Permafrost thawing impacts on roads and airfields: Problem assessment and review of possible solutions.

Canadian Museum of Civilization Corporation. (14 August 2001) The Inuvialuit of the Western Arctic. [Online] Available: http://www.warmuseum.ca/aborig/inuvial/inuviale.html

Cicuttini, Alexander. (December 2003). Developmental constraints of granular resources for the Mackenzie Gas Project within the Gwich'in Settlement Area. [Online] Available: http://pubs.aina.ucalgary.ca/gran/55010.pdf

Cohen, S. J., ed. (1997). Mackenzie Basin impact study: Final report. Environment Canada and the University of British Columbia. Ottawa: Minister of Supply and Services.

Comiso, J. C. (2003). Warming trends in the Arctic from clear sky satellite observations. Journal of Climate 16(21): 3498-3510.

Coneco Equipment. (December 2004) Northwind Industries Limited. [Online] Available: http://www.northwindindustries.ca/files/coneco december2004.pdf

Couture, R., et al. (June 2003) On the hazards to infrastructure in the north associated with thawing of permafrost. Proceedings of the Third Canadian Conference on Geotechnique and Natural Hazards, Edmonton.

Couture, R., Robinson, S.D., and Burgess, M.M. (2000) Climate change, permafrost degradation and infrastructure adaptation: preliminary results from a pilot community case study in the Mackenzie valley. Geological Survey of Canada.

Couture, R., Robinson, S., Burgess, M. and Solomon, S. (2002) Climate change, permafrost, and community infrastructure: A compilation of background material from a pilot study of Tuktoyaktuk, Northwest Territories. Geological Survey of Canada.

Department of Energy, Mines and Resources (1976) in Terriplan Consultants Ltd. (October 1999) Identification of land tenure options and issues respecting Inuvialuit Owned Lands: Inuvik to Tuktoyaktuk Road. Prepared for Transportation Planning Division, DOT, GNWT. 
Department of Indian Affairs and Northern Development (2006). SID Viewer Online. [Online] Available: http://nwt-tno.inac-ainc.gc.ca/ism-sid/index_e.asp

De Schutter, Paul. (May 2004) On the surface: thermokarst. Open University Geological Society. [Online] Available: http://ougs.org/about/index.php?branchcode=ouc

Detlor, T. (July 1989) Inuvik history. Town of Inuvik Website. [Online] Available: http://inuvik.ca/tourism/inuvikhistory.html

Duerden, F. (2001). Climate change and human activity in northern Canada: What we know, don't know, and need to know. Northern Review 24:150-160।

Duerden, F. (2004). Translating climate change impacts at the community level. Arctic (2) Duerden, F. and E. Beasley. (2006). Assessing community vulnerabilities to environmental change in the Inuvialuit Settlement Region, NWT. Aboriginal Press.

EBA Engineering Consultants, Ltd (a). (April 1987) Inuvialuit Settlement Region sand and gravel inventory and recommendations for development: Aklavik, NWT. Prepared for Indian and Northern Affairs Canada.

EBA Engineering Consultants, Ltd (b). (April 1987) Inuvialuit Settlement Region sand and gravel inventory and recommendations for development: Holman, NWT. Prepared for Indian and Northern Affairs Canada.

EBA Engineering Consultants, Ltd (c). (April 1987) Inuvialuit Settlement Region sand and gravel inventory and recommendations for development: Inuvik, NWT. Prepared for Indian and Northern Affairs Canada.

EBA Engineering Consultants, Ltd (d). (April 1987) Inuvialuit Settlement Region sand and gravel inventory and recommendations for development: Paulatuk, NWT. Prepared for indian and Northern Affairs Canada.

EBA Engineering Consultants, Ltd (e). (April 1987) Inuvialuit Settlement Region sand and gravel inventory and recommendations for development: Sachs Harbour, NWT. Prepared for Indian and Northern Affairs Canada.

EBA Engineering Consultants, Ltd (f). (April 1987) Inuvialuit Settlement Region sand and gravel inventory and recommendations for development: Tuktoyaktuk, NWT. Prepared for Indian and Northern Affairs Canada.

Eddy, B.G. (2001). Granular potential mapping of the inuvik-Tuktoyaktuk corridor. GSI GeoSystems Integration, Northern Affairs Program and Natural Resources and Environment Branch. Ottawa: GSI-GeoSystems Integration.

Esch, D.C. and T.E. Osterkamp. (1990). Cold regions engineering: Climate warming concerns for Alaska. Journal of Cold Regions Engineering. Volume 4, Issue 1. 
Ford, James D. and Barry Smit. (December 2004). A framework for assessing the vulnerability of communities in the Canadian Arctic to risks associated with climate change. Arctic. Volume 57 , Issue 4.

Fourie, W., Barnes, D., and Shur, Y. (2007) The formation of ice from the infiltration of water into a frozen coarse grained soil. Cold Regions Science and Technology. Vol. 48.

Fox, S. (2000). Arctic climate change: Observations from the Inuvialuit Settlement Region. In: Fetterer, P., and Radionov, V, eds. Arctic Climatology Project-Environmental Working Group Arctic Meteorology and Climate Atlas. Boulder, Colorado: National Snow and Ice Data Centre CD-ROM.

French, Hugh M. (2007) The Periglacial Environment, $3^{\text {rd }}$ Edition. England: John Wiley and Sons, Ltd.

Furgal, C., and Prowse, T.D. (2008): Northern Canada; in From Impacts to Adaptation: Canada in a Changing Climate 2007, edited by D.S. Lemmen, F.J.Warren, J. Lacroix and E. Bush; Government of Canada, Ottawa, ON, p. 57-118. Canadian Journal of Earth Science. Vol.42, pp. 37-48.

Geological Survey of Canada. (December 2007) Permafrost. [Online] Available: http://gsc.nrcan.gc.ca/permafrost/whatis e.php

GeoNorth Ltd. (March 1999) Granular Resources Directory: Northwest Territories. Prepared for DIAND, Ottawa.

Government of the Northwest Territories Department of Transportation. (1999a) Inuvik to Tuktoyaktuk Road: Executive summary part 1.

Government of the Northwest Territories Department of Transportation Highways and Engineering Division. (March 1999) Inuvik to Tuktoyaktuk road: Pre-engineering update.

Government of the Northwest Territories Municipal and Community Affairs. (nd) Lands Administration. [Online] Available: http://www.maca.gov.nt.ca/lands/lands/index.html

Government of the Northwest Territories Municipal and Community Affairs. (2008) Resources: forms. [Online] Available: http://www.maca.gov.nt.ca/resources/forms/

Gowan, R. J. (1993). DIAND northern granular resources inventory program. In: Mahnic, R.J., and Fujino, T.J.: Stanley Associates Engineering Granular Resource Requirements for Proposed Mackenzie Valley Pipelines: technical papers and workshop proceedings, p. 10-18.

Gowan, R. J. (June 1993). Granular resource requirements for proposed Mackenzie Valley Pipeline: Technical papers and workshop proceedings. Northern Oil and Gas Action Program Project A4: Granular Resources Inventory Management. 
REFERENCe

Hardy BBT Limited. (HWy 1990) Granular resources demand, Mackenzie Delta region. DRAFT.
For: Indian and Northern Affairs Canada. Quebec: Hull.

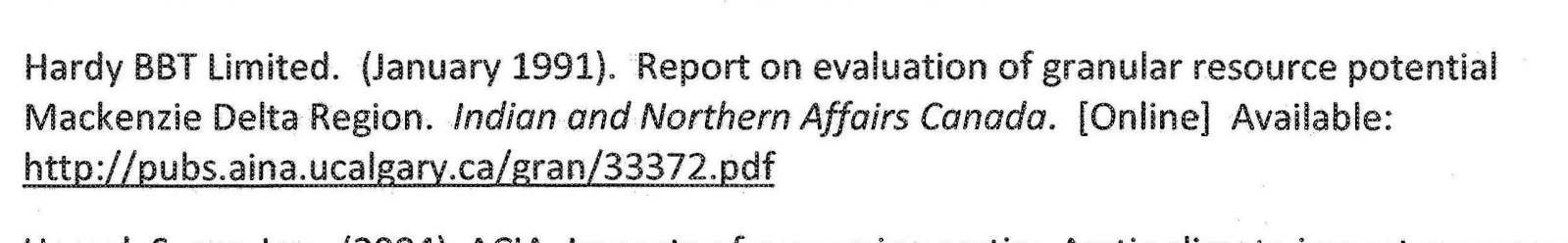
Hassol, Susan Joy. (2004) ACIA,
Cambridge University Press.

Harley, Don W. (January 2004) Climate change-an adaptation challenge for
engineers. The PEGG. [online] A vaialable:
httr://www.apegga.org/members/publications/pegss/web01-04/expert.htm 
Indian and Northern Affairs Canada (c). (21 February 2005) A Guide to Mineral Exploration and Development in the NWT: Surface Lease. [Online] Available: http://nwt-tno.inacainc.gc.ca/mpf/permits/srfleasd e.htm

Indian and Northern Affairs Canada (d). (21 February 2005) A guide to mineral exploration and development in the NWT: Airborne Surveys. [Online] Available: http://nwt-tno.inacainc.gc.ca/mpf/activity/airgsrvy e.htm

Indian and Northern Affairs Canada. (August 2005). Granular resource estimating tool. [Online] Available: http://legacy.grancalc.ca/

Indian and Northern Affairs Canada. (15 November 2007) Operations Lands Administration: Federal Crown Lands. [Online] Available: http://nwt-tno.inac-ainc.gc.ca/la-fcl e.htm Indian and Northern Affairs Canada (a). (3 January 2001) A Guide to Mineral Exploration and Development in the NWT: Inuvialuit Land Administrator Consultation with Communities. [Online] Available: http://nwt-tno.inac-ainc.gc.ca/mpf/process/ilaconsl_e.htm

Indian and Northern Affairs Canada. (14 March 2001) Will the project have significant environmental impact? A guide to mineral exploration and development in the NWT. [Online] Available: http://nwt-tno.inac-ainc.gc.ca/mpf/process/proinega e.htm

Indian and Northern Affairs Canada (b). (3 January 2001) A Guide to Mineral Exploration and Development in the NWT: Environmental Impact Screening and Review Process. [Online] Available: http://nwt-tno.inac-ainc.gc.ca/mpf/process/eisr-inu e.htm

Indian and Northern Affairs Canada. (2004) Understanding the Sand and Gravel Business. [Online] Available: http://www.ainc-inac.gc.ca/pr/pub/b/dg/snd/sgb e.html

Indian and Northern Affairs Canada. (21 February 2005) A Guide to Mineral Exploration and Development in the NWT: Inuvialuit Land Administration. [Online] Available: http://nwttho.inac-ainc.gc.ca/mpf/authorit/inuvladm e.htm

Infrastructure Canada. (nd) Transportation by land in northern Canada. [Online] Available: http://www.infrastructure.gc.ca/research-recherche/result/alt formats/pdf/hm01 e.pdf

Instanes, Arne, et al. (2005). Arctic climate impact assessment-Chapter 16, Infrastructure: Buildings, support systems and industrial facilities. Cambridge University Press. [Online] Available: http://www.acia.uaf.edu/PDFs/ACIA Science Chapters Final/ACIA Ch16 Final.pdf

Interdepartmental Granular Acquisition Committee, NWT. (May 2007) Territorial granular resource forecast report: The territorial granular strategy.

International Arctic Science Committee (1999). Impacts of global climate change in Arctic regions. Fairbanks: Centre for Global Change Research, University of Alaska. 
Inuvialuit Regional Corporation (a). (2007) Brief History. [Online] Available: http://www.irc.inuvialuit.com/about/history.html

Inuvialuit Regional Corporation. (2007) Modern Inuvialuit Culture. [Online] Available: http://www.irc.inuvialuit.com/culture/modern.html

Johnson, Ken. (January 2006) Backgrounder: Permafrost, pipes and people. The PEGG.

Jozic, Jennifer. (2005) Global warming in the north: Extreme climate, unpredictable change. University of Saskatchewan: Centre for Studies in Agriculture, Law and the Environment. [Online] Available: http://scaa.usask.ca/gallerv/northern/content?pg=ex08-3

Katz, Helena. (November/December 2007) Diamond alley. Canadian Geographic.

Kokeli, S.V. and Burn, C.R. (2003) Ground ice and soluble cations in near-surface permafrost, Inuvik, Northwest Territories, Canada. Permafrost and periglacial Process. Vol 14, pp. 275-289.

Kokelj, S.V. and Burn, C.R. (2005) Geochemistry of the active layer and near-surface permafrost, Mackenzie delta region, Northwest Territories, Canada.

Kokelj, S.V. and Burn, C.R. (2005) Near-surface ground ice in sediments of the Mackenzie Delta, Northwest Territories, Canada. Permafrost and Periglacial Process. Vol 16, pp. 291-303.

Lau, L. G. (10 May 2004) Influence of length of haulage distances on potential development of granular resources. Indian and Northern Affairs Canada. Quebec: Hull.

Lonegran, S. C., Difrancesco, R., and Woo, M. (1993). Climate change and transportation in northern Canada: An integrated impact assessment. Climatic Change 24:331-351.

Lunardini, V.J. (1996) Climatic warming and the degradation of warm permafrost. Permafrost and Periglacial Processes. Vol 7, pp. 311-320.

Mackenzie Gas Project. (January 2004). Infrastructure. [Online] Available: http://www.mackenziegasproject.com/morelnformation/publications/documents/Logistics\&lnf rastructure.pdf

Mackenzie Gas Project. (March 2006). ISR and GSA Quarrying Permit Application. [Online] Available:

http://www.mackenziegasproject.com/theProject/regulatoryProcess/applicationSubmission/D ocuments/Quarry_ISRGSA_Sections1_2.pdf

MacLeod, N.R. (1993). The feasibility of developing granular resources from the bed of the Mackenzie River. In: Mahnic, R.J. and Fujino, T.J. Stanley Associates Engineering Granular Resource Requirements for Proposed Mackenzie Valley Pipelines: technical papers and workshop proceedings, p. 54-65.

Maxwell, B., ed. (1997). Canada country study: Climate impacts and adaptation. Vol 2: Responding to global climate change in Canada's Arctic. Toronto: Environment Canada. 
McDougall, James C. (June 2001) A granular resource demand forecast for the Inuvialuit Settlement Region. Prepared for Indian and Northern Affairs Canada. North of 60 Engineering Ltd.

McGillivary, D.G., Agnew, T.A., McKay, C.A., Pilkington, G.R., and Hill, M.S. (1993). Impacts of climate change on the Beaufort Sea ice regime: Implications for the Arctic petroleum industry. Climate Change Digest 93-01. Downsview, Ontario: Atmospheric Environment Service.

Morrison, D. (10 January 2008) Environmental atlas of the Beaufort Coastlands: The people-a history. Geological Survey of Canada. [Online] Available:

http://cgc.rncan.gc.ca/beaufort/people history e.php

Municipal and Community Affairs NWT. (nd) What's the Big Deal? [Online] Available: htto://www.maca.gov.nt.ca/resources/NewDeala\&A webversion.pdf

Murton, Julian B. (2005) Ground-ice stratigraphy and formation at North Head, Tuktoyaktuk Coastlands, Western Arctic Canada: a product of glacier-permafrost interactions. Permafrost and Periglacial Process. Vol 16, pp. 31-50.

Natural Resources Canada (2007) Permafrost: Communities and climate change. [Online] Avallable: http://gsc.nrcan.gc.ca/permafrost/communities e.php

Natural Resources Canada. (2 October 2007) Climate change impacts and adaptation: A Canadian perspective. Impacts on transportation infrastructure. [Online] Available: http://adaptation.nrcan.gc.ca/perspective/transport_3_e.php

Nickels, S., Furgal, C., Buell, M. and Moquin, H. (2005) Unikkaaqatigiit-Putting the human face on climate change: Perspectives from Inuit in Canada. (Ottawa: Inuit Tapiriit Kanatami, Nasivvik Centre for Inuit Health, Changing Environments and Université Laval, Ajunnginiq Centre at the National Aboriginal Health Organization)

NWT Construction Association. (11 January 2008) NWTCA Bulletin. Vol. 27/No.1. [Online] Available: www.nwtca.ca/bulletin/2008-01-11.pdf

NWT Department of Justice (1990) Commissioner's Land Act. [Online] Avalable: http://www.justice.gov.nt.ca/PDF/REGS/COMMISSIONERS_LAND/Commissioners_Land.pdf NWT Department of Public Works and Services, Asset Management Division. (2001). Town of Inuvik, NT, granular resource appraisal material evaluation report: a joint PW\&S MACA and Town of Inuvik study. [Online] Available: htto://www.aina.ucalgary.ca/scripts/minisa.dll/144/ngrproe/ngrproe/sisn+54732?COMMANDS EARCH 
NWT Department of Transportation. (March 1999). Inuvik to Tuktoyaktuk Road Preengineering Update. [Online] Available:

http://www.dot.gov.nt.ca/ live/documents/documentManagerUpload/PROS InuvkTuk preeng ineeringupdate march1999.pdf

NWT Environment and Natural Resources. (2008) NWT Climate change impacts and adaptation report. [Online] Available:

http://www.enr.gov.nt.ca/eps/pdf/NWT\%20Climate $\% 20$ Change $\% 201$ mpacts $\% 20$ and\%20Adapta tion\%20Report1.pdf

Nuna Logistics. (28 April 2003) The winter road. [Online] Available: http://www.nunalogistics.com/projects/winter road/index.html

Overpeck, J., et al. (14 November 1997) Arctic environmental change of the last four centuries. Science. Vol 278.

Padilla, F., Villeneuve, J., and Stein, J. (1997) Simulation and analysis of frost heaving in subsoils and granular fills of roads. Cold Regions Science and Technology. Vol. 25.

Penner, E. (February 1962) Ground freezing and frost heaving. Canadian Building Digest. [Online] Available: http://irc.nrc-cnrc.gc.ca/pubs/cbd/cbd026_e.html

Pollard, Wayne. (2003). Massive ice in granular deposits study: background paper. Montreal: Subarctic Research Station, McGill University.

Shur, Y.L. and Jorgenson, M.T. (2007) Patterns of permafrost formation and degradation in relation to climate and ecosystems. Permafrost and Periglacial Process. Vol 18, pp. 7-19.

Slater, Andrew G. and Lawrence, David M. (2005) A projection of severe near-surface permafrost degradation during the $21^{\text {st }}$ century. Geophysical Research Letters. Vol. 32, December 2005.

Smith, S.L., Burgess, M.M., and Nixon, F.M. (2001) Response of active-layer and permafrost temperatures to warming during 1998 in the Mackenzie Delta, Northwest Territories and at Canadian Forces Station Alert and Baker Lake, Nunavut. Prepared for Geological Survey of Canada.

State of the Canadian Cryosphere. (2008) Future of Canadian Permafrost. [Online] Available: http://www.socc.ca/permafrost/permafrost future e.cfm

Stoneman-McNichol, Jane. (1983) On Blue Ice: The Inuvik Adventure. Yellowknife: Outcrop, the Northern Publishers.

Strub, Harold. (1996) Bare Poles: Building Design for High Altitudes. Canada: McGill-Queens Press. 
Terriplan Consultants Ltd. (October 1999) Identification of land tenure options and issues respecting Inuvialuit Owned Lands: Inuvik to Tuktoyaktuk Road. Prepared for Transportation Planning Division, DOT, GNWT.

Thompson, Frank. (March 1994) An interpretive manual for reports on granular deposits in the Inuvialuit Settlement Region. Prepared for Indian and Northern Affairs Canada.

Unknown (2002). Granular demand and supply assessment report, NWT communities, 2003/04-2007/08. [Online] Available:

http://www.aina.ucalgary.ca/scripts/minisa.dll/144/ngrproe/ngroroe/sisn+54731?COMMANDS EARCH

Weber, Bob. (5 June 2005) Canada: Studies show climate change melting permafrost under roads, runways in NWT. Macleans.

Wolfe, Stephen A., ed. (1998) Living with frozen ground: A field guide to permafrost in Yellowknife, Northwest Territories. Geological Survey of Canada: Miscellaneous Report 64.

Yi, S., Ming-ko W., and Arain, M. (2007) Impacts of peat and vegetation on permafrost degradation under climate warming. Geophysical Research Letters. Vol. 34. 


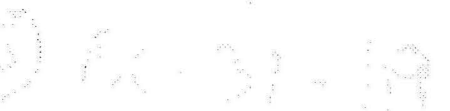

